\title{
(7) Cochrane Library
}

Cochrane Database of Systematic Reviews

\section{Adverse side effects of dexamethasone in surgical patients (Review)}

Polderman JAW, Farhang-Razi V, Van Dieren S, Kranke P, DeVries JH, Hollmann MW, Preckel B, Hermanides J

Polderman JAW, Farhang-Razi V, Van Dieren S, Kranke P, DeVries JH, Hollmann MW, Preckel B, Hermanides J.

Adverse side effects of dexamethasone in surgical patients.

Cochrane Database of Systematic Reviews 2018, Issue 8. Art. No.: CD011940.

DOI: 10.1002/14651858.CD011940.pub2.

www.cochranelibrary.com 


\section{TABLE OF CONTENTS}

HEADER

ABSTRACT

PLAIN LANGUAGE SUMMARY

. . . . . . . . . . . . . . . . . . . . . . . . . . . . . .

SUMMARY OF FINDINGS FOR THE MAIN COMPARISON ．．．．．．．．． . . . . . . . . . . . 4

BACKGROUND . . . . . . . . . . . . . . . . . . . . . . . . . . . . . . . . . . . . . 6

OBJECTIVES . . . . . . . . . . . . . . . . . . . . . . . . . . . . . . . . . . . . . 6

METHODS . . . . . . . . . . . . . . . . . . . . . . . . . . . . . . . . . . . . . . 6

RESULTS . . . . . . . . . . . . . . . . . . . . . . . . . . . . . . . . . . . 9

Figure 1. . . . . . . . . . . . . . . . . . . . . . . . . . . . . . . . . 10

Figure 2. . . . . . . . . . . . . . . . . . . . . . . . . . . . . . . . . . . . . .

Figure 3. . . . . . . . . . . . . . . . . . . . . . . . . . . . . . . . . . . . . . . .

Figure $4 . \quad$. . . . . . . . . . . . . . . . . . . . . . . . . . . . . . . . . . . . . 16

DISCUSSION . . . . . . . . . . . . . . . . . . . . . . . . . . . . . . . . . . . . . 19

AUTHORS' CONCLUSIONS . . . . . . . . . . . . . . . . . . . . . . . . . . . . . . . . . . . . . . .

ACKNOWLEDGEMENTS . . . . . . . . . . . . . . . . . . . . . . . . . . . . . . . . . . . . 21

REFERENCES . . . . . . . . . . . . . . . . . . . . . . . . . . . . . . . . . . . . . . 22

CHARACTERISTICS OF STUDIES . . . . . . . . . . . . . . . . . . . . . . . . . . . . . . . . . . . . . . . 28

DATA AND ANALYSES . . . . . . . . . . . . . . . . . . . . . . . . . . . . . . . . . . . . . . . . . . . . . . . . 89

Analysis 1.1. Comparison 1 Dexamethasone versus control, Outcome 1 Postoperative systemic or wound infection. . 90

Analysis 1.2. Comparison 1 Dexamethasone versus control, Outcome 2 Subgroup analysis for postoperative systemic or wound infection: single vs multiple doses of dexamethasone. . . . . . . . . . . . . . . . . . . . . . . 92

Analysis 1.3. Comparison 1 Dexamethasone versus control, Outcome 3 Delayed wound healing. . . . . . . . . 94

Analysis 1.4. Comparison 1 Dexamethasone versus control, Outcome 4 Glycaemic response. . . . . . . . . . . . .95

Analysis 1.5. Comparison 1 Dexamethasone versus control, Outcome 5 Re-admission or unplanned hospital admission. 96

Analysis 1.6. Comparison 1 Dexamethasone versus control, Outcome 6 Mortality. . . . . . . . . . . . . . . . .97

Analysis 1.7. Comparison 1 Dexamethasone versus control, Outcome 7 Sensitivity analysis excluding high risk of bias studies from Analysis 1.1.

Analysis 1.8. Comparison 1 Dexamethasone versus control, Outcome 8 Sensitivity analysis excluding skewed glucose data.

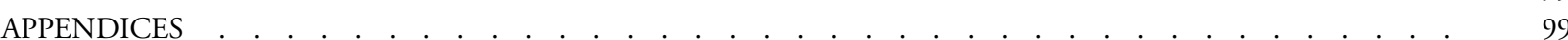

WHAT'S NEW . . . . . . . . . . . . . . . . . . . . . . . . . . . . . . . . . . . . . . 112

HISTORY . . . . . . . . . . . . . . . . . . . . . . . . . . . . . . . . . . . . . . . 112

CONTRIBUTIONS OF AUTHORS . . . . . . . . . . . . . . . . . . . . . . . . . . . . . . . . . . . . . . 112

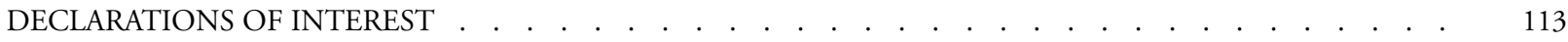

SOURCES OF SUPPORT . . . . . . . . . . . . . . . . . . . . . . . . . . . . . . . . . . . . . . . . . . . 114

DIFFERENCES BETWEEN PROTOCOL AND REVIEW . . . . . . . . . . . . . . . . . . . . . . . . . . 115

NOTES . . . . . . . . . . . . . . . . . . . . . . . . . . . . . . . . . . . 116 


\section{[Intervention Review]}

\section{Adverse side effects of dexamethasone in surgical patients}

Jorinde AW Polderman ${ }^{1}$, Violet Farhang-Razi ${ }^{1}$, Susan Van Dieren ${ }^{1}$, Peter Kranke ${ }^{2}$, J Hans DeVries ${ }^{3}$, Markus W Hollmann ${ }^{1}$, Benedikt Preckel $^{1}$, Jeroen Hermanides ${ }^{1}$

${ }^{1}$ Department of Anaesthesiology, Academic Medical Center (AMC) University of Amsterdam, Amsterdam, Netherlands. ${ }^{2}$ Department of Anaesthesia and Critical Care, University of Würzburg, Würzburg, Germany. ${ }^{3}$ Department of Internal Medicine, Academic Medical Centre, Amsterdam, Netherlands

Contact address: Jorinde AW Polderman, Department of Anaesthesiology, Academic Medical Center (AMC) University of Amsterdam, Meibergdreef 9, Amsterdam, 1105 AZ, Netherlands. j.a.polderman@amc.uva.nl.

Editorial group: Cochrane Anaesthesia, Critical and Emergency Care Group.

Publication status and date: Edited (no change to conclusions), published in Issue 10, 2018.

Citation: Polderman JAW, Farhang-Razi V, Van Dieren S, Kranke P, DeVries JH, Hollmann MW, Preckel B, Hermanides J. Adverse side effects of dexamethasone in surgical patients. Cochrane Database of Systematic Reviews 2018, Issue 8. Art. No.: CD011940. DOI: 10.1002/14651858.CD011940.pub2.

Copyright (C) 2018 The Cochrane Collaboration. Published by John Wiley \& Sons, Ltd.

\section{A B S T R A C T}

\section{Background}

In the perioperative period, dexamethasone is widely and effectively used for prophylaxis of postoperative nausea and vomiting (PONV), for pain management, and to facilitate early discharge after ambulatory surgery.

Long-term treatment with steroids has many side effects, such as adrenal insufficiency, increased infection risk, hyperglycaemia, high blood pressure, osteoporosis, and development of diabetes mellitus. However, whether a single steroid load during surgery has negative effects during the postoperative period has not yet been studied.

\section{Objectives}

To assess the effects of a steroid load of dexamethasone on postoperative systemic or wound infection, delayed wound healing, and blood glucose change in adult surgical patients (with planned subgroup analysis of patients with and without diabetes).

\section{Search methods}

We searched MEDLINE, Embase, the Cochrane Central Register of Controlled Trials (CENTRAL), in the Cochrane Library, and the Web of Science for relevant articles on 29 January 2018. We searched without language or date restriction two clinical trial registries to identify ongoing studies, and we handsearched the reference lists of relevant publications to identify all eligible trials.

\section{Selection criteria}

We searched for randomized controlled trials comparing an incidental steroid load of dexamethasone versus a control intervention for adult patients undergoing surgery. We required that studies include a follow-up of 30 days for proper assessment of the number of postoperative infections, delayed wound healing, and the glycaemic response.

\section{Data collection and analysis}

Two review authors independently screened studies for eligibility, extracted data from relevant studies, and assessed all included studies for bias. We resolved differences by discussion and pooled included studies in a meta-analysis. We calculated Peto odds ratios (ORs) for dichotomous outcomes and mean differences (MDs) for continuous outcomes. Our primary outcomes were postoperative systemic or wound infection, delayed wound healing, and glycaemic response within 24 hours. We created a funnel plot for the primary outcome postoperative (wound or systemic) infection. We used GRADE to assess the quality of evidence for each outcome.

Adverse side effects of dexamethasone in surgical patients (Review)

Copyright () 2018 The Cochrane Collaboration. Published by John Wiley \& Sons, Ltd. 


\section{Main results}

We included in the meta-analysis 38 studies that included adults undergoing a large variety of surgical procedures (i.e. abdominal surgery, cardiac surgery, neurosurgery, and orthopaedic surgery). Age range of participants was 18 to 80 years. There is probably little or no difference in the risk of postoperative (wound or systemic) infection with dexamethasone compared with no treatment, placebo, or active control (ramosetron, ondansetron, or tropisetron) (Peto OR 1.01, 95\% confidence interval (CI) 0.80 to 1.27; 4931 participants, 27 studies; $I^{2}=27 \%$; moderate-quality evidence). The effects of dexamethasone on delayed wound healing are unclear because the wide confidence interval includes both meaningful benefit and harm (Peto OR 0.99, 95\% CI 0.28 to 3.43; 1072 participants, eight studies; $\mathrm{I}^{2}=0 \%$; low-quality evidence). Dexamethasone may produce a mild increase in glucose levels among participants without diabetes during the first 12 hours after surgery (MD $13 \mathrm{mg} / \mathrm{dL}, 95 \%$ CI 6 to 21; 10 studies; 595 participants; I² = 50\%; low-quality evidence). We identified two studies reporting on glycaemic response after dexamethasone in participants with diabetes within 24 hours after surgery (MD $32 \mathrm{mg} / \mathrm{dL}, 95 \%$ CI 15 to 49; 74 participants; I² = 0\%; very low-quality evidence).

\section{Authors' conclusions}

A single dose of dexamethasone probably does not increase the risk for postoperative infection. It is uncertain whether dexamethasone has an effect on delayed wound healing in the general surgical population owing to imprecision in trial results. Participants with increased risk for delayed wound healing (e.g. participants with diabetes, those taking immunosuppressive drugs) were not included in the randomized studies reporting on delayed wound healing included in this meta-analysis; therefore our findings should be extrapolated to the clinical setting with caution. Furthermore, one has to keep in mind that dexamethasone induces a mild increase in glucose. For patients with diabetes, very limited evidence suggests a more pronounced increase in glucose. Whether this influences wound healing in a clinically relevant way remains to be established. Once assessed, the three studies awaiting classification and two that are ongoing may alter the conclusions of this review.

\section{PLAIN LANGUAGE SUMMARY}

\section{Adverse side effects of dexamethasone when administered to adult patients undergoing surgery}

\section{Background}

In the presence of an infection, the body starts an inflammation process. Dexamethasone is a steroid drug that slows down this inflammation process. Long-term treatment with steroid drugs has many side effects such as increased risk of infection, high blood pressure, and development of diabetes. During surgery, dexamethasone is given to the patient to reduce the risk of nausea and vomiting after surgery, to relieve pain, and to make the patient feel better. However, whether short-term treatment with dexamethasone leads to any adverse side effects is not known.

\section{Question}

The reviewers examined current evidence on the adverse side effects of short-term treatment with dexamethasone during surgery. They compared patients receiving dexamethasone to patients not receiving dexamethasone. They particularly looked at the number of infections after surgery and the number of wounds that did not heal well. Furthermore, as long-term treatment with steroids can lead to high blood sugar, they looked at the response of blood sugar within the first 24 hours postoperatively.

\section{What we found.}

Study characteristics: the reviewers searched four digital databases to find all relevant studies on this topic. The evidence is current to 29 January 2018. In total, they retrieved 38 relevant studies. All studies included adults undergoing surgery. A total of 27 studies (4931 participants) had assessed the occurrence of infection after surgery, nine studies (1072 participants) had investigated delayed wound healing, and 10 studies (595 participants) had looked at the effect of dexamethasone on blood sugar.

Key results: after pooling results, reviewers found that dexamethasone had no effect on the development of an infection after surgery, and that wounds healed equally well in both groups. However, the quality of the studies was moderate to low, which means that more studies are needed to support a definitive conclusion. Finally, the mean blood sugar of patients without diabetes receiving dexamethasone was slightly higher than that of patients not receiving dexamethasone (low-quality evidence). In patients with diabetes, this effect seemed to be larger. However, blood sugar was measured in only 74 patients with diabetes, which means that reviewers did not obtain a very accurate estimate. They qualified this as very low-quality evidence.

Adverse side effects of dexamethasone in surgical patients (Review)

Copyright @ 2018 The Cochrane Collaboration. Published by John Wiley \& Sons, Ltd. 
Authors' conclusions: dexamethasone probably does not increase the risk of infection after surgery. Not enough information is available to determine whether dexamethasone has an effect on the time it takes for surgical wounds to heal. However, included studies did not focus on patients with high risk for delayed wound healing, for example, patients with diabetes or those taking steroids; thus more studies are needed on this topic. Additionally, one has to keep in mind that taking dexamethasone leads to a mild increase in blood sugar. For patients with diabetes, very limited evidence suggests a greater increase in blood sugar. Whether or not the small increase in blood sugar has any effect on healing of surgical wounds has yet to be established. Three studies awaiting classification and two ongoing trials may alter the conclusions of this review, once assessed. 


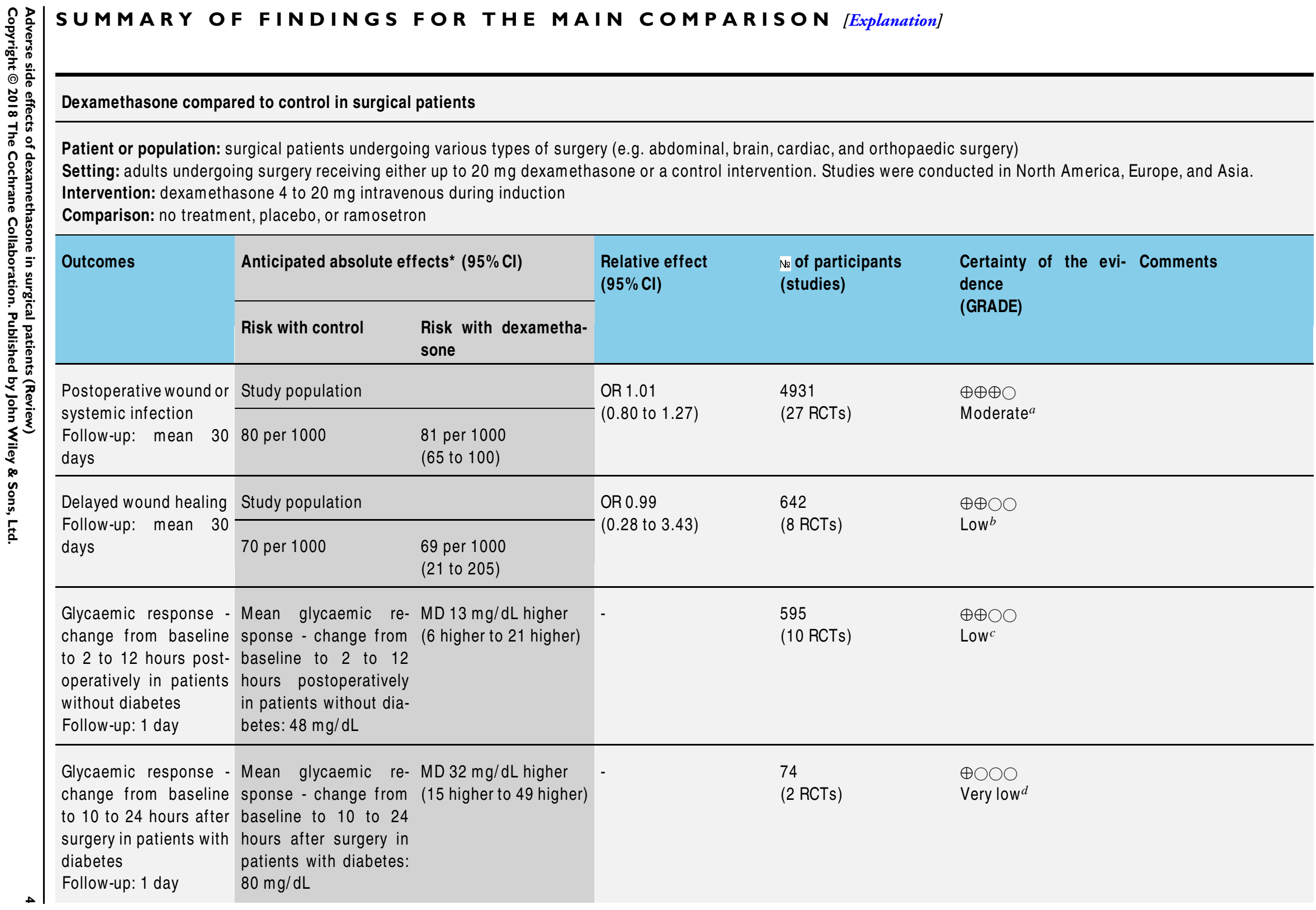


${ }^{*}$ The risk in the intervention group (and its $95 \%$ confidence interval) is based on the assumed risk in the comparison group and the relative effect of the intervention (and its $95 \% \mathrm{Cl})$.

Cl: confidence interval; MD: mean difference; OR: odds ratio; $\mathbf{R C T}$ : randomized controlled trial.

\section{GRADE Working Group grades of evidence}

High certainty: we are very confident that the true effect lies close to that of the estimate of the effect.

Moderate certainty: we are moderately confident in the effect estimate: the true effect is likely to be close to the estimate of the effect, but there is a possibility that it is substantially different.

Low certainty: our confidence in the effect estimate is limited: the true effect may be substantially different from the estimate of the effect.

Very low certainty: we have very little confidence in the effect estimate: the true effect is likely to be substantially different from the estimate of effect

${ }^{a}$ Downgraded by one level owing to imprecision. We chose not to downgrade for risk of bias, as the sensitivity analysis

showed that these studies had little effect on the outcome.

${ }^{b}$ Downgraded by two levels owing to high risk of bias in the included studies and imprecision.

${ }^{c}$ Downgraded by two levels owing to high risk of bias in the included studies and inconsistency.

${ }^{d}$ Downgraded by three levels: one level for high risk of bias and two levels for serious imprecision. 


\section{B A C K G R O U N D}

\section{Description of the condition}

Dexamethasone has several indications and is frequently administered in the perioperative period. First, it has been shown to prevent postoperative nausea and vomiting (PONV) (De Oliveira 2013); however, PONV is still experienced by $20 \%$ to $30 \%$ of surgical patients (Habib 2012). It has been recommended that every person undergoing surgery should be given multi-modal PONV prophylaxis to achieve a PONV-free hospital (Kranke 2014). This would substantially increase the number of people exposed to dexamethasone in the perioperative period. Second, previous metaanalyses have shown significantly lower pain scores two and 24 hours after surgery, plus an opioid-sparing effect after administration of low-dose dexamethasone when used as a co-analgesic (De Oliveira 2011; Waldron 2013). Third, dexamethasone prolongs the duration of peripheral nerve blocks when given in combination with the local anaesthetic, or intravenously (Pehora 2017). Finally, dexamethasone improves postoperative recovery and promotes discharge after ambulatory surgery (Coloma 2001; Murphy 2011b). Therefore, giving every patient a perioperative dose of dexamethasone might be advisable. When general (multi-modal) prophylaxis using dexamethasone is considered, a comprehensive evaluation of associated potential adverse effects is needed (Bartlett 2013). This review therefore focused on the side effects of incidental dexamethasone application at a low dose in the perioperative period. The side effects considered in this review are postoperative systemic or wound infection, delayed wound healing, and hyperglycaemia.

\section{Description of the intervention}

Dexamethasone is most often administered for prophylaxis of PONV and is effective at a single dose ( $4 \mathrm{mg}$ to $10 \mathrm{mg}$ ) given intravenously during surgery (De Oliveira 2013). It has been shown that doses of $1.25 \mathrm{mg}$ to $20 \mathrm{mg}$ administered during surgery lead to a significant reduction in postoperative pain scores (Waldron 2013). A single dose of $4 \mathrm{mg}$ of dexamethasone has been shown to decrease the time to discharge after ambulatory surgery (Coloma 2001), and this is the recommended dose for PONV prophylaxis (Gan 2014). Thus, the dose given intravenously during surgery for the above mentioned reasons ranges between $4 \mathrm{mg}$ and $20 \mathrm{mg}$. After administration of the drug, the concentration of dexamethasone rises quickly and peaks after two to 12 hours (Fauci 1976). However, dexamethasone has a rather long biological half-life of 36 to 72 hours, and it can suppress cortisol levels for up to one week (Fauci 1976).

\section{How the intervention might work}

It is known that long-term treatment with corticosteroids can produce many side effects, such as adrenal insufficiency, hyperglycaemia, and even development of diabetes mellitus (Liu 2014). It has been suggested that the anti-inflammatory and immunosuppressive properties (e.g. inhibition of pro-inflammatory cytokines, reduced ability of leucocytes to enter sites of infection, tissue injury, inhibitory effects on $\mathrm{T}$ and $\mathrm{B}$ cells) may have a negative effect on wound healing and might increase the risk of infection with longterm treatment (Busti 2005). Furthermore, dexamethasone induces hepatic gluconeogenesis and insulin resistance, thereby causing transient hyperglycaemia, which can lead to oxidative stress and endothelial and innate immune dysfunction (Dungan 2009; Qi 2004; Turina 2005). This has been associated with increased risk of wound infection in patients both with and without diabetes (Clement 2004; Smiley 2006). However, it is unknown whether a single dose of dexamethasone given in the perioperative period has the same adverse side effects as are seen with long-term treatment.

\section{Why it is important to do this review}

Although $32 \%$ to $45 \%$ of surgical patients will receive dexamethasone in the perioperative period as part of PONV prophylaxis or multi-modal pain treatment (Dahl 2014; Polderman 2015b), previous meta-analyses have only briefly mentioned the potential adverse effects of a single low dose of dexamethasone (De Oliveira 2013; Waldron 2013). Owing to multiple indications for dexamethasone, these meta-analyses might be subject to selective outcome reporting bias with regard to adverse side effects. Therefore, the current meta-analysis focused on the side effects of dexamethasone given once during the perioperative period for any of the indications mentioned above to guide clinical decision-making with regard to the risk-benefit ratio in patients both with and without diabetes.

\section{O B J E C T I VES}

To assess the effects of a steroid load of dexamethasone on postoperative systemic or wound infection, delayed wound healing, and blood glucose change in adult surgical patients (with planned subgroup analysis of patients with and without diabetes).

\section{METHODS}

\section{Criteria for considering studies for this review}


We searched for randomized controlled trials (RCTs), irrespective of blinding status. We placed no restrictions on publication date or language. We did not include quasi-randomized, cross-over, or observational trials, as these types of studies are more subject to bias, and we expected that a sufficient number of RCTs could be included in this meta-analysis.

\section{Types of participants}

We considered studies with adult participants (according to the definitions of respective study authors) undergoing surgery, both inpatient and day-case surgery, under general or regional anaesthesia.

We excluded studies with paediatric participants (according to the definitions of respective study authors), as paediatric participants might have received different dosages and could respond differently to a steroid load. When the study population consisted of both paediatric and adult participants, the studies had to report results of the adult subgroup separately.

\section{Types of interventions}

We considered RCTs comparing intravenous dexamethasone given during surgery versus no treatment, placebo, or another antiemetic or analgesic drug given to a control group. However, the drug in the control group must not have had any glucocorticosteroid properties. We excluded studies that provided oral, intramuscular, or perineural administration of dexamethasone. As dexamethasone for PONV prophylaxis and pain treatment is rarely given at a high dose, we chose $20 \mathrm{mg}$ as the maximum dose and included studies with repeated doses of dexamethasone up $20 \mathrm{mg}$. We performed a subgroup analysis for single and multiple doses of dexamethasone.

\section{Types of outcome measures}

As several meta-analyses have shown possible beneficial effects of perioperative dexamethasone treatment (De Oliveira 2013; Waldron 2013), we did not include treatment effects in the outcomes of this meta-analysis and focused only on the adverse side effects of dexamethasone. Consequently, we considered trials with intravenous dexamethasone administration for various indications and included trials with sufficient follow-up for assessment of postoperative infection or delayed wound healing and trials with glycaemic measurements. As this strategy might have led to selection bias, we documented all excluded studies based on lack of outcome data.

\section{Primary outcomes}

- Postoperative systemic or wound infection. Follow-up time for this outcome measure should be 30 days or longer. We used study authors' definitions of postoperative systemic and wound infection
- Delayed wound healing. Follow-up time for this outcome measure should be 30 days or longer. We measured the proportion of wounds that had not healed within 30 days

- Glycaemic response within 24 hours. We defined this as the difference between preoperative and postoperative blood glucose. As the peak serum level of dexamethasone is achieved two to 12 hours after injection, the postoperative glucose level had to be measured at least two hours but within 24 hours after dexamethasone administration. We looked at the change from baseline to 12 hours postoperatively and to 24 hours postoperatively on a continuous scale in patients without diabetes. We looked at the change from baseline to 24 hours postoperatively in patients with diabetes

\section{Secondary outcomes}

- Length of hospital stay, measured in days on a continuous scale

- Re-admission or unplanned hospital admission

- C-reactive protein (CRP), measured in the first 24 hours perioperatively

- 30-day all-cause mortality

\section{Search methods for identification of studies}

We searched for RCTs including surgical participants who received dexamethasone as an intervention and included a sufficient followup period (30 or more days) for adverse side effects. When it was stated in the results section that no adverse effects were found, but details of the assessment of adverse side effects (e.g. which adverse side effects, length of follow-up) were not described in the methods section, we contacted the corresponding author to retrieve data on details of the assessment of adverse side effects. We considered for inclusion in this meta-analysis only studies addressing at least one of our primary outcomes with sufficient duration of followup; however, as stated above, we documented all studies that we excluded for lack of outcome data. We placed no restrictions on time covered by the search. We excluded studies published by Yoshitaka Fuji because of the suggested invalidity of these results ( Carlisle 2012). We did not apply any full-text language restrictions. We translated papers that were written in a language other than English.

\section{Electronic searches}

We identified RCTs through literature searching via systematic and sensitive search strategies as outlined in Chapter 6.4 of the Cochrane Handbook for Systematic reviews of Interventions (Higgins 2011). We searched the Cochrane Central Register of Controlled Trials (CENTRAL; January 2018, Issue 1 of 12), in the Cochrane Library (Appendix 1), MEDLINE (1946 to 29 January 2018; Appendix 2), Embase (1947 to 29 January 2018; Appendix 3), and the Web of Science (1900 to 29 January 2018; Appendix 4). 
We searched the following websites for ongoing and unpublished studies on 28 Febuary 2017.

- https://clinicaltrials.gov/.

- http://www.controlled-trials.com.

We developed the search strategy in consultation with the Information Specialist.

\section{Searching other resources}

We handsearched the reference lists of the original included articles to retrieve additional relevant studies. In addition, we handsearched the citations and reference lists of relevant reviews and meta-analyses. When necessary, we contacted trial authors for additional information.

\section{Data collection and analysis}

We used Cochrane's standard methods to select eligible studies (Higgins 2011), and we used a data extraction form to extract data from relevant trials. When no agreement was reached, we planned that a third review author should make the decision, but we found that this was not necessary during the review process. We used the Review Manager statistical package provided by Cochrane to analyse the data (Review Manager 2014).

\section{Selection of studies}

After merging the search results using EndNote software, we removed all duplicate records of the same report (Higgins 2011). Two review authors (JP and VFR) independently screened reports for eligibility based on title and abstract. When we encountered a difference in opinion, we resolved this by discussion between the two review authors (JP and VFR). When necessary, we consulted a third review author (JH). Subsequently, two review authors (JP and VFR) independently screened the full text of eligible studies for compliance with the eligibility criteria. If it remained unclear which adverse side effects were assessed, we contacted the authors of the respective studies to request the relevant information. We documented the studies excluded based on lack of outcome data.

\section{Data extraction and management}

Two review authors (JP and VFR) independently extracted data from the included studies. We recorded all relevant data on the data extraction form that had been developed for the purpose of this review (Appendix 5), and we documented for each trial the following data.

- Details of the study (when and where the study was executed and major sources of funding).

- Details of study participants (demographic characteristics, type and length of surgery).
- Details of the type of intervention (dose, timing, additional medication).

- Details of relevant outcomes (definitions and times of measurement).

- Details of relevant results.

\section{Assessment of risk of bias in included studies}

Two review authors (JP and VFR) independently assessed risk of bias using the Cochrane 'Risk of bias' domains detailed in Appendix 6 and discussed below.

\section{Measures of treatment effect}

When meta-analysis is used to combine results from several studies with binary outcomes, adverse effects may be rare but possibly serious, and thus important (Sutton 2002). As recommended by the Cochrane Handbook for Systematic Reviews of Interventions ( Higgins 2011), we used Peto's odds ratio (OR) to summarise study effects. This provides an unbiased estimate of the treatment effect and has been shown to be particularly appropriate for examining zero-event data.

For the glycaemic response, we retrieved the change from baseline results, which is more objective than the final postoperative glucose measurement, as this latter highly depends on the preoperative value.

Blood glucose and length of hospital stay often are not normally distributed and frequently are reported as median values with an interquartile range. We converted these data to mean values with standard deviations so we could pool the data (Hozo 2005). Regarding secondary outcomes, we calculated Peto's OR for the number of unplanned admissions and for 30-day all-cause mortality, as we also expected these adverse effects to be rare.

\section{Unit of analysis issues}

For dichotomous outcomes, we documented for each group the total number of participants and the number of participants who experienced the outcome. For continuous glucose outcomes, we used the mean of the change from baseline along with the standard deviation for each group and the number of participants included in each group. For other continuous outcomes, we used mean, standard deviation, and number of participants in each group. We did not extract graphically presented data, as we were unable to determine the exact mean and standard deviation from these figures. Instead, we described these results in the appropriate respective section.

\section{Dealing with missing data}

We attempted to retrieve relevant data by contacting the corresponding author of each study with missing data for the outcome of adverse side effects. Furthermore, when more outcomes were reported as a composite endpoint, we contacted investigators to 
request the data for each outcome separately. When these data were nonetheless not available, we excluded the respective study.

\section{Assessment of heterogeneity}

We assessed clinical and methodological heterogeneity, which can lead to statistical heterogeneity. We considered a $\mathrm{Chi}^{2}$ test $\mathrm{P}<$ 0.05 and an $\mathrm{I}^{2}$ statistical value $>60 \%$ as cutoffs for statistical heterogeneity. When we identified heterogeneity, we explored possible causes. When we could not explain the heterogeneity, we proceeded with meta-analysis using a random-effects model. However, when we noted inconsistency in the direction of the effect, we did not perform a meta-analysis of the respective data.

Studies might use different definitions for wound or systemic infection, leading to heterogeneity. We documented the definitions used by the included studies.

\section{Assessment of reporting biases}

We constructed a funnel plot for the primary outcome (postoperative systemic or wound infection) to assess reporting bias. Possible sources of asymmetry in funnel plots - which should be derived from at least 10 studies (Egger 1997) - include selection bias, poor methodological quality leading to inflated effects in smaller studies, and true heterogeneity - artefactual and chance.

\section{Data synthesis}

We used Review Manager software to perform the analysis (Review Manager 2014). When multi-arm studies were included, we used the placebo group as the control group. However, when no 'placebo' group was enrolled in the study, we merged the noncorticosteroid groups to one control group to make a two-arm comparison and to avoid double-counting of participants. We expected that the interventions would be comparable between trials. However, although the intervention might contribute to the observed adverse side effect, it will not be the sole cause of the adverse side effect. Therefore, we believed that it was more appropriate to use a random-effects model and to assess the average intervention effect.

\section{Subgroup analysis and investigation of heterogeneity}

We carried out a subgroup analysis for participants with and without diabetes for the glycaemic response, as patients with diabetes might respond differently to a steroid load compared to patients without diabetes.

We carried out a subgroup analysis for different doses (e.g. $4 \mathrm{mg}$ to $5 \mathrm{mg}$ vs $8 \mathrm{mg}$ to $10 \mathrm{mg}$ vs $20 \mathrm{mg}$ of dexamethasone) to estimate whether the effect is robust for all doses. Furthermore, we carried out a subgroup analysis for a single dose versus multiple doses of dexamethasone, to estimate whether the effect was comparable.

\section{Sensitivity analysis}

We included a sensitivity analysis for the following outcomes: postoperative risk of systemic or wound infection, delayed wound healing, and glycaemic control, while excluding studies with high risk of bias. Furthermore, we carried out a sensitivity analysis that excluded trials with non-normality glucose data, to assess whether these trials introduced a systematic bias.

\section{'Summary of findings' table and GRADE}

We used the GRADE system to assess the methodological quality of trials included in our review, to assess the quality of the body of evidence associated with specific outcomes in our review (postoperative systemic or wound infection; delayed wound healing; glycaemic response: change from baseline to 12 hours postoperatively and change from baseline to 24 hours postoperatively and change from baseline to 24 hours postoperatively in participants with diabetes; re-admission; length of hospital stay; CRP; and mortality), and to construct a 'Summary of findings' table by using GradePro GDT (Guyatt 2008). We constructed one 'Summary of findings' table for the comparison dexamethasone versus control, reporting on postoperative systemic or wound infection, delayed wound healing, and glycaemic control in all participants (change from baseline to 2 to 24 hours) and in participants with diabetes (change from baseline to 10 to 24 hours). The GRADE approach appraises the quality of a body of evidence based on the extent to which one can be confident that an estimate of effect or association reflects the item being assessed. The quality of a body of evidence considers within-study risk of bias (methodological quality), directness of evidence, heterogeneity of data, precision of effect estimates, and risk of publication bias. We resolved differences of opinion by discussion.

\section{RE S U L T S}

\section{Description of studies}

See Summary of findings for the main comparison and Characteristics of included studies.

\section{Results of the search}

(See Figure 1.) 
Figure I. Flow diagram.

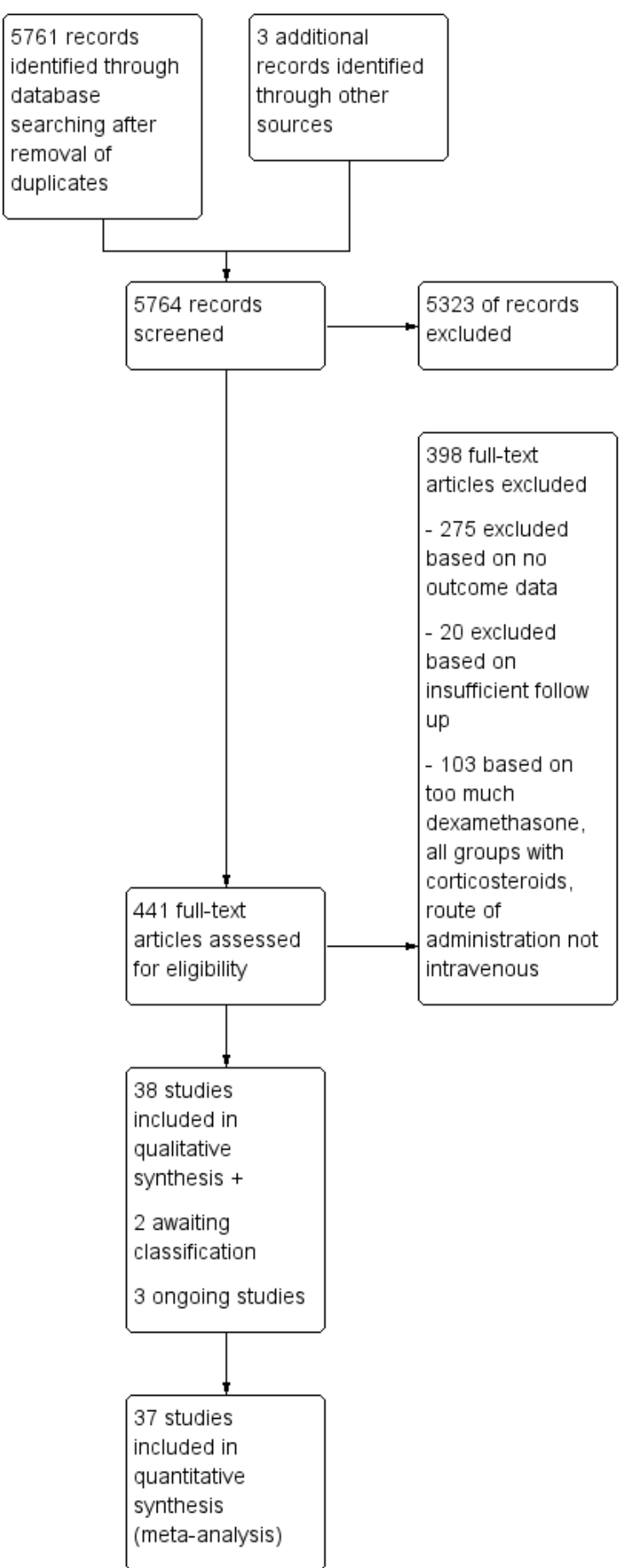

Adverse side effects of dexamethasone in surgical patients (Review) 
We screened 5764 articles on the basis of titles and abstracts; we identified 441 for full-text screening, of which we included 38 articles. We found that 274 studies reported the appropriate study design; however, follow-up for these studies was only 24 to 48 hours, and we therefore subsequently excluded them.

\section{Included studies}

We included 38 RCTs, of which 27 reported on postoperative (systemic or wound) infection, nine reported on delayed wound healing, and 12 reported on glycaemic control. In total, 2750 participants received dexamethasone, and 2640 participants received a control intervention. We have described details of these studies in the Characteristics of included studies table.

\section{Settings}

These RCTs were conducted in the following countries: Australia, Austria, Chile, China, Denmark, Ireland, Italy, Japan, Mexico, New Zealand, Norway, Romania, South Korea, Switzerland, Turkey, UK, and the USA. We have provided below an outline of study characteristics.

\section{Populations and types of surgery}

All of the included studies were conducted in adults undergoing the following different types of surgery.

- Acromioclavicular joint resection or arthroscopic

subacromial decompression repair surgery (Bjornholdt 2014).

- Arthroscopy (Kawanishi 2014).

- Cardiac surgery (Murphy 2011a; Rafiq 2014).

- Colorectal surgery (DREAMS trial collaborators; Kirdak

2008; Kurz 2015; Zargar-Shoshtari 2009).

- Craniotomy (Karacinar 2009).

- Different types of elective surgeries (Abdelmalak 2013a; Abdelmalak 2013b; Tien 2016; Wang 2009).

- Gastric bypass surgery (Nazar 2009).

- Hysterectomy (Murphy 2014).

- Laminectomy with or without fusion (Choi 2013).

- Laparoscopic appendectomy (Kleif 2017).

- Laparoscopic cholecystectomy (Bisgaard 2003; Cowie

2010; Ionescu 2014; Nazar 2011; Sanchez-Rodriguez 2010;

Wakasugi 2015).

- Laparoscopic gynaecological surgery (Corocan 2017).

- Lumbar discectomy (Nielsen 2015).

- Lumbosacral spine surgery (Kalappa 2017).

- Mastectomy (Cortes-Flores 2018).

- Nissen fundoplication (Schietroma 2010).

- Osteotomy (Abukawa 2017).

- Thyroid surgery (Doksrod 2012; Feroci 2011; Schietroma 2013; Worni 2008; Zhang 2016; Zhou 2012).
- Total hip or knee arthroplasty (Backes 2013; Koh 2013; Lei 2017).

\section{Diabetes}

It was unclear whether participants with diabetes were included in most of the studies.

Of the following 21 studies, participants with diabetes were eligible for inclusion in their respective studies (Abdelmalak 2013a; Abdelmalak 2013b; Backes 2013; Cortes-Flores 2018; Doksrod 2012; Feroci 2011; Kleif 2017; Koh 2013; Kurz 2015; Lei 2017; Murphy 2011a; Nazar 2011; Nielsen 2015; Rafiq 2014; Sanchez-Rodriguez 2010; Schietroma 2013; Tien 2016; Wakasugi 2015; Worni 2008; Zargar-Shoshtari 2009; Zhou 2012).

Of those 21 studies, four excluded participants with poorly controlled diabetes. Backes 2013 excluded glycosylated haemoglobin (HbA1c) > 7.5\%; Cortes-Flores 2018 excluded uncontrolled diabetes mellitus (serum glycated haemoglobin level $>8 \%$ ); Murphy 2011a did not define poorly controlled diabetes; and Sanchez-Rodriguez 2010 excluded HbA1c > 8\%.

Four of the 21 studies excluded participants treated with insulin (Feroci 2011; Nazar 2011; Worni 2008; Zhou 2012).

\section{Interventions and comparisons}

Different doses of dexamethasone were used in the perioperative period. Six of the included studies used a low dose ( 4 to $5 \mathrm{mg}$ ) of dexamethasone (Corocan 2017; Ionescu 2014; Karacinar 2009; Kawanishi 2014; Kurz 2015; Murphy 2014). Twenty-seven included studies used an intermediate dose of dexamethasone (8 to $10 \mathrm{mg}$ ) (Abdelmalak 2013b; Abukawa 2017; Backes 2013; Bisgaard 2003; Bjornholdt 2014; Cortes-Flores 2018; Cowie 2010; DREAMS trial collaborators; Feroci 2011; Kalappa 2017; Karacinar 2009; Kirdak 2008; Kleif 2017; Koh 2013; Murphy 2014; Nazar 2009; Nazar 2011; Rafiq 2014; Sanchez-Rodriguez 2010; Schietroma 2010; Schietroma 2013; Tien 2016; Wakasugi 2015; Wang 2009; Worni 2008; Zargar-Shoshtari 2009; Zhou 2012). Seven groups studied a high dose of dexamethasone (12 to $20 \mathrm{mg}$ ) (Abdelmalak 2013a; Doksrod 2012; Choi 2013; Karacinar 2009; Lei 2017; Murphy 2011a; Nielsen 2015).

Three studies used multiple dosis of dexamethasone according to their study design; however, the total dose of dexamethasone did not exceed 20 mg (Abdelmalak 2013a; Lei 2017; Murphy 2011a). Four studies were conducted with an active comparator in the control group: ramosetron (Koh 2013), ondansetron (Rafiq 2014; Tien 2016), or tropisetron (Zhou 2012). Two studies were conducted with an open-label control group, which received a placebo (Ionescu 2014; Kawanishi 2014). Backes 2013 and DREAMS trial collaborators conducted their studies in a 
blinded fashion; however, the control group did not receive a placebo. All other studies were blinded and were conducted with a placebo group (Abdelmalak 2013a; Abdelmalak 2013b; Bisgaard 2003; Bjornholdt 2014; Choi 2013; Corocan 2017; Cortes-Flores 2018; Cowie 2010; Doksrod 2012; Feroci 2011; Kalappa 2017; Karacinar 2009; Kirdak 2008; Kleif 2017; Kurz 2015; Lei 2017; Murphy 2011a; Murphy 2014; Nazar 2009; Nazar 2011; Nielsen 2015; Sanchez-Rodriguez 2010; Schietroma 2010; Schietroma 2013; Wakasugi 2015; Wang 2009; Worni 2008; Zargar-Shoshtari 2009).

\section{Funding}

Five studies (six articles) received commercial funding ( Abdelmalak 2013a; Abdelmalak 2013b; Backes 2013; Bjornholdt 2014; Kleif 2017; Kurz 2015); nine trial groups received funds from research grants (Abukawa 2017; Bisgaard 2003; Corocan 2017; Doksrod 2012; DREAMS trial collaborators; Ionescu 2014; Karacinar 2009; Tien 2016; Zargar-Shoshtari 2009); five studies were supported by the hospital or research department (Doksrod 2012; Murphy 2014; Nazar 2011; Nielsen 2015; Rafiq 2014); and 15 studies did not report on the source of funding (Choi 2013; Cowie 2010; Feroci 2011; Kawanishi 2014; Kirdak 2008; Koh 2013; Murphy 2011a; Nazar 2009; Sanchez-Rodriguez 2010; Schietroma 2010; Schietroma 2013; Wang 2009; Worni 2008; Zhang 2016; Zhou 2012). Two of the co-authors of Backes 2013 reported that they received royalties from DePuy. Authors of Corocan 2017 reported the following conflicts of interest: T.C. is a member of the executive committee of the ANZCA Clinical Trials Network (Australia and New Zealand College of Anaesthetists (ANZCA) CTN). M.P. is an editor of Anaesthesia and Intensive Care and is on the Editorial Board for International Journal of Obstetric Anesthesia, Obstetric Anesthesia Digest, Anesthesiology, and Pain Medicine.

\section{Outcomes}

The definitions used for postoperative wound or systemic infection varied between included studies. Five studies - Abdelmalak 2013a; Ionescu 2014; Kirdak 2008; Kurz 2015; Wakasugi 2015 - scored this according to the Centers for Disease Control and Prevention (CDC) criteria (Horan 2008). Kleif 2017 used the Dindo-Clavien postoperative complications checklist (Dindo 2004). Koh 2013 used the Musculoskeletal Infection Society criteria (Parvizi 2011). Three studies used their own criteria, which included, for example, treatment with antibiotics (Backes 2013; Nielsen 2015; ZargarShoshtari 2009). Seventeen studies did not report the definition used for scoring a postoperative systemic or wound infection ( Abukawa 2017; Bisgaard 2003; Bjornholdt 2014; Choi 2013; Corocan 2017; Cortes-Flores 2018; Doksrod 2012; DREAMS trial collaborators; Feroci 2011; Kawanishi 2014; Lei 2017; Rafiq 2014; Sanchez-Rodriguez 2010; Schietroma 2010; Schietroma 2013; Worni 2008; Zhou 2012).
Nine studies reported delayed wound healing (Bjornholdt 2014; Choi 2013; Doksrod 2012; Feroci 2011; Koh 2013; Kurz 2015; Rafiq 2014; Wakasugi 2015; Worni 2008), specifically assessed and reported by a surgeon performing follow-up, although the respective studies provided no definition for delayed wound healing. In Bjornholdt 2014, a physiotherapist, instead of the surgeon, was responsible for follow-up and diagnosis of delayed wound healing. Kurz 2015 used the Assessing Postoperative Wound Sepsis (ASEPSIS) system to quantify problems with delayed wound healing (Byrne 1989).

Sixteen studies reported glucose values in the perioperative period. However, they showed variability in the time points at which they measured glucose levels. Therefore, we chose to perform three subgroup analyses for the outcome glycaemic control: change from baseline to 2 to 12 hours postoperative, change from baseline to 24 hours postoperative, and change from baseline to 10 to 24 hours postoperative in participants with diabetes. Two studies reported change from baseline values (Abdelmalak 2013b; Tien 2016). Corocan 2017 and Murphy 2014 reported median glucose values with corresponding ranges and the median change from baseline, which we transformed to mean glucose values with standard deviations. Eight studies did not report the change from baseline (Cowie 2010; Doksrod 2012; Kalappa 2017; Murphy 2011a; Murphy 2014; Nazar 2009; Wang 2009; Zhang 2016). We therefore calculated the change from baseline using available data from these studies. We included nine studies in the meta-analysis for change from baseline within 12 hours after dexamethasone administration (Abdelmalak 2013b; Doksrod 2012; Kalappa 2017; Karacinar 2009; Murphy 2011a; Murphy 2014; Nazar 2009; Tien 2016; Wang 2009), as well as six studies for the analysis of change from baseline at 24 hours postoperatively (Corocan 2017; Cowie 2010; Kalappa 2017; Murphy 2014; Tien 2016; Zhang 2016). We performed a subgroup analysis for change from baseline 10 to 24 hours after surgery in participants with diabetes (Murphy 2014; Nazar 2009; Tien 2016).

Four studies evaluated the frequency of re-admission (Ionescu 2014; Kirdak 2008; Sanchez-Rodriguez 2010; Zargar-Shoshtari 2009).

Most often, study authors did not describe baseline CRP levels; however, we expected these levels to be low. Therefore, we assessed only the CRP level measured at 24 hours after surgery (Abdelmalak 2013a; Kirdak 2008; Lei 2017; Zargar-Shoshtari 2009).

We defined mortality as all-cause mortality at 30 days. Seven studies reported this outcome (Abdelmalak 2013a; Cortes-Flores 2018; DREAMS trial collaborators; Feroci 2011; Kirdak 2008; Kurz 2015; Rafiq 2014).

\section{Excluded studies}

We excluded 20 studies based on insufficient length of followup, most often between two and seven days (Abbaszadeh 2012; Al-Shehri 2004; Bianchin 2007; Coloma 2001; Halvorsen 2003; 
Ho 2001; Jung 2013; Kara 1999; Lei 2018a; Liu 2001; Nasiri 2013; Pasternak 2004; Sethi 2016; Snall 2014; Thangaswamy 2010; Tolver 2012; Wang 2000; Wang 2001; Weber 1994; Wu 2007). In three studies, participants received dexamethasone based on a clinical decision (Pasternak 2004; Sethi 2016; Snall 2014). Thus these studies were not randomized; therefore we did not include them (Characteristics of excluded studies).

\section{Studies awaiting classification}

Two studies are awaiting classification (Ko-Iam 2015; Simogai 2016). We could not retrieve the full text of these articles (Characteristics of studies awaiting classification).

\section{Ongoing studies}

We identified three ongoing studies, which will contribute to the body of evidence when they have been completed (Kitcharanant 2016; Sidhu 2017; Wang 2018; Characteristics of ongoing studies).

\section{Risk of bias in included studies}

Figure 2 and Figure 3 show the overall risk of bias and the risk of bias for each study separately. We downgraded the level of evidence for studies that we judged to be at high risk of bias. An expression of concern has been issued for Schietroma 2013. Scientific and ethical concerns have been raised regarding this paper; therefore we have set all domains to high risk of bias (Piccirillo 2017).

Figure 2. Risk of bias graph: review authors' judgements about each risk of bias item presented as percentages across all included studies.

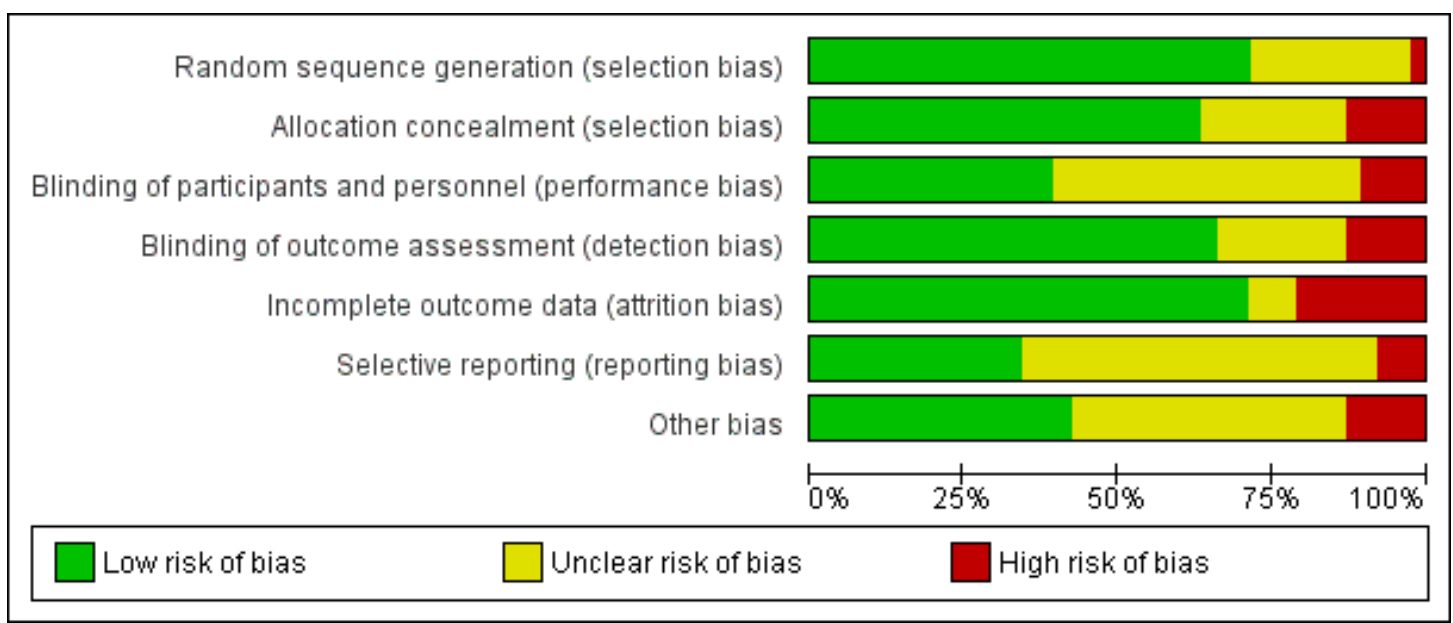


Figure 3. Risk of bias summary: review authors' judgements about each risk of bias item for each included study.

\begin{tabular}{|c|c|c|c|c|c|c|c|}
\hline & 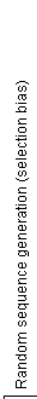 & 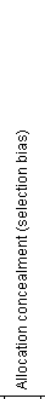 & 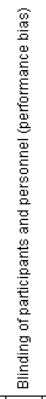 & 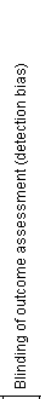 & 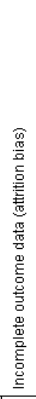 & 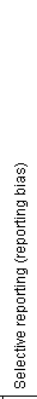 & 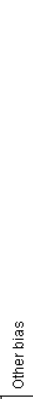 \\
\hline AbdeImalak 2013a & 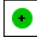 & 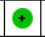 & $?$ & ๑ & (†) & + & $?$ \\
\hline Abdelmalak 2013b & + & $\odot$ & $?$ & $\odot$ & + & $?$ & $?$ \\
\hline Abukawa 2017 & $?$ & $?$ & $?$ & $?$ & ○ & $?$ & $?$ \\
\hline Backes 2013 & + & (†) & $?$ & (†) & + & $?$ & $?$ \\
\hline Bisgaard 2003 & + & + & $?$ & (†) & (†) & $?$ & $?$ \\
\hline Bjornholdt 2014 & + & + & $\odot$ & $\odot$ & $?$ & $\odot$ & + \\
\hline Choi 2013 & $\odot$ & O & 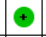 & $\odot$ & (†) & $?$ & ? \\
\hline Corocan 2017 & + & + & + & 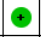 & (†) & $\odot$ & + \\
\hline Cortes-Flores 2018 & $?$ & $?$ & $?$ & $?$ & (†) & $\theta$ & + \\
\hline Cowie 2010 & + & $?$ & $?$ & ๑ & $?$ & $?$ & $?$ \\
\hline Doksrod 2012 & + & $\odot$ & 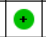 & $?$ & † & $\odot$ & + \\
\hline DREAMS trial collaborators & $\odot$ & $\odot$ & $?$ & ๑ & $\odot$ & $\odot$ & $\odot$ \\
\hline Feroci 2011 & + & - & + & $\odot$ & + & † & + \\
\hline lonescu 2014 & $\odot$ & $?$ & $?$ & ○ & (†) & $?$ & + \\
\hline Kalappa 2017 & $\odot$ & $?$ & $?$ & $?$ & ? & $?$ & + \\
\hline Karacinar 2009 & $?$ & $?$ & $?$ & $?$ & ? & $?$ & $?$ \\
\hline Kawanishi 2014 & $?$ & (†) & O & ○ & † & $?$ & $?$ \\
\hline Kirdak 2008 & $?$ & + & + & (†) & (†) & $?$ & + \\
\hline Kleif 2017 & + & + & + & ๑ & † & $\odot$ & + \\
\hline Koh 2013 & + & $\theta$ & - & ๑ & † & $?$ & $?$ \\
\hline Kurz 2015 & + & + & + & $\odot$ & + & $\theta$ & $?$ \\
\hline Lei 2017 & $?$ & 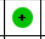 & $?$ & $\odot$ & $\odot$ & + & + \\
\hline Murphy 2011a & $\odot$ & $\odot$ & $\odot$ & $\odot$ & 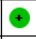 & $?$ & + \\
\hline Murphy 2014 & ๑ & $\odot$ & ( & ๑ & $\odot$ & + & $\odot$ \\
\hline Nazar 2009 & $\odot$ & $?$ & $?$ & $\odot$ & $?$ & $?$ & $?$ \\
\hline Nazar 2011 & + & ๑ & $?$ & $\odot$ & $\theta$ & $?$ & $?$ \\
\hline Nielsen 2015 & + & (†) & + & ๑ & + & + & + \\
\hline Rafiq 2014 & $?$ & + & $?$ & ○ & † & ๑ & ○ \\
\hline Sanchez-Rodriguez 2010 & $?$ & $\odot$ & $?$ & $?$ & - & $?$ & $?$ \\
\hline Schietroma 2010 & ๑ & (†) & $\odot$ & ๑) & † & $?$ & $?$ \\
\hline Schietroma 2013 & $\theta$ & $\theta$ & $\theta$ & ○ & ○ & ○ & ○ \\
\hline Tien 2016 & + & + & $\theta$ & ○ & (†) & $?$ & $?$ \\
\hline Wakasugi 2015 & $\odot$ & $\odot$ & - & ๑ & $\odot$ & $?$ & $?$ \\
\hline Wang 2009 & $?$ & $?$ & $?$ & $?$ & - & $?$ & ? \\
\hline Worni 2008 & + & + & + & • & (†) & $\odot$ & + \\
\hline Zargar-Shoshtari 2009 & + & $\odot$ & + & $\odot$ & + & 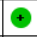 & + \\
\hline Zhang 2016 & $?$ & $?$ & $?$ & $?$ & - & $?$ & $\theta$ \\
\hline Zhou 2012 & + & $\theta$ & $?$ & 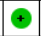 & 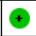 & $?$ & $?$ \\
\hline
\end{tabular}




\section{Random sequence generation}

Twenty-seven of the 38 studies used a computer-generated list for randomization (Abdelmalak 2013a; Abdelmalak 2013b; Backes 2013; Bisgaard 2003; Bjornholdt 2014; Choi 2013; Corocan 2017; Cowie 2010; Doksrod 2012; DREAMS trial collaborators; Feroci 2011; Ionescu 2014; Kalappa 2017; Kleif 2017; Koh 2013; Kurz 2015; Murphy 2011a; Murphy 2014; Nazar 2009; Nazar 2011; Nielsen 2015; Schietroma 2010; Tien 2016; Wakasugi 2015; Worni 2008; Zargar-Shoshtari 2009; Zhou 2012). Ten studies failed to report on the randomization process; therefore their risk of bias was unclear (Abukawa 2017; Cortes-Flores 2018; Karacinar 2009; Kawanishi 2014; Kirdak 2008; Lei 2017; Rafiq 2014; Sanchez-Rodriguez 2010; Wang 2009; Zhang 2016). However, overall we judged these studies to be at high risk of bias and downgraded their level of evidence (Abukawa 2017; Karacinar 2009; Schietroma 2013; Wang 2009; Zhang 2016).

\section{Allocation}

Twenty-four studies had adequate allocation concealment, usually with sequentially numbered opaque sealed envelopes ( Abdelmalak 2013a; Abdelmalak 2013b; Backes 2013; Bisgaard 2003; Bjornholdt 2014; Corocan 2017; Doksrod 2012; DREAMS trial collaborators; Kawanishi 2014; Kirdak 2008; Kleif 2017; Kurz 2015; Lei 2017; Murphy 2011a; Murphy 2014; Nazar 2011; Nielsen 2015; Rafiq 2014; Sanchez-Rodriguez 2010; Schietroma 2010; Tien 2016; Wakasugi 2015; Worni 2008; Zargar-Shoshtari 2009). Nine studies did not describe the randomization and allocation process other than that the study was a randomized study (Abukawa 2017; Cortes-Flores 2018; Cowie 2010; Ionescu 2014; Kalappa 2017; Karacinar 2009; Nazar 2009; Wang 2009; Zhang 2016). We judged these studies to have unclear risk of selection bias. Five studies had high risk of selection bias (Choi 2013; Feroci 2011; Koh 2013; Schietroma 2013; Zhou 2012).

\section{Blinding}

Fifteen studies clearly stated the blinding process for patients and personnel and had low risk of performance bias (Bjornholdt 2014; Choi 2013; Corocan 2017; Doksrod 2012; Feroci 2011; Kirdak 2008; Kleif 2017; Kurz 2015; Murphy 2011a; Murphy 2014; Nielsen 2015; Schietroma 2010; Wakasugi 2015; Worni 2008; Zargar-Shoshtari 2009). All placebo-controlled studies used normal saline in an identical syringe as placebo. In 26 studies, the outcome assessor was adequately blinded to avoid detection bias (Abdelmalak 2013a; Abdelmalak 2013b; Backes 2013; Bisgaard 2003; Bjornholdt 2014; Choi 2013; Corocan 2017; Cowie 2010; DREAMS trial collaborators; Feroci 2011; Kirdak 2008; Kleif 2017; Koh 2013; Kurz 2015; Lei 2017; Murphy 2011a; Murphy
2014; Nazar 2009; Nazar 2011; Nielsen 2015; Schietroma 2010; Schietroma 2013; Wakasugi 2015; Worni 2008; Zargar-Shoshtari 2009; Zhou 2012). Of the 28 studies reporting on postoperative infections, four did not report whether the outcome assessor was blinded, and we judged them to have unclear risk of detection bias (Abukawa 2017; Cortes-Flores 2018; Doksrod 2012; Sanchez-Rodriguez 2010). We judged three studies to have high risk of detection bias, as study authors stated that the outcome assessors in these studies were not blinded (Ionescu 2014; Kawanishi 2014; Rafiq 2014).

\section{Incomplete outcome data}

Seven studies reported no information about dropouts or withdrawals during the study (and we therefore judged them to have high risk of attrition bias) (Abukawa 2017; Kalappa 2017; Karacinar 2009; Nazar 2011; Sanchez-Rodriguez 2010; Wang 2009; Zhang 2016). We judged three studies to have unclear risk of attrition bias; it appeared that no dropouts occurred (Nazar 2009; Cowie 2010), or that more dropouts occurred in the placebo group (Bjornholdt 2014). The remaining studies had low risk of attrition bias (Abdelmalak 2013a; Abdelmalak 2013b; Backes 2013; Bisgaard 2003; Choi 2013; Corocan 2017; Cortes-Flores 2018; Doksrod 2012; DREAMS trial collaborators; Feroci 2011; Ionescu 2014; Kawanishi 2014; Kirdak 2008; Kleif 2017; Koh 2013; Kurz 2015; Lei 2017; Murphy 2011a; Murphy 2014; Nielsen 2015; Rafiq 2014; Schietroma 2010; Tien 2016; Wakasugi 2015; Worni 2008; Zargar-Shoshtari 2009; Zhou 2012).

\section{Selective reporting}

Twenty-one studies had unclear risk of reporting bias, as the study protocol was not published or registered in a trial registry (Abukawa 2017; Backes 2013; Bisgaard 2003; Choi 2013; Cowie 2010; Ionescu 2014; Kalappa 2017; Karacinar 2009; Kawanishi 2014; Kirdak 2008; Koh 2013; Murphy 2011a; Nazar 2009; Nazar 2011; Sanchez-Rodriguez 2010; Schietroma 2010; Tien 2016; Wakasugi 2015; Wang 2009; Zhang 2016; Zhou 2012. Abdelmalak 2013b performed a subgroup analysis of the original data from Abdelmalak 2013a. This subgroup analysis was not prespecified in the study protocol, which was published at the start of the trial. We judged this study to have unclear risk of reporting bias. We identified Kurz 2015 as having high risk of reporting bias. The study protocol was registered; however, not all prespecified outcomes were reported in the final manuscript, and new secondary outcomes were added to the analyses. Furthermore, the study protocol of Cortes-Flores 2018 was registered after enrolment of participants. The primary outcome and the sample size calculation were changed during the course of the study. We judged this study to be at high risk of reporting bias. 


\section{Other potential sources of bias}

We created a funnel plot for our primary outcome: postoperative wound or systemic infection. This plot showed a little asymmetry towards less infection in smaller studies. This could indicate a small risk of positive publication bias (Figure 4).

Figure 4. Funnel plot of comparison: I dexamethasone versus control, outcome: I.I Postoperative systemic or wound infection.

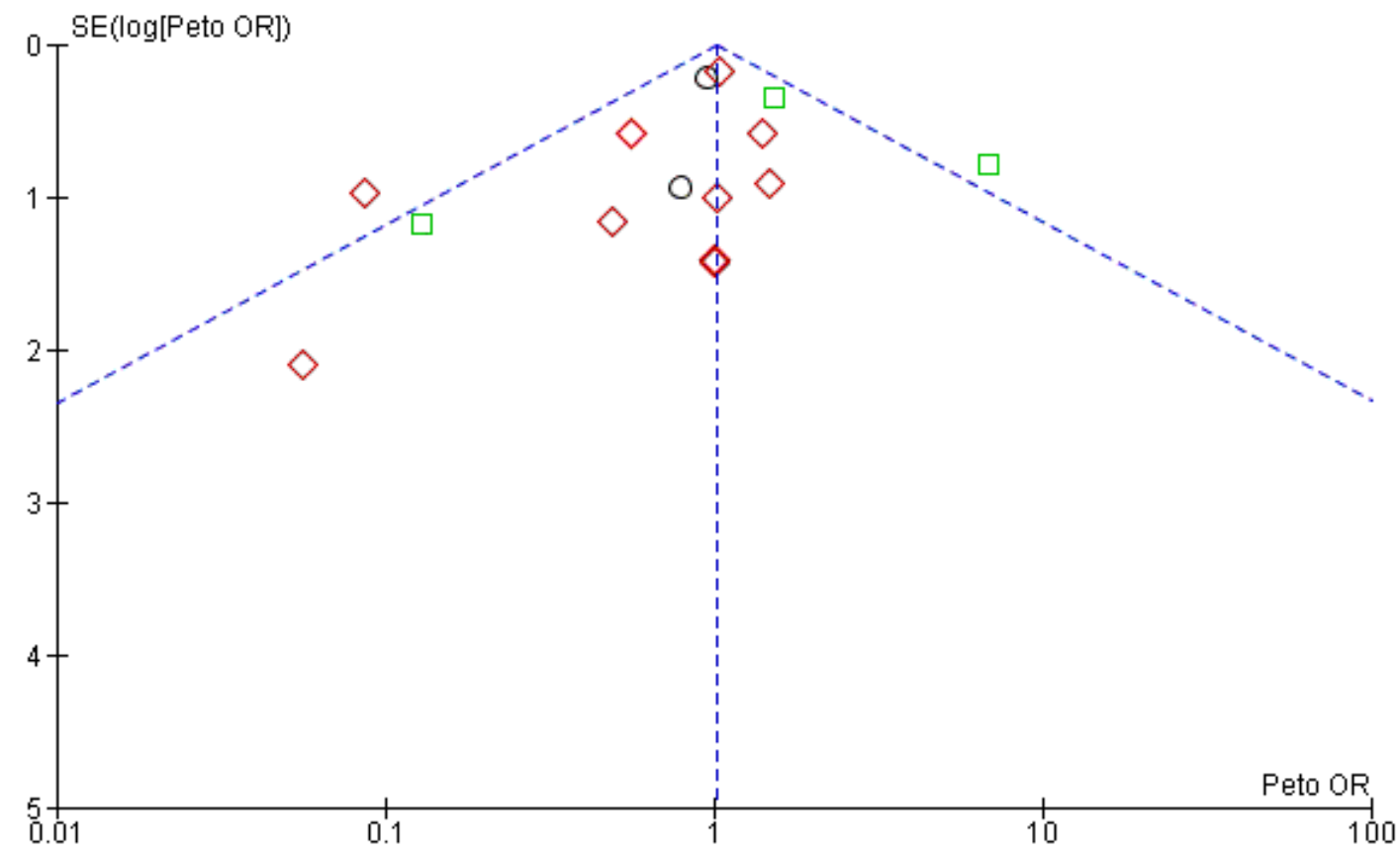

Subgroups

Low dose (4 to $5 \mathrm{mg}$ ) of dexamethasone

$\checkmark$ Intermediate dose ( 8 to $10 \mathrm{mg}$ ) of dexamethasone

High dose (12 to $20 \mathrm{mg}$ ) of dexamethasone

\section{Effects of interventions}

See: Summary of findings for the main comparison Dexamethasone compared to control in surgical patients All included studies can be found in Summary of findings for the main comparison. The assessment of the quality of evidence is shown in this table.

\section{Primary outcomes}

\section{Postoperative wound or systemic infection}

Analysis 1.1 displays the effect of dexamethasone on postoperative wounds or systemic infection.

Two studies reported on postoperative wound or systemic infections but without sufficient length of follow-up; therefore we did not include these studies in the quantitative analysis of postoperative infections (Murphy 2011a; Zhang 2016).

We pooled the results of 27 studies to estimate the effects of dexamethasone on postoperative wounds or systemic infection rates (Abdelmalak 2013a; Abukawa 2017; Backes 2013; Bisgaard 2003; 
Bjornholdt 2014; Choi 2013; Corocan 2017; Cortes-Flores 2018; Doksrod 2012; DREAMS trial collaborators; Feroci 2011; Ionescu 2014; Kawanishi 2014; Kirdak 2008; Kleif 2017; Koh 2013; Kurz 2015; Lei 2017; Nielsen 2015; Rafiq 2014; Sanchez-Rodriguez 2010; Schietroma 2010; Schietroma 2013; Wakasugi 2015; Worni 2008; Zargar-Shoshtari 2009; Zhou 2012). These studies included 4931 participants in total: 2516 in the intervention group and 2415 in the control group. Researchers found no between-group differences in the rate of postoperative wounds or systemic infection (Peto odds ratio (OR) 1.01, 95\% confidence interval (CI) 0.80 to $1.27 ; 4931$ participants; $I^{2}=27 \%$ ). In the subgroup analysis, we found no differences between different dosages ( 4 to $5 \mathrm{mg}$, 8 to $10 \mathrm{mg}$, and 12 to $20 \mathrm{mg}$ ) of dexamethasone. The sensitivity analysis, which excluded studies with high risk of bias, did not yield any different results (Analysis 1.7).

We downgraded the quality of evidence by one level to moderate owing to imprecision (few events). We decided not to downgrade for high risk of bias, as the sensitivity analysis showed that studies with high risk of bias had little effect on the results.

Two studies used multiple doses of dexamethasone in their study design (Analysis 1.2). Results show no differences between single (Peto OR 0.96, 95\% CI 0.76 to 1.22; 4410 participants; 25 studies) and multiple doses of dexamethasone (Peto OR 1.51, 95\% CI 0.75 to $3.02 ; 521$ participants).

\section{Delayed wound healing}

Analysis 1.3 displays the effect of dexamethasone on delayed wound healing.

One study assessed delayed wound healing using a different scoring system and not as a dichotomous outcome; therefore we did not include this study in the quantitative analysis of delayed wound healing (Kurz 2015).

We included eight studies (Bjornholdt 2014; Choi 2013; Doksrod 2012; Feroci 2011; Koh 2013; Rafiq 2014; Wakasugi 2015; Worni 2008), and we pooled the results of 1072 participants: 542 in the intervention group and 530 in the control group. In four studies including 302 participants (Bjornholdt 2014; Choi 2013; Feroci 2011; Worni 2008), delayed wound healing did not occur in either group. Dexamethasone did not increase the incidence of delayed wound healing (Peto OR 0.99, 95\% CI 0.28 to 3.43; 1072 participants, eight studies; $\mathrm{I}^{2}=0 \%$ ). We scored this outcome as having low-quality evidence. Three studies had high risk of bias in the selection, performance, or detection domain (Feroci 2011; Koh 2013; Rafiq 2014). Subsequently, we downgraded the quality of evidence by two levels - one level for high risk of bias and one level for imprecision (small number of events).

In the subgroup analysis, we did not find differences between different dosages of dexamethasone (8 to $10 \mathrm{mg}$ dexamethasone: Peto OR 0.98, 95\% CI 0.24 to 3.96; 912 participants, six studies; $\mathrm{I}^{2}=0 \%$ vs 12 to $20 \mathrm{mg}$ dexamethasone: Peto OR $1.0,95 \% \mathrm{CI}$ 0.06 to $16.21 ; 160$ participants, two studies; $\mathrm{I}^{2}=$ not applicable).
We were not able to perform a sensitivity analysis that excluded trials with high risk of bias. Only three trials without high risk of bias remained (Bjornholdt 2014; Doksrod 2012; Worni 2008). Two of these trials were zero-event trials (Bjornholdt 2014; Worni 2008), and Doksrod 2012 reported one event in either group.

\section{Glycaemic response}

We analysed glycaemic response in three subgroups (Analysis 1.4). we could not include four studies in the quantitative analyses ( Backes 2013; Choi 2013; Feroci 2011; Nazar 2011).

Feroci 2011 reported only postoperative glucose values, without baseline levels. We contacted the corresponding author but did not receive a response. Backes 2013 reported glucose values for participants with and without diabetes receiving dexamethasone; however, researchers reported no glucose values for the control group. Again, we contacted the corresponding author but did not receive a response. Nazar 2011 showed only glucose values in a graph. We contacted the corresponding author, but we were unable to retrieve these results. One study reported glucose levels 18 hours postoperatively, which was outside the range of our prespecified outcome measures (not within 2 to 12 hours or 24 hours after dexamethasone administration); therefore we did not include it in the meta-analysis (Choi 2013).

\section{3a. Glycaemic response within 2 to 12 hours}

Change from baseline was significantly larger in the dexamethasone group than in the control group. We used a random-effects model owing to moderate heterogeneity. We included 10 studies for this outcome (mean difference (MD) $13 \mathrm{mg} / \mathrm{dL}$, 95\% CI 6 to 21; 595 participants; $\mathrm{I}^{2}=50 \%$ ) (Abdelmalak 2013b; Cowie 2010; Doksrod 2012; Kalappa 2017; Karacinar 2009; Murphy 2011a; Murphy 2014; Nazar 2009; Tien 2016; Wang 2009). The quality of evidence was low. We downgraded the quality of evidence for high risk of bias and imprecision (wide confidence intervals).

The sensitivity analysis excluding skewed data showed similar results: MD $17 \mathrm{mg} / \mathrm{dL}, 95 \%$ CI 9 to 25; eight studies, 419 participants; $\mathrm{I}^{2}=47 \%$.

We did not include Feroci 2011 in the meta-analysis owing to lack of baseline measurements. Researchers found significantly higher glucose values in the dexamethasone group than in the control group at eight hours postoperatively.

\section{3b. Glycaemic response at 24 hours}

Six studies including 355 participants reported on this outcome (Corocan 2017; Cowie 2010; Kalappa 2017; Murphy 2014; Tien 2016; Zhang 2016). Change from baseline was greater in the dexamethasone group than in the control group (MD $21 \mathrm{mg} / \mathrm{dl}, 95 \%$ CI -0.2 to $43 ; 450$ participants; $\left.\mathrm{I}^{2}=92 \%\right)$. We downgraded the quality of evidence by three levels to very low quality owing to 
high risk of bias, significant heterogeneity, and small sample sizes with large confidence intervals.

We classified Zhang 2016 as having overall high risk of bias because study authors provided no information in the report about randomization strategy, blinding, and dropouts. This was the largest study for this outcome. When we excluded this study, the results did not change significantly (MD $23 \mathrm{mg} / \mathrm{dL}, 95 \%$ CI -5 to 51 ; 217 participants; $\mathrm{I}^{2}=92 \%$ ). Murphy 2014 used a lower dosage ( $4 \mathrm{mg}$ ) of dexamethasone, and excluding this study resulted in a greater change from baseline $(25 \mathrm{mg} / \mathrm{dL}, 95 \%$ CI 1 to $50 ; 383$ participants; $\mathrm{I}^{2}=93 \%$ ).

Choi 2013 found a $19 \mathrm{mg} / \mathrm{dL}$ increase in glucose 18 hours after surgery when dexamethasone was administered compared to $4 \mathrm{mg} /$ $\mathrm{dL}$ in the control group. However, no statistical analysis was performed on these data. Feroci 2011 found no differences in glucose values at 24 hours postoperatively between participants receiving dexamethasone and those given normal saline. Backes 2013 found a reduction in glucose $(5.0 \mathrm{mg} / \mathrm{dL}) 24$ hours after surgery among participants without diabetes receiving dexamethasone.

\section{3c. Glycaemic response within 10 to 24 hours in participants with diabetes}

We found four studies reporting on glycaemic response within 10 to 24 hours among participants with diabetes (Backes 2013; Nazar 2009; Nazar 2011; Tien 2016). Nazar 2011 depicted glucose values only in a graph, and we did not include this study in the quantitative analysis. However, among participants with diabetes receiving dexamethasone, researchers found a maximum difference in glucose of $34 \mathrm{mg} / \mathrm{dL}$ at 10 hours after dexamethasone administration. The graph shows a smaller maximum difference in glucose for participants with diabetes not receiving dexamethasone. Study authors did not report whether this difference was significant. Backes 2013 did not report glucose values for the control group and therefore could not be included in the quantitative analysis. However, researchers found that participants with diabetes receiving dexamethasone had a change from baseline of $4.8 \mathrm{mg} / \mathrm{dL}$ at 24 hours after the intervention.

Our meta-analysis showed that among participants with diabetes, the change from baseline was significantly greater in the dexamethasone group than in the control group (MD $32 \mathrm{mg} / \mathrm{dL}, 95 \%$ CI 15 to 49 ; 74 participants, two studies; $\mathrm{I}^{2}=0 \%$ ). We downgraded the quality of evidence by three levels to very low, as both studies had high risk of bias and included a very small sample size with very large confidence intervals.

\section{Secondary outcomes}

Fourteen studies reported on length of hospital stay. We did not include three of these studies, as they did not report a standard deviation and we were unable to retrieve these results (Schietroma 2010; Schietroma 2013; Zargar-Shoshtari 2009). Thus, we were able to include 11 studies in the quantitative analysis with a total of 1794 participants for whom this outcome was reported (Backes 2013; Bisgaard 2003; Feroci 2011; Kirdak 2008; Kurz 2015; Lei 2017; Murphy 2011a; Rafiq 2014; Sanchez-Rodriguez 2010; Wakasugi 2015; Worni 2008). However, pooling these data showed high heterogeneity (81\%) combined with inconsistency in the direction of effect. Therefore, we decided not to perform the meta-analysis. We downgraded the quality of evidence by three levels to very low quality owing to high risk of bias, imprecision, and inconsistency.

\section{Re-admission}

We pooled the data on 339 participants (Ionescu 2014; Kirdak 2008; Sanchez-Rodriguez 2010; Zargar-Shoshtari 2009). Use of dexamethasone was not associated with greater risk of re-admission (risk ratio (RR) 1.18, 95\% CI 0.43 to 3.25 ; 339 participants; $\left.\mathrm{I}^{2}=0 \%\right)$. The largest study contributing to this outcome had high risk of bias (Sanchez-Rodriguez 2010). We scored the quality of evidence for this outcome as very low (downgraded by three levels) owing to high risk of bias, imprecision, and significant heterogeneity (Analysis 1.5).

\section{C-reactive protein (CRP) levels one day postoperatively}

Six studies reported on CRP levels one day postoperatively (Abdelmalak 2013a; Bisgaard 2003; Kirdak 2008; Schietroma 2010; Schietroma 2013; Zargar-Shoshtari 2009). Three of these studies displayed CRP levels only in a figure, without error bars (Bisgaard 2003; Schietroma 2010; Schietroma 2013). We contacted the corresponding authors to retrieve the original data, but we were unable to retrieve these data. All figures showed lower CRP levels in the dexamethasone group at day one postoperatively. The other four studies, with a total of 468 participants, reported CRP levels at one day postoperatively (Abdelmalak 2013a; Kirdak 2008; Lei 2017; Zargar-Shoshtari 2009). Owing to the imprecise estimate, high heterogeneity, and inconsistency in the direction of effect, we decided not to conduct a meta-analysis for this outcome but only described the outcome data from the different trials. Abdelmalak 2013a and Lei 2017 reported that CRP increased significantly more in the control group than in the dexamethasone group. Kirdak 2008 and Zargar-Shoshtari 2009 reported no differences in CRP levels between the dexamethasone and control groups at postoperative day one.

We downgraded the quality of evidence by three levels to very low owing to high risk of bias, inconsistency, and imprecision.

\section{Length of hospital stay}

\section{Mortality}

Adverse side effects of dexamethasone in surgical patients (Review) 
Seven studies including 2646 participants reported 30-day mortality scores (Abdelmalak 2013a; Cortes-Flores 2018; DREAMS trial collaborators; Feroci 2011; Kirdak 2008; Kurz 2015; Rafiq 2014). Perioperative dexamethasone was not associated with higher 30day mortality (Peto OR $0.80,95 \%$ CI 0.38 to 1.66 ; $\mathrm{I}^{2}=0 \%$ ). Owing to high risk of bias and imprecision, we downgraded the quality of evidence to low (Analysis 1.6).

\section{DISCUSSION}

\section{Summary of main results}

The objective of this systematic review was to assess whether intraoperative use of a low dose of dexamethasone increased the risk of postoperative systemic or wound infection, delayed wound healing, and hyperglycaemia in surgical patients. We identified 27 randomized controlled trials (RCTs) that reported on postoperative systemic or wound infection, eight trials that reported on delayed wound healing, and 11 studies that reported on glycaemic response, to help us answer our questions. We found that a single dose of dexamethasone did not increase the risk of postoperative systemic or wound infection (Peto odds ratio (OR) 1.01, 95\% confidence interval (CI) 0.80 to 1.27 ; 4931 participants, 27 studies; $\mathrm{I}^{2}=27 \%$, low-quality evidence) and did not increase the risk of delayed wound healing (Peto OR 0.99, 95\% CI 0.28 to 3.43; 1072 participants, eight studies; $\mathrm{I}^{2}=0 \%$; low-quality evidence) but significantly increased glucose values in the first 12 hours after surgery (mean difference (MD) $13.31 \mathrm{mg} / \mathrm{dL}, 95 \%$ CI 5.91 to 20.71 ; 595 participants, 10 studies; $\mathrm{I}^{2}=50 \%$; low-quality evidence).

\section{Overall completeness and applicability of evidence}

\section{Postoperative infection}

We included studies with a wide spectrum of surgical interventions, and this increases the applicability of our findings to everyday practice. Infection rates differed between studies, ranging from $0 \%$ to $18 \%$ and reflecting the different surgical populations. We observed no statistical heterogeneity for this outcome; however, we noted a large variety of definitions for postoperative (wound or systemic) infection. Incidences of postoperative infection in the individual studies are likely to be an underestimation, as most studies were very small. However, larger studies and this sensitivity analysis also did not show any effect of dexamethasone on postoperative infection, indicating the validity of current results (Analysis 1.7; Abdelmalak 2013a; DREAMS trial collaborators). Nonetheless, the required information size probably exceeds currently available evidence, and further studies are needed for a definitive conclusion.

\section{Delayed wound healing}

Only eight studies included in this meta-analysis reported on delayed wound healing, with an incidence of 0 to $2 \%$ (Bjornholdt 2014; Choi 2013; Doksrod 2012; Feroci 2011; Koh 2013; Rafiq 2014; Wakasugi 2015; Worni 2008), as opposed to incidences of $7 \%$ to $32 \%$ that have been reported in observational and retrospective studies (Althumairi 2016; SanGiovanni 2016). Participants at increased risk for delayed wound healing (e.g. participants with diabetes, those on immunosuppressive drugs) were not included in the randomized studies reporting on delayed wound healing included in this meta-analysis; therefore our findings should be extrapolated to the clinical setting with care.

\section{Glycaemic response}

Twelve studies measured blood glucose values in the perioperative period when dexamethasone was given (Abdelmalak 2013b; Corocan 2017; Cowie 2010; Doksrod 2012; Kalappa 2017; Karacinar 2009; Murphy 2011a; Murphy 2014; Nazar 2009; Tien 2016; Wang 2009; Zhang 2016). Only one study adequately reported on the relation between blood glucose values and the incidence of postoperative complications (Doksrod 2012). This metaanalysis showed that glucose was $13 \mathrm{mg} / \mathrm{dL}$ higher when participants had received dexamethasone than when participants had not received dexamethasone in the first 12 hours after surgery. In a clinical setting, we can therefore expect a mild increase in glucose values when dexamethasone is administered. However, as shown above, this mild increase in glucose is probably not associated with increased risk of postoperative infection.

For patients with diabetes, very limited evidence is available on the glycaemic response to dexamethasone. We could identify only two studies reporting on this outcome (74 participants) (Nazar 2009; Tien 2016). This group is too small to support definitive conclusions. However, data so far suggest an increase in glucose values when dexamethasone is administered in the perioperative period to patients with diabetes mellitus.

\section{Quality of the evidence}

We used the GRADE criteria to assess the quality of evidence per outcome measure. We scored evidence on postoperative infections as moderate quality. We downgraded the level of evidence by one level owing to imprecision. The sensitivity analysis showed little to no effect of studies at high risk of bias; therefore we chose not to downgrade for high risk of bias. We scored delayed wound healing and glycaemic response in the first 12 hours as low-quality evidence because of high risk of bias and limited events per study, 
leading to imprecision. We downgraded glycaemic response in participants with diabetes to very low quality of evidence - two levels for imprecision and one for high risk of bias. For glycaemic response at 24 hours, we downgraded the level of evidence to very low quality owing to imprecision, risk of bias, and inconsistency. Although we do not question the estimated direction of the effect, we are not confident that we found a reliable effect size for these outcomes. Additionally, we did not perform a meta-analysis for length of hospital stay and C-reactive protein (CRP) values owing to high heterogeneity and inconsistency in the direction of effect.

\section{Potential biases in the review process}

During the review process, we adhered to the guidelines set by the Cochrane Review Group to minimise bias.

This systematic review assessed the adverse effects of an incidental steroid load of dexamethasone in the surgical population. The incidence of adverse effects reported in individual studies is generally low, which suggests that the incidence is actually low or that these effects are easily missed, especially in small studies. Pooling of data from small studies creates a much larger sample size. However, if adverse effects did not occur in the small studies, pooling results of these studies could reveal a falsely low incidence of adverse effects. In this systematic review, owing to the very low incidence of delayed wound healing and re-admission, the effect of dexamethasone on these outcomes might be underestimated.

We did an exploratory analysis and included Murphy 2011a and Zhang 2016 in the analysis of postoperative wound or systemic infection, although follow-up for these studies was too short. This yielded similar results (Peto OR 1.01, 95\% CI 0.80 to $1.27 ; 5273$ participants, 29 studies; $\mathrm{I}^{2}=23 \%$; low-quality evidence, analysis not shown).

We included studies that reported on a large variety of surgical procedures. Each procedure has its own risk of postoperative infection. This could potentially bias our results. Two studies excluded patient groups with high risk of postoperative infection from analyses during the trial (Choi 2013; Rafiq 2014). This could also bias the results of our meta-analysis.

Furthermore, the large variety of surgical procedures reported led to a large variety of surgical wounds, ranging from very small wounds (e.g. laparoscopy) to large wounds (sternotomy). Also the length of hospital stay depends significantly on the type of surgery performed.

When length of follow-up was not specifically stated in the full text of the article, we contacted the corresponding author, to minimise this bias. Still, we excluded 270 trials owing to insufficient followup for adverse events, which could have introduced selection bias. Also, four studies depicted glucose values and CRP only in a graph, not numerically (Bisgaard 2003; Nazar 2011; Schietroma 2010; Schietroma 2013). We tried to obtain these results from the corresponding authors but learned that they are not available. Therefore, we reported these studies only descriptively.
Ongoing studies and those awaiting classification could have a potential impact on the body of evidence and thus are a potential source of bias (Kitcharanant 2016; Ko-Iam 2015; Sidhu 2017; Simogai 2016; Wang 2018).

Finally, we think it is worth mentioning that an expression of concern has been issued for one of the included studies (Schietroma 2013). Scientific and ethical concerns surround this paper (Piccirillo 2017). As the paper is not retracted, we judged this paper to be at very high risk of bias.

\section{Agreements and disagreements with other studies or reviews}

The objective of this review was to assess the effects of a steroid load of dexamethasone on postoperative systemic or wound infection, delayed wound healing, and blood glucose change in adult surgical patients. Owing to the multiple indications for dexamethasone, previous systematic reviews on the beneficial effects of dexamethasone were subject to selective outcome reporting bias regarding the adverse effects. Waldron 2013 and De Oliveira 2011 conducted a systematic review on the effects of dexamethasone on postoperative pain; both assessed adverse effects as secondary outcomes and found no increase in the risk of infection. Waldron 2013 also performed an analysis on delayed wound healing as a secondary outcome and found no increase in the risk of delayed wound healing. De Oliveira 2011 was unable to perform an analysis on delayed wound healing, as review authors included only zero-event trials in this systematic review. Waldron 2013 also looked at the glycaemic effect of dexamethasone after 24 hours, which showed mildly higher blood glucose levels in the dexamethasone group. More recently, a meta-analysis was performed to examine the safety of glucocorticosteroids in non-cardiac surgery. This meta-analysis included studies with dexamethasone, methylprednisolone, or hydrocortisone. Toner 2017 assessed the effect on the incidence of 'any infection' as a primary outcome and assessed glucose and length of hospital stay as secondary outcomes. Similar to our study, these review authors found no increase in the risk of infection (odds ratio (OR) $0.8,95 \%$ CI 0.6 to 1.2 ), a higher glucose value 12 hours after surgery in patients without diabetes (weighted mean difference (WMD) $14 \mathrm{mg} / \mathrm{dL}, 95 \%$ CI 2.0 to 25.9 ), and no difference in length of stay (WMD -0.3 days, 95\% CI -1.4 to 0.9). Given that the incidence of postoperative infection is low, and because it is easily missed in small studies, it could be helpful to review retrospective evidence on this topic. Assante 2015 identified five large retrospective studies, which included from 235 to 3449 participants and assessed the effect of dexamethasone on postoperative infection. Four studies found no increase in the risk of postoperative infection in the dexamethasone group (Bolac 2013; Corcoran 2010; Eberhart 2011a; Gali 2012). One study found an increased risk of postoperative infection; however, researchers excluded specific types of infections from the analysis (Percival 2010). In summary, available evidence from larger studies suggests 
no harmful effect of an incidental steroid load of dexamethasone with respect to risk of postoperative infection.

In this systematic review, we assessed dexamethasone administered only via the intravenous route. Only two studies assessed the effects of oral dexamethasone on postoperative infection and glycaemic response (Eberhart 2006; Eberhart 2011b). Both studies have presented findings consistent with the conclusions provided in this systematic review. Adding these studies to the respective analysis showed the same results (postoperative systemic or wound infection: Peto OR 1.01, 95\% CI 0.80 to $1.27 ; 5082$ participants, 28 studies; $\mathrm{I}^{2}=23 \%$; low-quality evidence).

On the other hand, we consistently found that dexamethasone increased blood glucose levels, which could impair leucocyte function and formation of epithelia in the wound (Durmus 2003). However, as this meta-analysis now shows that a single dose of dexamethasone in patients without diabetes does not increase the risk of infection, mild transient hyperglycaemia induced by dexamethasone probably is not clinically relevant. One has to keep in mind that patients with higher risk of postoperative infection and delayed wound healing (e.g. patients with diabetes) probably were not included in most of the included trials. Therefore, further research is needed to establish the safety of dexamethasone, especially in high-risk patients. The PADDI trial is currently recruiting patients (Sidhu 2017). This trial aims to assess the impact of dexamethasone on surgical site infection 30 days after surgery, with stratification for diabetes status. Researchers randomize patients undergoing surgery under general anaesthesia to receive either 8 $\mathrm{mg}$ of dexamethasone or placebo during the perioperative period. They aim to include 8880 adults. As of 26 March 2018, 51 sites were recruiting and 4310 participants had been enrolled.

\section{A U THORS, CONCLUSIONS}

\section{Implications for practice}

A single dose of dexamethasone probably does not increase the risk for postoperative infection. It is uncertain whether it has an effect on delayed wound healing in the general surgical population because of imprecision in trial results. Participants with increased risk for delayed wound healing (e.g. participants with diabetes, those on immunosuppressive drugs) were not included in the randomized studies reporting on delayed wound healing included in this meta-analysis; therefore, our findings should be extrapolated to the clinical setting with caution. Furthermore one has to keep in mind that dexamethasone induces a mild increase in glucose. For patients with diabetes, very limited evidence suggests a more pronounced increase in glucose. Whether this influences wound healing in a clinically relevant way remains to be established. Three studies awaiting classification and two ongoing trials may alter the conclusions of this review, once assessed (Kitcharanant 2016; Ko-Iam 2015; Sidhu 2017; Simogai 2016; Wang 2018).

\section{Implications for research}

Patients at high risk for delayed wound healing or postoperative infection are not adequately represented in the current body of evidence. Future research should focus on the clinical implications of dexamethasone-induced hyperglycaemia for patients with diabetes or at high risk for delayed wound healing. We are awaiting results of the PADDI trial, in which these patients are represented (Sidhu 2017).

\section{ACKNOWLEDGEMENTS}

We would like to thank Arash Afshari (Content Editor), Nathan Pace (Statistical Editor), Francisco Pasquel and Albert Moore (Peer Reviewers), Brian Stafford (Consumer Referee), and Andrew Smith (Co-ordinating Editor), for their help and editorial advice during preparation of this systematic review.

We also would like to thank Rodrigo Cavallazzi (Content Editor), Jing (Sophia) Xie (Statistical Editor), and Anthony Absalom and Francisco Pasquel (Peer Reviewers) for their help and editorial advice during preparation of the protocol for the systematic review (Polderman 2015a).

We acknowledge K Hovhannisyan, J Vendt, and FS van EttenJamaludin for their help with the search strategy. We acknowledge Yvonne Jelting for her critical review and comments with regards to the bias domains discussed in the manuscript. 


\section{R E F E R E NCES}

\section{References to studies included in this review}

Abdelmalak 2013a \{published data only\}

Abdelmalak BB, Bonilla A, Mascha EJ, Maheshwari A,

Tang WH, You J, et al. Dexamethasone, light anaesthesia, and tight glucose control (DeLiT) randomized controlled trial. British Journal of Anaesthesia 2013;111(2):209-21. PUBMED: 23539236]

Abdelmalak 2013b \{published data only\} Abdelmalak BB, Bonilla AM, Yang D, Chowdary HT, Gottlieb A, Lyden SP, et al. The hyperglycemic response to major noncardiac surgery and the added effect of steroid administration in patients with and without diabetes. Anesthesia and Analgesia 2013;116(5):1116-22. PUBMED: 23558840]

Abukawa 2017 \{published data only\}

Abukawa H, Ogawa T, Kono M, Koizumi T, Kawase-Koga Y, Chikazu D. Intravenous dexamethasone administration before orthognathic surgery reduces the postoperative edema of the masseter muscle: a randomized controlled trial. Journal of Oral Maxillofacial Surgery 2017;75(6): 1257-62. PUBMED: 28157491$]$

Backes 2013 \{published data only\}

Backes JR, Bentley JC, Politi JR, Chambers BT. Dexamethasone reduces length of hospitalization and improves postoperative pain and nausea after total joint arthroplasty: a prospective, randomized controlled trial. Journal of Arthroplasty 2013;28(8 Suppl):11-7. PUBMED: 23937923 ]

Bisgaard 2003 \{published data only\}

Bisgaard T, Klarskov B, Kehlet H, Rosenberg J. Preoperative dexamethasone improves surgical outcome after laparoscopic cholecystectomy: a randomized double-blind placebocontrolled trial. Annals of Surgery 2003;238(5):651-60. PUBMED: 14578725]

Bjornholdt 2014 \{published data only\}

Bjornholdt KT, Monsted PN, Soballe K, Nikolajsen L. Dexamethasone for pain after outpatient shoulder surgery: a randomised, double-blind, placebo-controlled trial. Acta Anaesthesiologica Scandinavica 2014;58(6):751-8. PUBMED: 24825530]

Choi 2013 \{published data only\}

Choi YS, Shim JK, Song JW, Kim JC, Yoo YC, Kwak YL. Combination of pregabalin and dexamethasone for postoperative pain and functional outcome in patients undergoing lumbar spinal surgery: a randomized placebocontrolled trial. Clinical Journal of Pain 2013;29(1):9-14. PUBMED: 22751028]

Corocan 2017 \{published data only\}

Corocan T, Paech M, Law D, Muchatuta NA, French M, Ho KM. Intraoperative dexamethasone alters immune cell populations in patients undergoing elective laparoscopic gynaecological surgery. British Journal of Anaesthesia 2017; 119(2):221-30. PUBMED: 28854534]
Cortes-Flores 2018 \{published data only (unpublished sought but not used)\}

Cortés-Flores AO, Jiménez-Tornero J, Morgan-Villela G, Delgado-Gómez M, Zuloaga-Fernández Del Valle CJ, García-Rentería J, et al. Effects of preoperative dexamethasone on postoperative pain, nausea, vomiting and respiratory function in women undergoing conservative breast surgery for cancer: results of a controlled clinical trial. European Journal of Cancer Care 2018;27(1):DOI: 10.1111. PUBMED: 28474341]

\section{Cowie 2010 \{published data only\}}

Cowie BS, Allen KJ, Said SA, Inder WJ. Anti-emetic doses of dexamethasone suppress cortisol response in laparoscopic cholecystectomy. Anaesthesia and Intensive Care 2010;38(4): 667-70. PUBMED: 20715729]

Doksrod 2012 \{published data only\}

Doksrod S, Sagen O, Nostdahl T, Raeder J. Dexamethasone does not reduce pain or analgesic consumption after thyroid surgery: a prospective, randomized trial. Acta Anaesthesiologica Scandinavica 2012;56(4):513-9. PUBMED: 22924169]

\section{DREAMS trial collaborators \{published data only\}} DREAMS Trial Collaborators and West Midlands Research Collaborative. Dexamethasone versus standard treatment for postoperative nausea and vomiting in gastrointestinal surgery: randomised controlled trial (DREAMS Trial). BMJ 2017;357(1455):10.1136/bmj.j1455. PUBMED: 28420629]

Feroci 2011 \{published data only\} Feroci F, Rettori M, Borrelli A, Lenzi E, Ottaviano A, Scatizzi M. Dexamethasone prophylaxis before thyroidectomy to reduce postoperative nausea, pain, and vocal dysfunction: a randomized clinical controlled trial. Head \& Neck 2011;33(6):840-6. PUBMED: 20737495]

\section{Ionescu 2014 \{published data only\}}

Ionescu DC, Hadade AI, Mocan TA, Margarit SD. The influence of a prophylactic dose of dexamethasone for postoperative nausea and vomiting on plasma interleukin concentrations after laparoscopic cholecystectomy: a randomised trial. European Journal of Anaesthesiology 2014; 31(4):204-11. PUBMED: 23880908 ]

Kalappa 2017 \{published data only\}

Kalappa S, Sridhar RB, Nagappa S. Comparing the efficacy of caudal with intravenous dexamethasone in the management of pain following lumbosacral spine surgeries: a randomized double blinded controlled study. Anesthesia Essays and Researches 2017;11(2):416-20. PUBMED: 28663633]

\section{Karacinar 2009 \{published data only\}}

Karacinar M, Madenoglu H, Aksu R, Bicer C, Dogru K, Boyaci A. The effect of different doses of dexamethasone on blood glucose, serum electrolytes and postoperative nauseavomiting in craniotomies [Kraniyotomilerde farkli dozlarda deksametazonun kan glukozu, elektrolitler ve postoperatif 
bulanti kusma uzerine etkisi LA]. Erciyes Tip Dergisi

[Internet] 2009;31(3):218-25. EMBASE: 2010030961]

\section{Kawanishi 2014 \{published data only\}}

Kawanishi R, Yamamoto K, Tobetto Y, Nomura K, Kato M, Go R, et al. Perineural but not systemic low-dose dexamethasone prolongs the duration of interscalene block with ropivacaine: a prospective randomized trial. Local and Regional Anesthesia 2014;7:5-9. PUBMED: 24817819]

Kirdak 2008 \{published data only\}

Kirdak T, Yilmazlar A, Cavun S, Ercan I, Yilmazlar T. Does single, low-dose preoperative dexamethasone improve outcomes after colorectal surgery based on an enhanced recovery protocol? Double-blind, randomized clinical trial. American Surgeon 2008;74(2):160-7. PUBMED: 18306871]

\section{Kleif 2017 \{published data only\}}

Kleif J, Kirkegaard A, Vilandt J, Gogenur I. Randomized clinical trial of preoperative dexamethasone on postoperative nausea and vomiting after laparoscopy for suspected appendicitis. British Journal of Surgery 2017;104(4): 384-92. PUBMED: 28072446]

Koh 2013 \{published data only\} Koh IJ, Chang CB, Lee JH, Jeon YT, Kim TK. Preemptive low-dose dexamethasone reduces postoperative emesis and pain after TKA: a randomized controlled study. Clinical Orthopaedics and Related Research 2013;471(9):3010-20. PUBMED: 23645340]

Kurz 2015 \{published data only\}

Kurz A, Fleischmann E, Sessler DI, Buggy DJ, Apfel C, Akca O, et al. Effects of supplemental oxygen and dexamethasone on surgical site infection: a factorial randomized trial. British Journal of Anaesthesia 2015;115 (3):434-43. PUBMED: 25900659]

Lei 2017 \{published data only\} Lei Y, Huang Q, Xu B, Zhang S, Cao G, Pei F. Multiple low-dose dexamethasone further improves clinical outcomes following total hip arthroplasty. Journal of Arthroplasty 2017; S0883-5403(17):doi: 10.1016. PUBMED: 29258763]

Murphy 2011a \{published data only\}

Murphy GS, Sherwani SS, Szokol JW, Avram MJ, Greenberg SB, Patel KM, et al. Small-dose dexamethasone improves quality of recovery scores after elective cardiac surgery: a randomized, double-blind, placebo-controlled study. Journal of Cardiothoracic and Vascular Anesthesia 2011;25(6):950-60. PUBMED: 21565530]

Murphy 2014 \{published data only\} Murphy GS, Szokol JW, Avram MJ, Greenberg SB, Shear T, Vender JS, et al. The effect of single low-dose dexamethasone on blood glucose concentrations in the perioperative period: a randomized, placebo-controlled investigation in gynecologic surgical patients. Anesthesia and Analgesia 2014;118(6):1204-12. PUBMED: 24299928 ]

Nazar 2009 \{published data only\}

Nazar CE, Lacassie HJ, Lopez RA, Munoz HR. Dexamethasone for postoperative nausea and vomiting prophylaxis: effect on glycaemia in obese patients with impaired glucose tolerance. European Journal of Anaesthesiology 2009;26(4):318-21. PUBMED: 19401661]

\section{Nazar 2011 \{published data only\}}

Nazar CE, Echevarria GC, Lacassie HJ, Flores RA, Munoz HR. [Effects on blood glucose of prophylactic dexamethasone for postoperative nausea and vomiting in diabetics and non-diabetics]. Revista Medica de Chile 2011; 139(6):755-61. PUBMED: 22051756 ]

\section{Nielsen 2015 \{published data only\}}

Nielsen RV, Siegel H, Fomsgaard JS, Andersen JDH, Martusevicius R, Mathiesen O, et al. Preoperative dexamethasone reduces acute but not sustained pain after lumbar disk surgery: a randomized, blinded, placebocontrolled trial. Pain 2015;156(12):2538-44. PUBMED: 26270586 ]

\section{Rafiq 2014 \{published data only\}}

Rafiq S, Steinbruchel DA, Wanscher MJ, Andersen LW, Navne A, Lilleoer NB, et al. Multimodal analgesia versus traditional opiate based analgesia after cardiac surgery: a randomized controlled trial. Journal of Cardiothoracic Surgery 2014;9(1):52. PUBMED: 24650125]

Sanchez-Rodriguez 2010 \{published data only\} Sanchez-Rodriguez PE, Fuentes-Orozco C, Gonzalez-Ojeda A. Effect of dexamethasone on postoperative symptoms in patients undergoing elective laparoscopic cholecystectomy: randomized clinical trial. World Journal of Surgery 2010;34 (5):895-900. PUBMED: 20151129 ]

Schietroma 2010 \{published data only\} Schietroma M, Giuliani M, Zoccali G, Carnei F, Bianchi $Z$, Amiccucci G, et al. How does dexamethasone influence surgical outcome after laparoscopic Nissen fundoplication? A randomized double-blind placebo-controlled trial. Updates in Surgery 2010;62(1):47-54. PUBMED: 20845101]

\section{Schietroma 2013 \{published data only\}} Schietroma M, Cecilia EM, Carlei F, Sista F, De Santis G, Lancione L, et al. Dexamethasone for the prevention of recurrent laryngeal nerve palsy and other complications after thyroid surgery: a randomized double-blind placebocontrolled trial. JAMA Otolaryngology - Head \& Neck Surgery 2013;139(5):471-8. PUBMED: 23681030]

\section{Tien 2016 \{published data only\}}

Tien M, Gan TJ, Dhakal I, White WD, Olufolabi AJ, Fink $\mathrm{R}$, et al. The effect of anti-emetic doses of dexamethasone on postoperative blood glucose levels in non-diabetic and diabetic patients: a prospective randomised controlled study. Anaesthesia 2016;71(9):1037-43. PUBMED: 27523051]

\section{Wakasugi 2015 \{published data only\}}

Wakasugi M, Tori M, Shimizu J, Kim YK, Noda T, Dono K, et al. Efficacy of preoperative dexamethasone for postoperative nausea and vomiting after laparoscopic cholecystectomy: a large-scale, multicenter, randomized, double-blind, placebo-controlled trial in Japan. Journal of Hepato-Biliary-Pancreatic Sciences 2015;22(11):802-9. PUBMED: 26288165] 
Wang 2009 \{published data only\}

Wang Y, Song XH, Wu LL. Effects of different glucocorticoids on blood glucose during surgery under general anesthesia. Zhonghua Yi Xue Za Zhi 2009;89(27): 1913-5. PUBMED: 19953915]

Worni 2008 \{published data only\}

Worni M, Schudel HH, Seifert E, Inglin R, Hagemann $\mathrm{M}$, Vorburger SA, et al. Randomized controlled trial on single dose steroid before thyroidectomy for benign disease to improve postoperative nausea, pain, and vocal function. Annals of Surgery 2008;248(6):1060-6. PUBMED: 19092351]

Zargar-Shoshtari 2009 \{published data only\} Zargar-Shoshtari K, Sammour T, Kahokehr A, Connolly AB, Hill AG. Randomized clinical trial of the effect of glucocorticoids on peritoneal inflammation and postoperative recovery after colectomy. British Journal of Surgery 2009;96(11):1253-61. PUBMED: 19847865 ]

Zhang 2016 \{published data only\} Zhang HW, Fan YB, Lu J, Wu B, Xu C, Zhou QH. Protective effect of perioperative low-dose dexamethasone on sore throat after thyroidectomy. Journal of Shanghai Jiaotong University (Medical Science) 2016;36(6):870-4.

Zhou 2012 \{published data only\} Zhou H, Xu H, Zhang J, Wang W, Wang Y, Hu Z. Combination of dexamethasone and tropisetron before thyroidectomy to alleviate postoperative nausea, vomiting, and pain: randomized controlled trial. World Journal of Surgery 2012;36(6):1217-24. PUBMED: 22146946 ]

\section{References to studies excluded from this review}

\section{Abbaszadeh 2012 \{published data only\}}

Abbaszadeh M, Khan ZH, Mehrani F, Jahanmehr H. Perioperative intravenous corticosteroids reduce incidence of atrial fibrillation following cardiac surgery: a randomized study. Revista Brasileira De Cirurgia Cardiovascular 2012;27 (1):18-23. PUBMED: 22729297]

Al-Shehri 2004 \{published data only\} Al-Shehri AM. Steroid therapy for post-tonsillectomy symptoms in adults: a randomized, placebo-controlled study. Annals of Saudi Medicine 2004;24(5):365-7. PUBMED: 15573850]

Bianchin 2007 \{published data only\} Bianchin A, De Luca A, Caminiti A. Postoperative vomiting reduction after laparoscopic cholecystectomy with single dose of dexamethasone. Minerva Anestesiologica 2007;73 (6):343-6. PUBMED: 17589423]

Coloma 2001 \{published data only\} Coloma M, Duffy LL, White PF, Kendall Tongier W, Huber PJ. Dexamethasone facilitates discharge after outpatient anorectal surgery. Anesthesia and Analgesia 2001;92(1): 85-8. PUBMED: 11133606]

Halvorsen 2003 \{published data only\} Halvorsen P, Raeder J, White PF, Almdahl SM, Nordstrand K, Saatvedt K, et al. The effect of dexamethasone on side effects after coronary revascularization procedures. Anesthesia and Analgesia 2003;96(6):1578-83, table of contents. PUBMED: 12760978]

Ho 2001 \{published data only\}

Ho ST, Wang JJ, Tzeng JI, Liu HS, Ger LP, Liaw WJ. Dexamethasone for preventing nausea and vomiting associated with epidural morphine: a dose-ranging study. Anesthesia and Analgesia 2001;92(3):745-8. PUBMED: 11226112]

Jung 2013 \{published data only\}

Jung H, Kim HJ. Dexamethasone contributes to the patient management after ambulatory laryngeal microsurgery by reducing sore throat. European Archives of Oto-rhinolaryngology 2013;270(12):3115-9. PUBMED: 24057101 ]

Kara 1999 \{published data only\}

Kara CO, Gokalan I. Effects of single-dose steroid usage on edema, ecchymosis, and intraoperative bleeding in rhinoplasty. Plastic and Reconstructive Surgery 2001;104(7): 2213-8. PUBMED: 11149790]

Lei 2018a \{published data only\} Lei YT, Xu B, Xie XW, Xie JW, Huang Q, Pei FX. The efficacy and safety of low-dose peri-operative dexamethasone on pain and recovery following total hip arthroplasty: a randomized controlled trial. International Orthopaedics 2018;42(3):499-505. PUBMED: 28647788]

Liu 2001 \{published data only\} Liu YH, Li MJ, Wang PC, Ho ST, Chang CF, Ho CM, et al. Use of dexamethasone on the prophylaxis of nausea and vomiting after tympanomastoid surgery. Laryngoscope 2001; 111(7):1271-4. PUBMED: 11568553 ]

Nasiri 2013 \{published data only\}

Nasiri S, Shafag S, Khorgami Z, Sodagari N, Aminian A, Hedayat A. Does corticosteroid have any beneficial effect on voice change after thyroidectomy?. American Surgery 2013; 79(12):1258-62. PUBMED: 24351352]

Pasternak 2004 \{published data only\} Pasternak JJ, McGregor DG, Lanier WL. Effect of singledose dexamethasone on blood glucose concentration in patients undergoing craniotomy. Journal of Neurosurgical Anesthesiology 2004;16(2):122-5. PUBMED: 15021280]

Sethi 2016 \{published data only\}

Sethi R, Naqash IA, Bajwa SJ, Dutta V, Ramzan AU, Zahoor SA. Evaluation of hyperglycaemic response to intra-operative dexamethasone administration in patients undergoing elective intracranial surgery: a randomised, prospective study. Asian Journal of Neurosurgery 2016;11 (2):98-102. PUBMED: 27057213]

Snall 2014 \{published data only\} Snall J, Kormi E, Koivusalo AM, Lindqvist C, Suominen AL, Tornwall J, et al. Effects of perioperatively administered dexamethasone on surgical wound healing in patients undergoing surgery for zygomatic fracture: a prospective study. Oral Surgery Oral Medicine Oral Pathology Oral Radiology 2014;117(6):685-9. PUBMED: 24842445] 
Thangaswamy 2010 \{published data only\}

Thangaswamy CR, Rewari V, Trikha A, Chandralekha DM. Dexamethasone before total laparoscopic hysterectomy: a randomized controlled dose-response study. Journal of Anesthesia 2010;24(1):24-30. PUBMED: 20052502]

Tolver 2012 \{published data only\}

Tolver MA, Strandfelt P, Bryld EB, Rosenberg J, Bisgaard T. Randomized clinical trial of dexamethasone versus placebo in laparoscopic inguinal hernia repair. British Journal of Surgery 2012;99(10):1374-80. PUBMED: 22961516]

Wang 2000 \{published data only\}

Wang JJ, Ho ST, Lee SC, Liu YC, Ho CM. The use of dexamethasone for preventing postoperative nausea and vomiting in females undergoing thyroidectomy: a doseranging study. Anesthesia and Analgesia 2000;91(6):1404-7. PUBMED: 11093989]

Wang 2001 \{published data only\}

Wang JJ, Ho ST, Wong CS, Tzeng JI, Liu HS, Ger LP. Dexamethasone prophylaxis of nausea and vomiting after epidural morphine for post-Cesarean analgesia. Canadian Journal of Anaesthesia 2001;48(2):185-90. PUBMED: 11220429]

Weber 1994 \{published data only\}

Weber CR, Griffin JM. Evaluation of dexamethasone for reducing postoperative edema and inflammatory response after orthognathic surgery. Journal of Oral and Maxillofacial Surgery 1994;52(1):35-9. PUBMED: 8263640]

Wu 2007 \{published data only\}

Wu JI, Lo Y, Chia YY, Liu K, Fong WP, Yang LC, et al. Prevention of postoperative nausea and vomiting after intrathecal morphine for Cesarean section: a randomized comparison of dexamethasone, droperidol, and a combination. International Journal of Obstetric Anesthesia 2007;16(2):122-7. PUBMED: 17275282 ]

\section{References to studies awaiting assessment}

Ko-Iam 2015 \{published data only\}

Ko-Iam W, Sandhu T, Paiboonworachat S, Pongchairerks P, Junrungsee $S$, Chotirosniramit $A$, et al. Metoclopramide versus its combination with dexamethasone in the prevention of postoperative nausea and vomiting after laparoscopic cholecystectomy: a double-blind randomized controlled trial. Journal of the Medical Association of Thailand 2015;98(3):265-72. PUBMED: 25920297]

Simogai 2016 \{published data only\}

Simogai M, Kayo R. Prevention of postoperative nausea and vomiting associated with postoperative fentanyl infusion by dexamethasone and combined diphenhydramine and diprophylline preparation (Travelmin). [Japanese]. Medical Journal of Minami Osaka Hospital 2016;63(1):17-20.

\section{References to ongoing studies}

Kitcharanant 2016 \{unpublished data only\}

Kitcharanant N. Effects of perioperative intravenous dexamethasone on the severity of persistent postsurgical pain after total knee arthroplasty: a prospective, randomized, double-blind, placebo-controlled trial. ClinicalTrials.gov: NCT02760459.

Sidhu 2017 \{unpublished data only\}

Sidhu J. Perioperative ADministration of Dexamethasone and Infection trial. www.paddi.org.au (accessed 16 August 2018).

Wang 2018 \{published data only\}

Wang DX. Dexamethasone, flurbiprofen, axetil and delirium after lung cancer surgery. ClinicalTrials.gov: NCT02300600. Clinicaltrials.gov NCT03200600]

\section{Additional references}

\section{Althumairi 2016}

Althumairi AA, Canner JK, Gearhart SL, Safar B, Sacks J, Efron JE. Predictors of perineal wound complications and prolonged time to perineal wound healing after abdominoperineal resection. World Journal of Surgery 2016; 40(7):1755-62. [PUBMED: 26908238 ]

\section{Assante 2015}

Assante J, Collins S, Hewer I. Infection associated with single-dose dexamethasone for prevention of postoperative nausea and vomiting: a literature review. AANA Journal 2015;83(4):281-8. [PUBMED: 26390747]

\section{Bartlett 2013}

Bartlett R, Hartle AJ. Routine use of dexamethasone for postoperative nausea and vomiting: the case against. Anaesthesia 2013;68(9):892-6. [PUBMED: 23848377]

Bolac 2013

Bolac CS, Wallace AH, Broadwater G, Havrilesky LJ, Habib AS. The impact of postoperative nausea and vomiting prophylaxis with dexamethasone on postoperative wound complications in patients undergoing laparotomy for endometrial cancer. Anesthesia and Analgesia 2013;116(5): 1041-7. [PUBMED: 23337415 ]

Busti 2005

Busti AJ, Hooper JS, Amaya CJ, Kazi S. Effects of perioperative antiinflammatory and immunomodulating therapy on surgical wound healing. Pharmacotherapy 2005; 25(11):1566-91. [PUBMED: 16232020]

Byrne 1989

Byrne DJ, Malek MM, Davey PG, Cuschieri A.

Postoperative wound scoring. Biomedical Pharmacotherapy 1989;43(9):669-73. [PUBMED: 2696565]

\section{Carlisle 2012}

Carlisle JB. The analysis of 168 randomised controlled trials to test data integrity. Anaesthesia 2012;67(5):521-37. [PUBMED: 22404311]

\section{Clement 2004}

Clement S, Braithwaite SS, Magee MF, Ahmann A, Smith EP, Schafer RG, et al. American Diabetes Association Diabetes in Hospitals Writing Committee. Management of diabetes and hyperglycemia in hospitals. Diabetes Care 2004;27(2):553-91. [PUBMED: 14747243] 


\section{Corcoran 2010}

Corcoran TB, Truyens EB, Ng A, Moseley N, Doyle AC, Margetts L. Anti-emetic dexamethasone and postoperative infection risk: a retrospective cohort study. Anaesthesia and Intensive Care 2010;38(4):654-60. [PUBMED: 20715727]

\section{Dahl 2014}

Dahl RM, Wetterslev J, Jorgensen LN, Rasmussen LS, Moller AM, Meyhoff CS, et al. The association of perioperative dexamethasone, smoking and alcohol abuse with wound complications after laparotomy. Acta Anaesthesiologica Scandinavica 2014;58(3):352-61. [PUBMED: 24471786]

\section{De Oliveira 2011}

De Oliveira GS Jr, Almeida MD, Benzon HT, McCarthy RJ. Perioperative single dose systemic dexamethasone for postoperative pain: a meta-analysis of randomized controlled trials. Anesthesiology 2011;115(3):575-88. [PUBMED: 21799397]

\section{De Oliveira 2013}

De Oliveira GS Jr, Castro-Alves LJ, Ahmad S, Kendall MC, McCarthy RJ. Dexamethasone to prevent postoperative nausea and vomiting: an updated meta-analysis of randomized controlled trials. Anesthesia and Analgesia 2013; 116(1):58-74. [PUBMED: 23223115]

\section{Dindo 2004}

Dindo D, Demartines N, Clavien P-A. Classification of surgical complications: a new proposal with evaluation in a cohort of 6336 patients and results of a survey. Annals of Surgery 2004;240(2):205-13. [PUBMED: 15273542]

\section{Dungan 2009}

Dungan KM, Braithwaite SS, Preiser JC. Stress hyperglycaemia. Lancet 2009;373(9677):1798-807. [PUBMED: 19465235]

\section{Durmus 2003}

Durmus M, Karaaslan E, Ozturk E, Gulec M, Iraz M, Edali $\mathrm{N}$, et al. The effects of single-dose dexamethasone on wound healing in rats. Anesthesia and Analgesia 2003;97(5): 1377-80. [PUBMED: 14570655]

\section{Eberhart 2006}

Eberhart LHJ, Kleine Büning E, Folz B, Maybauer DM, Kästner M, Kalder M, et al. Anti-emetic prophylaxis with oral tropisetron and/or dexamethasone. European Journal of Clinical Investigation 2006;36:580-7. [PUBMED: 16893381]

\section{Eberhart 2011a}

Eberhart LH, Holdorf S, Albert US, Kalder M, Kerwat K, Kranke P, et al. Impact of a single perioperative dose of dexamethasone on the incidence of surgical site infections: a case-control study. Journal of Obstetrics and Gynaecology Research 2011;37(12):1807-12. [PUBMED: 21794004]

\section{Eberhart 2011b}

Eberhart LH, Graf J, Morin AM, Stief T, Kalder M, Lattermann R, et al. Randomised controlled trial of the effect of oral premedication with dexamethasone on hyperglycaemic response to abdominal hysterectomy.
European Journal of Anaesthesiology 2011;28(3):195-201. [PUBMED: 21192268]

Egger 1997

Egger M, Smith GD, Philips AN. Meta-analysis: principles and procedures. BMJ 1997;315(7121):1533-7. [PUBMED: 9432252]

\section{Fauci 1976}

Fauci AS, Dale DC, Balow JE. Glucocorticosteroid therapy: mechanisms of action and clinical considerations. Annals of Internal Medicine 1976;84(3):304-15. [PUBMED: 769625]

Gali 2012

Gali B, Burkle CM, Klingele CJ, Schroeder D, Jankowski CJ. Infection after urogynecologic surgery with the use of dexamethasone for nausea prophylaxis. Journal of Clinical Anesthesia 2012;24(7):549-54. [PUBMED: 23101769 ]

\section{Gan 2014}

Gan TJ, Diemunsch P, Habib AS, Kovac A, Kranke P, Meyer TA, et al. Consensus guidelines for the management of postoperative nausea and vomiting. Anesthesia and Analgesia 2014;118(1):85-113. [PUBMED: 24356162]

\section{GradePro GDT [Computer program]}

McMaster University (developed by Evidence Prime). GRADEpro GDT. Version accessed 15 April 2018. Hamilton (ON): McMaster University (developed by Evidence Prime), 2015.

\section{Guyatt 2008}

Guyatt GH, Oxman AD, Kunz R, Vist GE, Falck-Ytter Y, Schunemann HJ, et al. What is "quality of evidence" and why is it important to clinicians?. BMJ 2008;336(7651): 995-8. [PUBMED: 18456631]

\section{Habib 2012}

Habib AS, Gan TJ. Postoperative nausea and vomiting: then \& now. Anesthesia and Analgesia 2012;115(3):493-5. [PUBMED: 22910636]

\section{Higgins 2011}

Higgins JP, Green S, editor(s). Cochrane Handbook for Systematic Reviews of Interventions Version 5.1.0 (updated March 2011). The Cochrane Collaboration, 2011. Available from handbook.cochrane.org.

\section{Horan 2008}

Horan TC, Andrus M, Dudeck MA. CDC/NHSN surveillance definition of health care-associated infection and criteria for specific types of infections in the acute care setting. American Journal of Infection Control 2008;36(5): 309-32. [PUBMED: 18538699]

\section{Hozo 2005}

Hozo SP, Djulbegovic B, Hozo I. Estimating the mean and variance from the median, range, and the size of a sample. BMC Medical Research Methodology 2005;5:13. [PUBMED: 15840177]

\section{Kranke 2014}

Kranke P, Diemunsch P. The 2014 consensus guidelines for the management of postoperative nausea and vomiting: a leapfrog towards a postoperative nausea and vomiting-free 
hospital. European Journal of Anaesthesiology 2014;31(12): 651-3. [PUBMED: 25350527]

\section{Liu 2014}

Liu XX, Zhu XM, Miao Q, Ye HY, Zhang ZY, Li YM. Hyperglycemia induced by glucocorticoids in nondiabetic patients: a meta-analysis. Annals of Nutrition and Metabolism 2014;65(4):324-32. [PUBMED: 25402408]

\section{Murphy 2011b}

Murphy GS, Szokol JW, Greenberg SB, Avram MJ, Vender JS, Nisman M, et al. Preoperative dexamethasone enhances quality of recovery after laparoscopic cholecystectomy: effect on in-hospital and postdischarge recovery outcomes. Anesthesiology 2011;114(4):882-90. [PUBMED: 21297442]

\section{Parvizi 2011}

Parvizi J, Zmistowski B, Berbari EF, Bauer TW, Springer BD, Della Valle CJ, et al. New definition for periprosthetic joint infection: from the Workgroup of the Musculoskeletal Infection Society. Clinical Orthopaedic and Related Research 2011;469(11):2992-4. [PUBMED: 21938532]

\section{Pehora 2017}

Pehora C, Pearson AME, Kaushal A, Crawford MW, Johnston B. Dexamethasone as an adjuvant to peripheral nerve block. Cochrane Database of Systematic Reviews 2017, Issue 11. DOI: 10.1002/14651858.CD011770.pub2

\section{Percival 2010}

Percival VG, Riddell J, Corcoran TB. Single dose dexamethasone for postoperative nausea and vomiting a matched case-control study of postoperative infection risk. Anaesthesia and Intensive Care 2010;38(4):661-6. [PUBMED: 20715728]

\section{Piccirillo 2018}

Piccirillo JF, Bauchner H. Notice of Retraction: Schietroma M, Cecilia EM, Carlei F, Sista F, De Santis G, Lancione L, Amicucci G. Dexamethasone for the prevention of recurrent laryngeal nerve palsy and other complications after thyroid Surgery: a randomized double-blind placebo-controlled trial. JAMA Otolaryngology - Head \& Neck Surgery 2013; 139(5):471-8. doi:10.1001/jamaoto.2013.2821. JAMA Otolaryngology - Head \& Neck Surgery 2018:Epub ahead of print. DOI: 10.1001/jamaoto.2018.3018.

Piccirillo 2017

Piccirillo JF, Bauchner H. Expression of Concern: Schietroma M, Cecilia EM, Carlei F, Sista F, De Santis G, Lancione L, Amicucci G. Dexamethasone for the prevention of recurrent laryngeal nerve palsy and other complications after thyroid surgery: a randomized doubleblind placebo-controlled trial. JAMA Otolaryngology Head \& Neck Surgery 2013;139(5):471-8. doi:10.1001/ jamaoto.2013.2821. JAMA Otolaryngology - Head \& Neck Surgery 2017;143(9):869.

Polderman 2015b

Polderman JA, Van Velzen L, Wasmoeth LG, Eshuis JH, Houweling PL, Hollmann MW, et al. Hyperglycemia and ambulatory surgery. Minerva Anestesiologica 2015; Vol. 81, issue 9:951-9. [PUBMED: 25592489]

Qi 2004

Qi D, Pulinilkunnil T, An D, Ghosh S, Abrahani A, Pospisilik JA, et al. Single-dose dexamethasone induces whole-body insulin resistance and alters both cardiac fatty acid and carbohydrate metabolism. Diabetes 2004;53(7): 1790-7. [PUBMED: 15220203]

\section{Review Manager 2014 [Computer program]}

The Nordic Cochrane Centre, The Cochrane Collaboration. Review Manager 5 (RevMan 5). Version 5.3. Copenhagen: The Nordic Cochrane Centre, The Cochrane Collaboration, 2014.

SanGiovanni 2016

SanGiovanni TP, Kiebzak GM. Prospective randomized evaluation of intraoperative application of autologous platelet-rich plasma on surgical site infection or delayed wound healing. Foot \& Ankle International 2016;37(5): 470-7. [PUBMED: 26683126]

Smiley 2006

Smiley DD, Umpierrez GE. Perioperative glucose control in the diabetic or nondiabetic patient. Southern Medical Journal 2006;99(6):580-9; quiz 590-1. [PUBMED: $16800413]$

\section{Sutton 2002}

Sutton AJ, Cooper NJ, Lambert PC, Jones DR, Abrams KR, Sweeting MJ. Meta-analysis of rare and adverse event data. Expert Review of Pharmacoeconomics \& Outcomes Research 2002;2(4):367-79. [PUBMED: 19807443]

\section{Toner 2017}

Toner AJ, Ganeshanathan V, Chan MT, Ho KM, Corcoran TB. Safety of perioperative glucocorticoids in elective noncardiac surgery. Anesthesiology 2017;126(2):234-48. [PUBMED: 27922839]

\section{Turina 2005}

Turina M, Fry DE, Polk HC Jr. Acute hyperglycemia and the innate immune system: clinical, cellular, and molecular aspects. Critical Care Medicine 2005;33(7):1624-33. [PUBMED: 16003073]

Waldron 2013

Waldron NH, Jones CA, Gan TJ, Allen TK, Habib AS Impact of perioperative dexamethasone on postoperative analgesia and side-effects: systematic review and metaanalysis. British Journal of Anaesthesia 2013;110(2): 191-200. [PUBMED: 23220857]

\section{References to other published versions of this review}

\section{Polderman 2015a}

Polderman JAW, Farhang-Razi V, Van Dieren S, Kranke P, DeVries JH, Hollmann MW, et al. Adverse side effects of dexamethasone in surgical patients. Cochrane Database of Systematic Reviews 2015, Issue 11. DOI: 10.1002/ 14651858.CD011940

* Indicates the major publication for the study 


\title{
CHARACTERISTICS OF STUDIES
}

\section{Characteristics of included studies [ordered by study ID]}

\author{
Abdelmalak 2013a
}

Methods

- Three-way factorial design randomized controlled trial

- Enrolment was from 2007 to 2010.

- Study was conducted in the USA.

Participants

\section{Inclusion criteria}

- Patients over 40 years undergoing major elective surgery

Exclusion criteria

- Intravenous or oral steroid therapy within 30 days

- Any contraindications to the proposed interventions

- ASA Physical Status (ASA PS) IV

- Not fluent in English

381 patients (193 intervention and 188 placebo) over 40 years undergoing elective surgery were randomized

- Mean age: 64 years

- $68 \%$ male

- $26 \%$ with diabetes

- $26 \%$ ASA II status

- $63 \%$ ASA III status

- $11 \%$ ASA IV status
Randomization for dexamethasone vs placebo, tight glycaemic control vs conventional control, deep anaesthetic depth vs light anaesthetic depth

- Intervention group received $8 \mathrm{mg}$ dexamethasone 1 to 2 hours before surgery, 4 mg dexamethasone on day 1 postoperatively, and $2 \mathrm{mg}$ dexamethasone on day 2 postoperatively.

- Placebo group received normal saline at these time points.
Outcomes

Notes

\section{Primary outcomes}

- Composite endpoint of postoperative complications (sepsis, severe surgical site infection, myocardial infarction, heart failure, stroke, unstable ventricular arrhythmias, pulmonary embolism, pneumonia, respiratory failure, dialysis-dependent renal failure, large pleural or peritoneal effusions, major bleeding, major wound and surgical site healing complications, vascular graft thrombosis)

- 30-day mortality

- Postoperative infection assessed 30 days after surgery, according to Centers for Disease Control and Prevention (CDC) criteria

\section{Secondary outcomes}

- One-year mortality rates (obtained from electronic medical records)

- CRP levels in the first 2 postoperative days. Blood samples were taken on day 1 and day 2 postoperatively. CRP was expressed as $\mathrm{mg} / \mathrm{L}$

\section{Sources of funding}

- Aspect Medical (now Covidien)

- Cleveland Clinic Research Project Committee 
Abdelmalak 2013a (Continued)

- Anesthesiology Institute (departmental funds)

- Abbott Laboratories Inc (limited support; supplied reagents for CRP analysis)

- W.H.W.T. received grant support (money to the institution) in support of other studies from Abbott Laboratories

- This is an investigator-initiated trial independent of the study sponsors.

Conflict of interest

- None declared

\section{Risk of bias}

\begin{tabular}{|c|c|c|}
\hline Bias & Authors' judgement & Support for judgement \\
\hline $\begin{array}{l}\text { Random sequence generation (selection } \\
\text { bias) }\end{array}$ & Low risk & Computer programme generated \\
\hline Allocation concealment (selection bias) & Low risk & Web-based programme \\
\hline $\begin{array}{l}\text { Blinding of participants and personnel } \\
\text { (performance bias) } \\
\text { All outcomes }\end{array}$ & Unclear risk & $\begin{array}{l}\text { Participants and personnel were blinded to } \\
\text { dexamethasone. They were not blinded for } \\
\text { randomization, result for tight glycaemic } \\
\text { control, or anaesthetic depth }\end{array}$ \\
\hline
\end{tabular}

Blinding of outcome assessment (detection Low risk

Outcome assessor was blinded.

bias)

All outcomes

\begin{tabular}{l|ll}
\hline $\begin{array}{l}\text { Incomplete outcome data (attrition bias) } \\
\text { All outcomes }\end{array}$ & Low risk & No withdrawals \\
\hline Selective reporting (reporting bias) & Low risk & $\begin{array}{l}\text { Consistent with the protocol. Protocol was } \\
\text { published. }\end{array}$ \\
\hline Other bias & Unclear risk & Study was stopped early owing to futility. \\
\hline
\end{tabular}

Abdelmalak 2013b

\begin{tabular}{l|l}
\hline Methods & $\begin{array}{l}\text { - Three-way factorial design randomized controlled trial } \\
\text { - Enrolment was from } 2007 \text { to } 2010 .\end{array}$ \\
- Study was conducted in the USA. & Inclusion criteria \\
- Patients over 40 years undergoing major elective surgery \\
Exclusion criteria \\
- Intravenous or oral steroid therapy within 30 days \\
- Any contraindications to proposed interventions \\
- ASA Physical Status (ASA PS) IV \\
- Not fluent in English \\
185 participants (90 intervention, 95 placebo) over 40 years old undergoing major
\end{tabular}


Abdelmalak 2013b (Continued)

elective surgery were randomized to the conservative glycaemic control group

- 49 with diabetes (21 intervention, 28 placebo)

- 136 without diabetes (69 intervention, 67 placebo)

- Mean age: 64 years

- $68 \%$ male

- $30 \%$ ASA II status

- $60 \%$ ASA III status

- $10 \%$ ASA IV status

Interventions

Randomization for dexamethasone vs placebo, tight glycaemic vs conventional control, deep anaesthetic depth vs light anaesthetic depth

- Intervention group received $8 \mathrm{mg}$ dexamethasone 1 to 2 hours before surgery, 4 mg dexamethasone on day 1 postoperatively, and $2 \mathrm{mg}$ dexamethasone on day 2 postoperatively.

- Placebo group received normal saline at these time points.

Outcomes

Primary outcome

- Hyperglycaemic surgical stress response, defined as the glucose change from preoperative to maximal intraoperative glucose concentration

- Glycaemic response assessed in the subgroup that did not receive tight glycaemic control

- Change from baseline to maximum intraoperative glucose

Notes

\section{Sources of funding}

- Aspect Medical (now Covidien)

- Cleveland Clinic Research Project Committee

- Anesthesiology Institute (departmental funds)

- Abbott Laboratories Inc (limited support; supplied reagents for CRP analysis)

- W.H.W.T. received grant support (money to the institution) in support of other studies from Abbott Laboratories.

- This is an investigator-initiated trial independent of the study sponsors.

Conflict of interest

- None declared

Risk of bias

Bias

Authors' judgement

Support for judgement

Random sequence generation (selection Low risk

Computer programme generated bias)

Allocation concealment (selection bias) Low risk

Blinding of participants and personnel Unclear risk (performance bias)

All outcomes

\section{Web-based programme}

Participants and personnel were blinded for dexamethasone. They were not blinded for randomization, result for tight glycaemic control, or anaesthetic depth 
Abdelmalak 2013b (Continued)

\begin{tabular}{l|l|l}
\hline $\begin{array}{l}\text { Blinding of outcome assessment (detection } \\
\text { bias) } \\
\text { All outcomes }\end{array}$ & Low risk & Outcome assessor was blinded. \\
\hline $\begin{array}{l}\text { Incomplete outcome data (attrition bias) } \\
\text { All outcomes }\end{array}$ & Low risk & No withdrawals \\
\hline Selective reporting (reporting bias) & Unclear risk & $\begin{array}{l}\text { Protocol was published. Glycaemic re- } \\
\text { sponse during surgery was not a planned } \\
\text { subanalysis }\end{array}$ \\
\hline Other bias & Unclear risk & Study was stopped early owing to futility. \\
\hline
\end{tabular}

Abukawa 2017

Methods

Methods

Participants

- Parallel-group randomized double-blind placebo-controlled trial

- All participants were operated on at Tokyo Medical University Hospital from 2007 to 2013.

\section{Inclusion criteria}

- ASA physical status I or II and agreement to participate in this study

Exclusion criteria

- Underwent genioplasty and extraction of third molars in addition to BSSO

- Body mass index (BMI) > 25

- Older than 50 years

24 adult patients undergoing bilateral sagittal split osteotomy were divided into 3 groups

- 8 given $16 \mathrm{mg}$ dexamethasone

- 8 given $8 \mathrm{mg}$ dexamethasone

- 8 given $0 \mathrm{mg}$ dexamethasone

Patients were not older than 50 years.

- Patients with diabetes were eligible.

- Mean age: between 24 and 28 years

- Average surgery time: 226 to 263 minutes

- 8 given $8 \mathrm{mg}$ dexamethasone

- 8 given $0 \mathrm{mg}$ dexamethasone

Interventions

$16 \mathrm{mg}$ dexamethasone vs $8 \mathrm{mg}$ dexamethasone vs $0 \mathrm{mg}$ dexamethasone

- This was administered preoperatively; the exact time point was not described.

Outcomes

\section{Study endpoints were as follows.}

- Postoperative changes in buccal soft tissue thickness and masseter muscle thickness.

- Postoperative changes in MIO.

- Postoperative changes in sensation of the chin and lower lip region.

- Postoperative changes in blood test findings (CRP levels were measured at day 1 and day 2 postoperatively).

- Types of complications (steroid-induced psychosis, avascular osteonecrosis, nonunion, and infection). 
Definition of postoperative infection was not stated.

Length of follow-up: 2 years

\begin{tabular}{l|l}
\hline Sotes & $\begin{array}{c}\text { Sources of funding } \\
\text { Supported by Tokyo Medical University research grants } \\
\text { Conflicts of interest } \\
- \text { None of the study authors have any relevant financial relationship(s) with a } \\
\text { commercial interest. }\end{array}$ \\
\hline
\end{tabular}

Risk of bias

\begin{tabular}{l|l|l}
\hline Bias & Authors' judgement & Support for judgement \\
\hline $\begin{array}{l}\text { Random sequence generation (selection } \\
\text { bias) }\end{array}$ & Unclear risk & Not described \\
\hline Allocation concealment (selection bias) & Unclear risk & Not described \\
\hline $\begin{array}{l}\text { Blinding of participants and personnel } \\
\text { (performance bias) } \\
\text { All outcomes }\end{array}$ & Unclear risk & Not described \\
\hline $\begin{array}{l}\text { Blinding of outcome assessment (detection } \\
\text { bias) } \\
\text { All outcomes }\end{array}$ & Unclear risk & Not described \\
\hline $\begin{array}{l}\text { Incomplete outcome data (attrition bias) } \\
\text { All outcomes }\end{array}$ & High risk & $\begin{array}{l}\text { Inclusion period was } 6 \text { years; only 24 pa- } \\
\text { tients were included in the trial. No drop- } \\
\text { outs were described }\end{array}$ \\
\hline \begin{tabular}{l} 
Selective reporting (reporting bias) \\
\hline \begin{tabular}{l} 
Other bias \\
\hline
\end{tabular}
\end{tabular} & Unclear risk & Unclear risk \\
\hline
\end{tabular}

Backes 2013

\begin{tabular}{l|l}
\hline Methods & - Prospective randomized double-blind controlled trial \\
& - Enrolment from 2011 to 2012 \\
- Conducted at a single centre in the USA & \\
\hline Participants & Inclusion criteria \\
- Patients undergoing elective, unilateral, total hip or knee arthroplasty \\
Exclusion criteria \\
- Poorly controlled diabetes (HbA1c $>7.5 \%$ on pre-admission testing) \\
- Steroid or immunosuppressive drug use within 6 months of surgery \\
- Renal failure \\
- Hepatic failure
\end{tabular}


Backes 2013 (Continued)

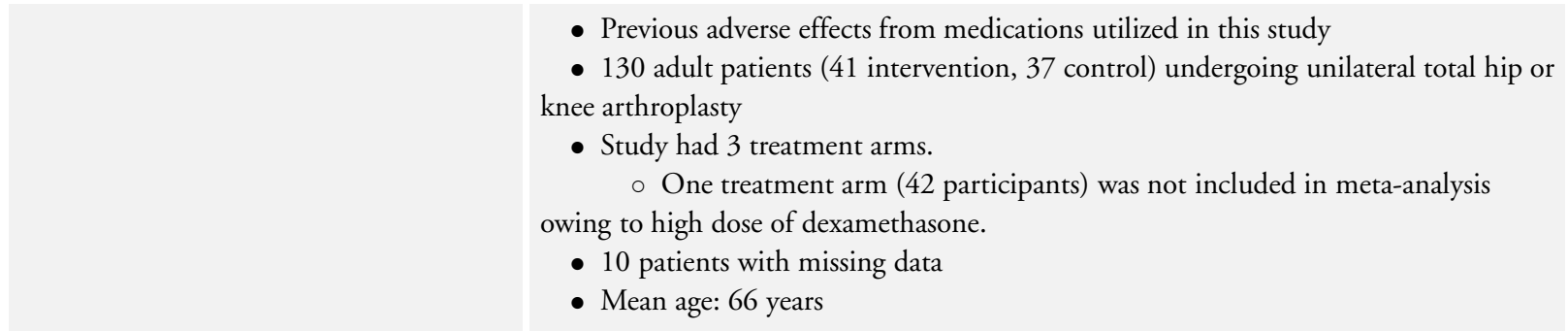

Interventions

Dexamethasone (10 $\mathrm{mg}$ before induction and $4 \mathrm{mg}$ ondansetron before skin closure) vs control ( $4 \mathrm{mg}$ ondansetron before skin closure)

Outcomes

Notes

\section{Primary outcomes}

- Length of hospital stay (measured as number of calendar days patient was hospitalized)

- Length of ambulation

- Knee ROM

- Cumulative hydromorphone PCA use

- Daily hydrocodone consumption

- Patient pain scores

- Daily rescue anti-emetic consumption

- Patient nausea/vomiting scores

\section{Secondary outcomes}

- Changes in WBC

- Changes in blood sugar

- Wound complications

- Other adverse effects

Definition of postoperative infection

- Wound still draining at office follow-up, requiring any form of antibiotics or requiring return to the operating room

Total length of follow-up: 6 months

\section{Source of funding/Conflicts of interest}

- JP received funds from Depuy.

- BC is a paid consultant for Smith and Nephew.

\section{Risk of bias}

Bias Authors' judgement

Random sequence generation (selection Low risk bias)

Allocation concealment (selection bias)

Low risk

\section{Support for judgement}

Computer-based randomization

Computer-based programme; person who was in charge of the randomization process was not involved in the follow-up of the trial 
Backes 2013 (Continued)

\begin{tabular}{|c|c|c|}
\hline $\begin{array}{l}\text { Blinding of participants and personnel } \\
\text { (performance bias) } \\
\text { All outcomes }\end{array}$ & Unclear risk & $\begin{array}{l}\text { Patients, physiotherapists, and } \\
\text { surgeons were blinded. Anaesthesiologists } \\
\text { and nurses were not blinded } \\
\text { No placebo was used. Therefore, surgeons } \\
\text { could theoretically be aware of which study } \\
\text { group participants belonged to }\end{array}$ \\
\hline $\begin{array}{l}\text { Blinding of outcome assessment (detection } \\
\text { bias) } \\
\text { All outcomes }\end{array}$ & Low risk & Outcome assessors were blinded. \\
\hline $\begin{array}{l}\text { Incomplete outcome data (attrition bias) } \\
\text { All outcomes }\end{array}$ & Low risk & $\begin{array}{l}10 \text { participants with incomplete data, } \\
\text { equally divided over the groups }\end{array}$ \\
\hline Selective reporting (reporting bias) & Unclear risk & $\begin{array}{l}\text { Protocol not published. Glucose data were } \\
\text { inconsistently reported }\end{array}$ \\
\hline Other bias & Unclear risk & Not all expected data are reported. \\
\hline
\end{tabular}

\section{Bisgaard 2003}

\section{Methods}

Participants
- Randomized double-blind placebo-controlled trial

- Enrolment from 1999 to 2000 at a single centre in Denmark

\section{Participants

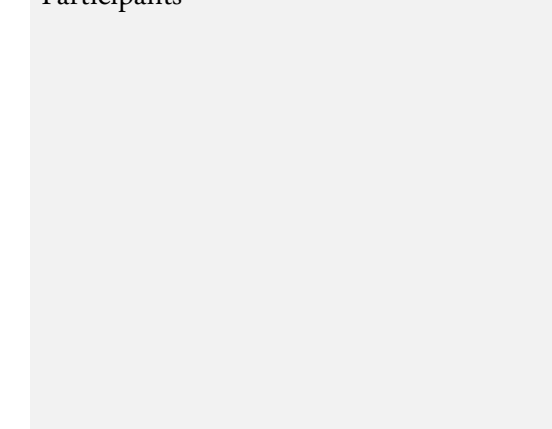 \\ - Adult patients undergoing a laparoscopic cholecystectomy, ASA I-II \\ Exclusion criteria \\ - ASA III-IV \\ - Age $>75$ \\ - Pregnancy \\ - ECRP in history 1 month before operation \\ - Chronic pain disease \\ - Endocrine, liver, or renal disease \\ - Tranquillizer use \\ - 88 adult patients (40 intervention, 40 placebo, 8 excluded) undergoing \\ laparoscopic cholecystectomy \\ - Mean age: 39 to 46 years \\ - Average duration of surgery: 68 to 78 minutes}

\section{Inclusion criteria}

- $75 \%$ female
$8 \mathrm{mg}$ dexamethasone vs placebo (normal saline) 90 minutes before skin incision. Drug/ placebo was drawn into a syringe and looked identical

Outcomes

\section{Primary outcome}

- Fatigue/pain, measured as a VAS score

\section{Secondary outcomes}

- PONV measured on a VRS

- Pulmonary function measured with a spirometer in sitting position before surgery 
and 1,2, 3, 6, and 24 hours after surgery

- Convalescence measured as number of days away from work

- CRP measured 6 and 24 hours after surgery

- Body temperature measured 6 and 24 hours after surgery

- 30-day morbidity follow-up was performed in all cases (no definition was given for the morbidity score).

\begin{tabular}{|c|c|c|}
\hline Notes & \multicolumn{2}{|c|}{$\begin{array}{l}\text { Source of funding } \\
\text { - Grants from the University of Copenhagen and the Danish Medical Research } \\
\text { Council (journal no. 9902757) supported this study. } \\
\text { Conflict of interest } \\
\text { - Not reported }\end{array}$} \\
\hline \multicolumn{3}{|l|}{ Risk of bias } \\
\hline Bias & Authors' judgement & Support for judgement \\
\hline $\begin{array}{l}\text { Random sequence generation (selection } \\
\text { bias) }\end{array}$ & Low risk & Block-randomized computer-generated list \\
\hline Allocation concealment (selection bias) & Low risk & $\begin{array}{l}\text { Randomization code was kept separate and } \\
\text { was not known to any of the investigators } \\
\text { until the study was finished }\end{array}$ \\
\hline $\begin{array}{l}\text { Blinding of participants and personnel } \\
\text { (performance bias) } \\
\text { All outcomes }\end{array}$ & Unclear risk & $\begin{array}{l}\text { Patients and investigators were masked to } \\
\text { group assignment. A nurse not participat- } \\
\text { ing in the study prepared and administered } \\
\text { the study medication }\end{array}$ \\
\hline $\begin{array}{l}\text { Blinding of outcome assessment (detection } \\
\text { bias) } \\
\text { All outcomes }\end{array}$ & Low risk & $\begin{array}{l}\text { Participants, treating physicians, and Inves- } \\
\text { tigators were masked to group assignment }\end{array}$ \\
\hline $\begin{array}{l}\text { Incomplete outcome data (attrition bias) } \\
\text { All outcomes }\end{array}$ & Low risk & $\begin{array}{l}\text { Numbers and reasons for dropouts were } \\
\text { documented. }\end{array}$ \\
\hline Selective reporting (reporting bias) & Unclear risk & $\begin{array}{l}\text { No study protocol; however all outcome } \\
\text { data consistently reported }\end{array}$ \\
\hline Other bias & Unclear risk & $\begin{array}{l}\text { Different analgesics and anaesthetics could } \\
\text { be used; not standardized for all partici- } \\
\text { pants } \\
\text { This has no effect on our primary outcome. }\end{array}$ \\
\hline
\end{tabular}


Methods

Participants

Interventions

Outcomes
- Parallel-group placebo-controlled randomized controlled trial

- Enrolment was conducted in 2011 at a single centre in Denmark.

\begin{tabular}{|c|c|}
\hline Participants & $\begin{array}{l}\text { Inclusion criteria } \\
\text { - Planned ambulatory shoulder surgery } \\
\text { Exclusion criteria } \\
\text { - Planned nerve block } \\
\text { - Concomitant other surgery } \\
\text { - Age below } 18 \text { or above } 90 \text { years } \\
\text { - Allergy to dexamethasone } \\
\text { - Glaucoma } \\
\text { - Untreated hypertension } \\
\text { - Diabetes } \\
\text { - Daily use of glucocorticoids } \\
\text { - Daily use of strong opioids } \\
\text { - Daily use of analgesics for reasons other than shoulder pain. } \\
\text { - A secondary exclusion criterion was more extensive surgery than planned, such as } \\
\text { repair of rotator cuff or labrum, biceps tenodesis, or arthrolysis } \\
\text { 101 adult patients undergoing ambulatory acromioclavicular joint resection or arthro- } \\
\text { scopic subacromial decompression repair } \\
\text { - Study had } 3 \text { study arms. } \\
\text { - } \quad 32 \text { randomized to intervention, } 26 \text { analysed } \\
\text { - } 37 \text { randomized to placebo, } 22 \text { analysed } \\
\text { - } 53 \% \text { Patients in the third study arm received too much dexamethasone and were } \\
\text { - Average duration of surgery: } 55 \text { to } 56 \text { minutes } \\
\text { - Mean age: } 49 \text { to } 55 \text { years }\end{array}$ \\
\hline
\end{tabular}

$8 \mathrm{mg}$ dexamethasone before induction vs placebo (normal saline) before induction

Primary outcome

- Present pain intensity (NRS 0 to 10$) 8$ hours after surgery

Secondary outcomes

- Pain intensity

- Analgesic consumption and side effects recorded for 3 days after surgery

- Complications such as infection or delayed wound healing were assessed after 2 months at outpatient follow-up with a hospital physiotherapist or by telephone No definition was stated in the article for delayed wound healing or postoperative infection

Follow-up: 2 months

\section{Source of funding}

- Supported by the Health Research Fund of Central Denmark Region

- Family Hede Nielsen Foundation

- Danish Rheumatism Association

- Augustinus Foundation 
Bjornholdt 2014 (Continued)

\section{Conflict of interest}

- None declared

\section{Risk of bias}

\begin{tabular}{|c|c|c|}
\hline Bias & Authors' judgement & Support for judgement \\
\hline $\begin{array}{l}\text { Random sequence generation (selection } \\
\text { bias) }\end{array}$ & Low risk & Random sequence table \\
\hline Allocation concealment (selection bias) & Low risk & $\begin{array}{l}\text { Pharmacy handled randomization and } \\
\text { stored the randomization list }\end{array}$ \\
\hline $\begin{array}{l}\text { Blinding of participants and personnel } \\
\text { (performance bias) } \\
\text { All outcomes }\end{array}$ & Low risk & $\begin{array}{l}\text { Pharmacy delivered identical bags with } \\
\text { medication. }\end{array}$ \\
\hline $\begin{array}{l}\text { Blinding of outcome assessment (detection } \\
\text { bias) } \\
\text { All outcomes }\end{array}$ & Low risk & $\begin{array}{l}\text { Investigators were blinded. Pharmacy kept } \\
\text { the list until follow-up was complete }\end{array}$ \\
\hline $\begin{array}{l}\text { Incomplete outcome data (attrition bias) } \\
\text { All outcomes }\end{array}$ & Unclear risk & $\begin{array}{l}\text { All dropouts were accounted for; however } \\
\text { the group of dropouts in the placebo group } \\
\text { was larger }\end{array}$ \\
\hline Selective reporting (reporting bias) & Low risk & Protocol was published. \\
\hline Other bias & Low risk & No apparent other bias \\
\hline
\end{tabular}

Choi 2013

Methods

Participants
- Parallel randomized controlled trial

- Study was conducted in Korea.

- Unknown when enrolment took place

\section{Inclusion criteria}

- Patients aged 20 and 70 years, with American Society of Anesthesiologists physical status I or II who were scheduled to undergo elective lumbar laminectomy with or without fusion

\section{Exclusion criteria}

- Steroids administered within 24 hours before surgery or during 72 hours after surgery

- Any known allergy or contraindication to steroids or pregabalin

- Diabetes mellitus

- Previous lumbar spinal surgery

- Epidural injection for lumbosacral radiculopathy in the previous 6 weeks

- Preoperative use of antidepressants or anticonvulsants

- Body mass index $>35 \mathrm{~kg} / \mathrm{m}^{2}$ 
Choi 2013 (Continued)

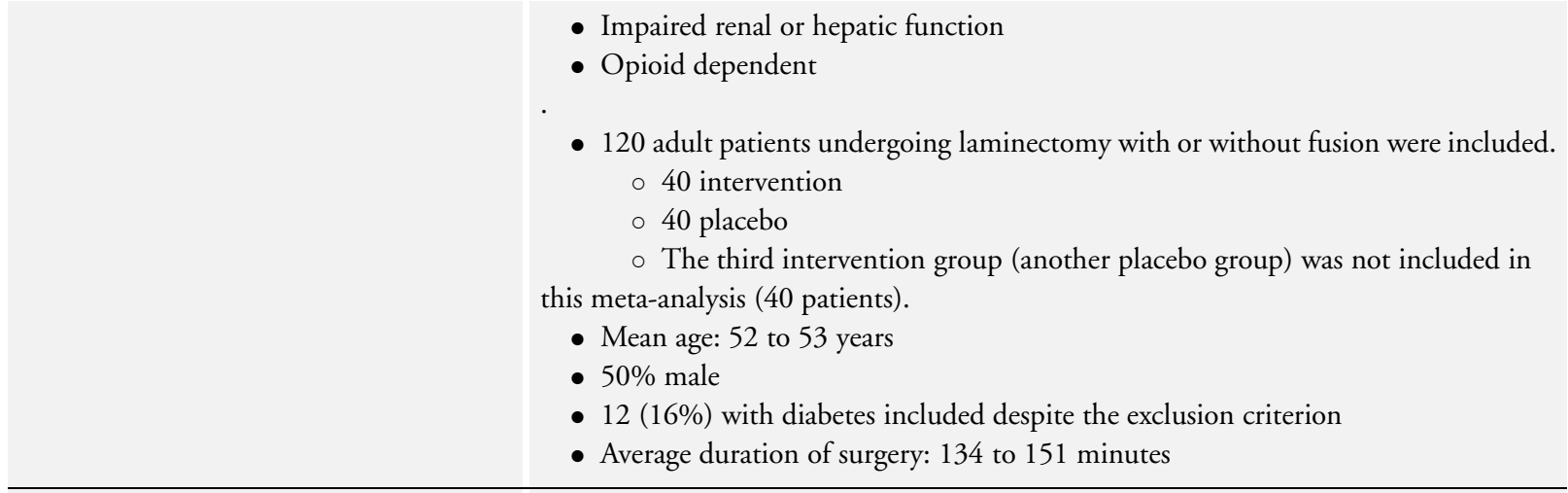

Interventions

$16 \mathrm{mg}$ dexamethasone plus pregabalin before induction vs $3.2 \mathrm{~mL}$ saline plus pregabalin before induction

Outcomes

Primary outcomes

- Postoperative pain intensity during rest and movement

- Frequency of rescue analgesic administered during the first 72 hours after surgery

Secondary outcomes

- Back and leg pain relief vs functional outcome in terms of daily activity

performance over a 6-month period after surgery

- Wound infection (definition for wound infection not described)

- Delayed wound healing

- Glucose values

Outcomes were assessed at 1, 3, and 6 months after surgery.

\begin{tabular}{|c|c|c|} 
Notes & $\begin{array}{c}\text { Sources of funding } \\
\bullet \text { Not reported } \\
\text { Conflict of interest } \\
\bullet \text { None declared }\end{array}$ \\
\hline
\end{tabular}

\section{Risk of bias}

Bias Authors' judgement

Random sequence generation (selection Low risk bias)

\section{Support for judgement}

Computer-generated randomization table

Open table; unknown who kept this

Staff nurse not participating in the study prepared study drugs - identical looking

(performance bias)

All outcomes

Blinding of outcome assessment (detection Low risk bias)

Surgeon assessing outcome was unaware of randomization. 
Choi 2013 (Continued)

\begin{tabular}{l|ll}
\hline $\begin{array}{l}\text { Incomplete outcome data (attrition bias) } \\
\text { All outcomes }\end{array}$ & Low risk & $\begin{array}{l}\text { Reasons for dropouts and withdrawals were } \\
\text { provided. }\end{array}$ \\
\hline Selective reporting (reporting bias) & Unclear risk & $\begin{array}{l}\text { Definition for wound infection is not doc- } \\
\text { umented. }\end{array}$ \\
\hline Other bias & High risk & $\begin{array}{l}\text { Reoperation excluded; reason for reopera- } \\
\text { tion unknown - could be due to wound in- } \\
\text { fection }\end{array}$ \\
\hline
\end{tabular}

Corocan 2017

Methods

Participants

Interventions

Outcomes

Notes
- Prospective double-blind randomized trial

- Enrolment took place in Australia.

\section{Inclusion criteria}

- Women were recruited at pre-assessment clinics and from preoperative wards.

- Adult females, ASA I or II, age 18 to 60 years, undergoing elective major laparoscopic gynaecological surgery expected to require at least 90 minutes of operative time, requiring a hospital stay to include at least the first postoperative night

\section{Exclusion criteria}

- Currently or recently taking immunosuppressive agents

- Known or suspected malignancy

- Hypertension

- Diabetes mellitus

- History of peptic ulceration

- Chronic pain syndrome requiring regular opioid consumption

- Predicted requirement for IV patient-controlled analgesia

- Known hypersensitivity to dexamethasone or granisetron

- 32 patients were included.

- 16 in the intervention group

$\circ 16$ in the control group

- Intervention group received $4 \mathrm{mg}$ dexamethasone after induction.

- Control group received normal saline after induction.

- Serum glucose

- IL-6

- Full blood count

- Lymphocyte analysis and postoperative infection data assessed 6 weeks postoperatively

\section{Sources of funding}

- Health Department of Western Australia (Raine Foundation Clinical Practitioner Fellowship to T.C.); University of Western Australia (T.C.)

Conflicts of interest

- T.C. is a member of the executive committee of the ANZCA Clinical Trials Network (Australia and New Zealand College of Anaesthetists (ANZCA) CTN). 
- M.P. is an editor of Anaesthesia and Intensive Care and is on the Editorial Board for International Journal of Obstetric Anesthesia, Obstetric Anesthesia Digest, Anesthesiology, and Pain Medicine.

- Other study authors declare no conflicts of interest.

\section{Risk of bias}

\begin{tabular}{|c|c|c|}
\hline Bias & Authors' judgement & Support for judgement \\
\hline $\begin{array}{l}\text { Random sequence generation (selection } \\
\text { bias) }\end{array}$ & Low risk & Computer-generated random sequence \\
\hline Allocation concealment (selection bias) & Low risk & Opaque envelopes \\
\hline $\begin{array}{l}\text { Blinding of participants and personnel } \\
\text { (performance bias) } \\
\text { All outcomes }\end{array}$ & Low risk & $\begin{array}{l}\text { Study drug was prepared by an observer } \\
\text { who was not connected to the study and } \\
\text { was diluted to a total volume of } 4 \mathrm{~mL} \text { with } \\
0.9 \% \text { sodium chloride in an unmarked } \\
\text { syringe. The patient, the patient's anaes- } \\
\text { thetist, and all investigators were blinded } \\
\text { to study drug identity }\end{array}$ \\
\hline
\end{tabular}

Blinding of outcome assessment (detection Low risk bias)

All outcomes
Study drug was prepared by an observer who was not connected to the study and was diluted to a total volume of $4 \mathrm{~mL}$ with $0.9 \%$ sodium chloride in an unmarked syringe. The patient, the patient's anaesthetist, and all investigators were blinded to study drug identity

CONSORT flow diagram included; 1 dropout in intervention group

Study was registered.

Selective reporting (reporting bias) Low risk

Low risk

No other apparent form of bias

\section{Cortes-Flores 2018}

Methods

Participants
- Randomized double-blind trial

- Enrolment took place in Mexico between June 2013 and October 2014.

\section{Inclusion criteria}

- All ASA I or II patients scheduled to receive an elective partial mastectomy with or without axillary gland removal, according to the positivity or negativity of sentinel lymph nodes

Exclusion criteria

- American Society of Anesthesiologists class III or IV disease 
Cortes-Flores 2018 (Continued)

\begin{tabular}{|l|}
\hline - Age $>70$ years \\
- Pregnancy \\
- Previous steroid therapy \\
- Uncontrolled diabetes mellitus (serum glycated haemoglobin level $>8 \%$ ) \\
- Use of opioids, sedatives, or analgesics within a week before surgery \\
- Any history of alcohol or drug abuse \\
- History of inner ear disease and/or uncontrollable severe PONV after any surgical \\
procedure \\
- 80 participants were included. \\
$\circ 40$ in the intervention group \\
$\circ 40$ in the control group
\end{tabular}

Interventions

- Intervention group received $8 \mathrm{mg}$ dexamethasone 1 hour before surgery.

- Control group received normal saline 1 hour before surgery.

\begin{tabular}{l|l}
\hline Outcomes & $\begin{array}{c}\text { Primary outcomes } \\
\text { - Postoperative nausea and vomiting score } \\
\text { - Pain scores } \\
\text { - Spirometry parameters } \\
\text { - Postoperative complications after } 30 \text { days }\end{array}$ \\
\hline Notes & $\begin{array}{l}\text { Sources of funding } \\
\text { - Study authors did not receive any funding } \\
\text { Conflicts of interest } \\
\text { - None }\end{array}$ \\
\hline
\end{tabular}

Risk of bias

\begin{tabular}{l|l|l} 
Bias & Authors' judgement & Support for judgement \\
\hline $\begin{array}{l}\text { Random sequence generation (selection } \\
\text { bias) }\end{array}$ & Unclear risk & Procedure not described in report \\
\hline Allocation concealment (selection bias) & Unclear risk & Procedure not described in report \\
\hline $\begin{array}{l}\text { Blinding of participants and personnel } \\
\text { (performance bias) } \\
\text { All outcomes }\end{array}$ & Unclear risk & Procedure not described in report \\
\hline
\end{tabular}

Blinding of outcome assessment (detection Unclear risk bias)

All outcomes

Procedure not described in report

Incomplete outcome data (attrition bias) Low risk

All outcomes

CONSORT flow diagram is included in the report.

Selective reporting (reporting bias) High risk

Study was retrospectively registered at clinicaltrials.gov (NCT02305173). Furthermore, the primary outcome parameter was 
Cortes-Flores 2018 (Continued)

changed from spirometry parameters to PONV

\begin{tabular}{l|l|l}
\hline Other bias & Low risk & No other apparent form of bias
\end{tabular}

\section{Cowie 2010}

Methods

Participants

Interventions

$8 \mathrm{mg}$ dexamethasone plus $2 \mathrm{mg}$ tropisetron before inductions vs placebo (normal saline) plus $2 \mathrm{mg}$ tropisetron before induction
- Randomized placebo-controlled trial

- Study was conducted at a single centre in Australia.

\section{Inclusion criteria}

- Adult patients undergoing laparoscopic cholecystectomy

Exclusion criteria

- Patients already on dexamethasone or with diabetes

- 14 adult patients undergoing a laparoscopic cholecystectomy

$$
\circ 7 \text { intervention }
$$$$
\text { - } 7 \text { placebo }
$$

- Mean age: 35 to 49 years

- Average duration of surgery: 63 to 77 minutes

\begin{tabular}{l|l} 
& plus $2 \mathrm{mg}$ tropisetron before induction \\
\hline Outcomes & $\begin{array}{c}\text { Primary outcomes } \\
\text { - Plasma glucose and cortisol levels measured at } 5 \text { and } 24 \text { hours after surgery } \\
\text { Study did not assess any secondary outcomes. }\end{array}$ \\
\hline
\end{tabular}

\begin{tabular}{c|c}
\hline Sources of funding \\
$\bullet$ Not reported \\
Conflict of interest \\
$\bullet$ Not reported
\end{tabular}

\section{Risk of bias}

\begin{tabular}{l|l|l} 
Bias & Authors' judgement & Support for judgement \\
\hline $\begin{array}{l}\text { Random sequence generation (selection } \\
\text { bias) }\end{array}$ & Low risk & Computer-generated random numbers \\
\hline Allocation concealment (selection bias) & Unclear risk & Not described \\
\hline $\begin{array}{l}\text { Blinding of participants and personnel } \\
\text { (performance bias) } \\
\text { All outcomes }\end{array}$ & Unclear risk & $\begin{array}{l}\text { Participants and investigators were masked } \\
\text { to group assignment. How this was } \\
\text { achieved is unknown. The anaesthesiolo- } \\
\text { gist was not blinded }\end{array}$
\end{tabular}


Cowie 2010 (Continued)

Blinding of outcome assessment (detection Low risk

bias)

All outcomes
Participants and investigators were masked to group assignment; objective outcome data

No description of dropouts or withdrawals, but very small sample size

Outcome data are consistently reported.

No study protocol has been published

Other bias

Unclear risk

Unknown

Doksrod 2012

Methods

Participants

- Parallel randomized controlled trial

- Between 2008 and 2009, patients were enrolled at the Telemark Hospital in Norway.

\section{Inclusion criteria}

- Adult patients ASA I-III, undergoing total thyroidectomy, hemithyroidectomy, or parathyroidectomy

\section{Exclusion criteria}

- Body weight $>100 \mathrm{~kg}$ or body mass index $>35$

- Regular or recent use of corticosteroids, anti-emetics, or opioids

- 121 adult patients undergoing thyroid surgery

- 41 intervention

- 40 placebo)

- Third study group not included in meta-analysis owing to high dose of dexamethasone (40 patients).

- Patients with diabetes were eligible.

- Baseline characteristics were not described in the article but were similar between groups.

Interventions

Dexamethasone $0.15 \mathrm{mg} / \mathrm{kg}^{-1}$ at induction vs placebo (normal saline $0.1 \mathrm{~mL} / \mathrm{kg}^{-1}$ ). Study medication was prepared at the pharmacy in neutral ampoules

Outcomes

- NRS of pain (0 to 10) at rest and coughing

- PONV (0 lowest with no symptoms and 5 maximum)

- Consumption of opioids and antiemetics was recorded at 2 hours, 4 hours, 24 hours, 36 hours, 48 hours, 72 hours, and 30 days after surgery.

- Blood glucose levels were measured at 2 hours and 4 hours after surgery.

- Postoperative infection and wound healing were assessed by a questionnaire and by follow-up by a surgeon 30 days postoperatively.

- No definition stated in article for postoperative infection or delayed wound healing 
Doksrod 2012 (Continued)

\begin{tabular}{|c|c|c|}
\hline Notes & $\begin{array}{l}\text { Sources of funding } \\
\text { - Telemark Hospital } \\
\text { Conflict of interest } \\
\text { - None declared }\end{array}$ & \\
\hline \multicolumn{3}{|l|}{ Risk of bias } \\
\hline Bias & Authors' judgement & Support for judgement \\
\hline $\begin{array}{l}\text { Random sequence generation (selection } \\
\text { bias) }\end{array}$ & Low risk & Computer-generated codes \\
\hline Allocation concealment (selection bias) & Low risk & Sequentially numbered sealed envelopes \\
\hline $\begin{array}{l}\text { Blinding of participants and personnel } \\
\text { (performance bias) } \\
\text { All outcomes }\end{array}$ & Low risk & $\begin{array}{l}\text { Study medication was prepared at the phar- } \\
\text { macy and delivered in identical-looking } \\
\text { ampoules }\end{array}$ \\
\hline $\begin{array}{l}\text { Blinding of outcome assessment (detection } \\
\text { bias) } \\
\text { All outcomes }\end{array}$ & Unclear risk & $\begin{array}{l}\text { Not specified if surgeon doing the follow- } \\
\text { up was blinded }\end{array}$ \\
\hline $\begin{array}{l}\text { Incomplete outcome data (attrition bias) } \\
\text { All outcomes }\end{array}$ & Low risk & Reasons for dropouts documented \\
\hline Selective reporting (reporting bias) & Low risk & Protocol was published (NCT00569920). \\
\hline Other bias & Low risk & No apparent other bias \\
\hline
\end{tabular}

\section{DREAMS trial collaborators}

Methods
- Pragmatic blinded multi-centre randomized controlled trial at 45 centres in the UK

- Inclusion period was from July 2011 to January 2014.
Participants

\section{Inclusion criteria}

- Adults (aged 18 and over)

- Ability to consent

- Undergoing elective open or laparoscopic bowel surgery for malignant or benign pathology

Exclusion criteria

- Pregnancy

- Gastrointestinal obstruction

- Diabetes

- Glaucoma

- Active gastric ulceration confirmed by endoscopy

- 1350 patients were recruited.

○ 674 were allocated to $8 \mathrm{mg}$ dexamethasone during induction. 
DREAMS trial collaborators (Continued)

- 676 were allocated to standard care.

- $58 \%$ male

- All underwent bowel surgery.

Interventions

- Intervention group received $8 \mathrm{mg}$ dexamethasone after induction.

- Control group received standard care.

- Placebo was not used.

Outcomes

\section{Primary outcome}

- Any vomiting within 24 hours postoperatively, defined as episodes of expulsion of gastric contents

\section{Secondary outcomes}

- Number of episodes of vomiting postoperatively (with an interval of 5 minutes defining separate episodes)

- Use of postoperative antiemetics

- Severity of postoperative nausea and vomiting (measured with the PONV intensity scale)

- Fatigue (measured with the FACIT-F (functional assessment of chronic illnessfatigue) questionnaire)

- Time to toleration of oral diet

- Length of hospital stay

- Health-related quality of life (measured with EQ-5D-3L22 23)

Participants were seen 30 days postoperatively and assessments were made of wound and chest infections and other complications

Attempts were made by telephone to contact participants who did not attend

Notes Sources of funding

- This trial was supported in both development and delivery by the Birmingham Surgical Trials Consortium and the Royal College of Surgeons and Rosetrees Clinical Research Initiative.

- Local support for the pilot phase was also provided by the Birmingham ECMC.

\section{Conflicts of interest}

- All study authors have completed the ICMJE uniform disclosure form at www. icmje.org/coi_disclosure.pdf and declare the following.

- No support from any organization for the submitted work beyond the study grants listed above

- No financial relationships in the previous 3 years with any organizations that might have an interest in the submitted work

- No other relationships or activities that could appear to have influenced the submitted work

\section{Risk of bias}

\section{Bias}

Random sequence generation (selection Low risk bias)
Support for judgement

Allocation was made by a web-based central randomization service at the University of Birmingham clinical trials unit, with telephone backup 


\section{DREAMS trial collaborators (Continued)}

\begin{tabular}{|c|c|c|}
\hline Allocation concealment (selection bias) & Low risk & Computer-based, with algorithm \\
\hline $\begin{array}{l}\text { Blinding of participants and personnel } \\
\text { (performance bias) } \\
\text { All outcomes }\end{array}$ & Unclear risk & $\begin{array}{l}\text { Only anaesthetist was not blinded, but ad- } \\
\text { ministration of dexamethasone was noted } \\
\text { only in the trial files, not in the anaesthetic } \\
\text { record. However, no placebo was used. }\end{array}$ \\
\hline $\begin{array}{l}\text { Blinding of outcome assessment (detection } \\
\text { bias) } \\
\text { All outcomes }\end{array}$ & Low risk & $\begin{array}{l}\text { Research staff blinded. Anaesthetist not in- } \\
\text { volved in postoperative care }\end{array}$ \\
\hline $\begin{array}{l}\text { Incomplete outcome data (attrition bias) } \\
\text { All outcomes }\end{array}$ & Low risk & Detailed CONSORT flow diagram \\
\hline Selective reporting (reporting bias) & Low risk & $\begin{array}{l}\text { Trial was registered. All logical outcomes } \\
\text { are reported. }\end{array}$ \\
\hline Other bias & Low risk & No other apparent form of bias \\
\hline
\end{tabular}

\section{Feroci 2011}

Methods

Participants
- Double-blind randomized controlled trial

- Enrolment took place at a single centre in Italy in 2009.

\begin{tabular}{|l} 
- Adult patients with ASA classification status I and II undergoing thyroid surgery \\
Exclusion criteria \\
- Younger than 18 years \\
- Previous malignant disease \\
- Previous thyroid surgery \\
- Previous neck surgery \\
- Received antiemetic therapy within 48 hours before surgery \\
- Chronic pain disorder \\
- Insulin-dependent diabetes mellitus \\
- History of severe and/or repeated PONV after previous minor surgery \\
- Pregnancy \\
- 102 adult patients were included. \\
$\quad 051$ intervention. \\
- Mean age: 54 to 57 years \\
- $68 \%$ female \\
- Duration of surgery: 84 to 89 minutes
\end{tabular}




\begin{tabular}{|c|c|}
\hline Outcomes & $\begin{array}{l}\text { Primary outcome } \\
\text { - PONV, measured as follows: 0: no nausea; } 1 \text { : mild nausea; } 2 \text { : severe nausea; } 3 \text { : } \\
\text { retching and/or vomiting } \\
\text { Use of postoperative antiemetics (frequency, amount of intake, and substance) was } \\
\text { recorded during the observation period } \\
\text { Secondary outcomes } \\
\text { - Pain (assessed with a standardized visual analogue scale (VAS) that ranged from } 0 \\
\text { (no pain) to } 100 \text { (worst pain imaginable)) } \\
\text { - Subjective voice disturbances (assessed by a voice visual analogue scale (VVAS: } \\
1001 / 4 \text { normal voice, } 01 / 4 \text { worst voice imaginable)) } \\
\text { - Pain assessed with a standardized VAS that ranged from } 0 \text { (no pain) to } 100 \text { (worst } \\
\text { pain imaginable) } \\
\text { Occurrence of side effects accompanying dexamethasone usage, such as transient insulin- } \\
\text { dependent diabetes, wound infection, systemic infection, or delayed wound healing, was } \\
\text { evaluated and reported. Glycaemia measurements were obtained } 24 \text { hours postopera- } \\
\text { tively } \\
\text { Hospitalization time was also recorded. } \\
\text { Postoperative wound infection and wound healing were assessed } 30 \text { days after surgery } \\
\text { (no definition stated in the article) }\end{array}$ \\
\hline
\end{tabular}

\begin{tabular}{|c|c|}
\hline Notes & $\begin{array}{l}\text { Sources of funding } \\
\text { - Not reported } \\
\text { Conflict of interest } \\
\text { - Not reported }\end{array}$ \\
\hline
\end{tabular}

\section{Risk of bias}

\begin{tabular}{l|l|l} 
Bias & Authors' judgement & Support for judgement \\
\hline $\begin{array}{l}\text { Random sequence generation (selection } \\
\text { bias) }\end{array}$ & Low risk & Computer-generated random number list \\
\hline Allocation concealment (selection bias) & High risk & $\begin{array}{l}\text { Random number list; unclear how and } \\
\text { where the list was stored and who had ac- } \\
\text { cess }\end{array}$ \\
\hline
\end{tabular}

Blinding of participants and personnel Low risk (performance bias)

All outcomes

Blinding of outcome assessment (detection Low risk bias)

All outcomes

Incomplete outcome data (attrition bias) Low risk All outcomes
Staff not participating in the trial prepared drugs; patients, anaesthesiologist, and researchers were blinded to the randomization process and outcomes

Investigators who collected postoperative data were blinded to the randomization process and to the types of drugs administered

Reasons for dropouts documented 
Feroci 2011 (Continued)

\begin{tabular}{|c|c|c|}
\hline Selective reporting (reporting bias) & Low risk & $\begin{array}{l}\text { Study was registered at trialregister.gov } \\
\text { (NCT00888303). }\end{array}$ \\
\hline Other bias & Low risk & No apparent other bias \\
\hline
\end{tabular}

Ionescu 2014

Methods

Participants
- Parallel-group randomized controlled trial

- Enrolment took place at a single centre in Romania from 2008 to 2009.

\section{Inclusion criteria}

- ASA status I and II and undergoing a laparoscopic cholecystectomy

\section{Exclusion criteria}

- Immune system disorders

- Known inflammatory disease (including acute cholecystitis)

- Abnormal white cell count

- Asthma

- Obesity $\left(\mathrm{BMI}>30 \mathrm{~kg} / \mathrm{m}^{2}\right)$

- Diabetes

- Gastric ulcer

- Allergies

- History of PONV

- Current steroid medication

- Anti-inflammatory medication

- 46 adult patients were included.
- 22 intervention
- 20 placebo
- 4 dropouts

- Mean age: 50 to 55

- $56 \%$ female.

- Average duration of surgery: 42 to 45 minutes
Participants received $4 \mathrm{mg}$ dexamethasone at induction ( $1 \mathrm{~mL}$ clear solution) vs normal saline at induction ( $1 \mathrm{~mL}$ clear solution)

Outcomes

\section{Primary outcomes}

- Plasma concentrations of both pro-inflammatory and anti-inflammatory interleukins measured by commercially available ELISA kits before surgery, after intubation, 2 hours after recovery, and 24 hours after anaesthesia

- Surgical site infection assessed according to SSI criteria, at 30 days after surgery

\begin{tabular}{l} 
Notes $\begin{array}{c}\text { Sources of funding } \\
\text { - Research grant from the National Center for the Management of Project Romania } \\
\text { Conflict of interest } \\
- \text { None declared }\end{array}$ \\
\hline
\end{tabular}

\section{Risk of bias}


Ionescu 2014 (Continued)

\begin{tabular}{|c|c|c|}
\hline Bias & Authors' judgement & Support for judgement \\
\hline $\begin{array}{l}\text { Random sequence generation (selection } \\
\text { bias) }\end{array}$ & Low risk & Random sequence generator (computer) \\
\hline Allocation concealment (selection bias) & Unclear risk & Not described \\
\hline $\begin{array}{l}\text { Blinding of participants and personnel } \\
\text { (performance bias) } \\
\text { All outcomes }\end{array}$ & Unclear risk & $\begin{array}{l}\text { Participants and personnel were not } \\
\text { blinded; however no expected influence on } \\
\text { outcome parameter }\end{array}$ \\
\hline $\begin{array}{l}\text { Blinding of outcome assessment (detection } \\
\text { bias) } \\
\text { All outcomes }\end{array}$ & High risk & Outcome assessors were not blinded. \\
\hline $\begin{array}{l}\text { Incomplete outcome data (attrition bias) } \\
\text { All outcomes }\end{array}$ & Low risk & Reasons for dropouts described \\
\hline Selective reporting (reporting bias) & Unclear risk & No study protocol published \\
\hline Other bias & Low risk & No apparent other bias \\
\hline
\end{tabular}

\section{Kalappa 2017}

\begin{tabular}{|c|c|}
\hline Methods & $\begin{array}{l}\text { - Prospective double-blind randomized trial } \\
\text { - Enrolment took place in India in } 2015 \text { and } 2016 .\end{array}$ \\
\hline Participants & $\begin{array}{l}\text { Inclusion criteria } \\
\text { - Undergoing lumbosacral spine surgeries (caudal to T12 spine) } \\
\text { - Aged between } 18 \text { and } 70 \text { years } \\
\text { - American Society of Anesthesiologists (ASA) Grades I and II } \\
\text { - Under general anaesthesia } \\
\text { Exclusion criteria } \\
\text { - Diabetes } \\
\text { - Coagulopathy } \\
\text { - Peptic ulcer disease } \\
\text { - Anomalies of sacrum } \\
\text { - On steroid medications within the past } 6 \text { months } \\
\text { - } 96 \text { patients were included in this trial. } \\
\text { - Randomly divided over } 3 \text { groups } \\
\circ 32 \text { in group A } \\
\circ 32 \text { in group B } \\
\circ 32 \text { in group C. Patients in group C were not included in this meta-analysis, } \\
\text { as they received dexamethasone via the caudal route. }\end{array}$ \\
\hline Interventions & $\begin{array}{l}\text { - Group A received normal saline IV and ropivacaine via the caudal route. } \\
\text { - Group B received } 8 \mathrm{mg} \text { dexamethasone IV after induction and ropivacaine via the } \\
\text { caudal route. }\end{array}$ \\
\hline
\end{tabular}


Kalappa 2017 (Continued)

\begin{tabular}{|c|c|c|}
\hline Outcomes & \multicolumn{2}{|c|}{$\begin{array}{l}\text { - Glucometric random blood sugar was recorded at baseline, } 4 \text { hours, } 8 \text { hours, } 12 \\
\text { hours, and } 24 \text { hours after the caudal block. } \\
\text { - Pain scores } \\
\text { - Length of hospital stay }\end{array}$} \\
\hline Notes & \multicolumn{2}{|l|}{$\begin{array}{l}\text { Sources of funding } \\
\text { - None } \\
\text { Conflicts of interest } \\
\text { - None reported }\end{array}$} \\
\hline \multicolumn{3}{|l|}{ Risk of bias } \\
\hline Bias & Authors' judgement & Support for judgement \\
\hline $\begin{array}{l}\text { Random sequence generation (selection } \\
\text { bias) }\end{array}$ & Low risk & Computer-generated random sequence \\
\hline Allocation concealment (selection bias) & Unclear risk & This is not described in the paper. \\
\hline $\begin{array}{l}\text { Blinding of participants and personnel } \\
\text { (performance bias) } \\
\text { All outcomes }\end{array}$ & Unclear risk & This is not described in the paper. \\
\hline $\begin{array}{l}\text { Blinding of outcome assessment (detection } \\
\text { bias) } \\
\text { All outcomes }\end{array}$ & Unclear risk & $\begin{array}{l}\text { The senior registrar who assessed pain } \\
\text { scores was blinded to group assignment. } \\
\text { However, it is unclear if medication was } \\
\text { registered in the anaesthesia records }\end{array}$ \\
\hline $\begin{array}{l}\text { Incomplete outcome data (attrition bias) } \\
\text { All outcomes }\end{array}$ & High risk & No flow diagram or dropout rate reported. \\
\hline Selective reporting (reporting bias) & Unclear risk & Study was not registered in a trial register. \\
\hline Other bias & Low risk & No apparent other bias \\
\hline
\end{tabular}

Karacinar 2009

Methods

Participants
- Randomized double-blind placebo-controlled trial

- Enrolment took place at a single centre in Turkey.

\section{Inclusion criteria}

- Adult patients undergoing a craniotomy

\section{Exclusion criteria}

- Diabetes

- Glucose intolerance

- Corticosteroid use

- 68 ASA I or II patients were included. 
Karacinar 2009 (Continued)

\begin{tabular}{|c|c|c|}
\hline & \multicolumn{2}{|c|}{$\begin{array}{l}\circ 17 \text { group D4. } \\
\circ 17 \text { group D8. } \\
\circ 17 \text { group D16. } \\
\quad 17 \text { placebo. } \\
\text { - Mean age: } 44 \text { to } 51 \text { years } \\
\text { - } 60 \% \text { male } \\
\text { - Average duration of surgery: } 229 \text { to } 243 \text { minutes }\end{array}$} \\
\hline Interventions & \multicolumn{2}{|c|}{$\begin{array}{l}\text { Participants received } 4 \mathrm{mg}, 8 \mathrm{mg} \text {, or } 16 \mathrm{mg} \text { dexamethasone at induction vs } 5 \mathrm{~mL} \text { normal } \\
\text { saline at induction }\end{array}$} \\
\hline Outcomes & \multicolumn{2}{|c|}{$\begin{array}{l}\text { Primary outcome } \\
\text { - Glucose and electrolyte values, measured } 1,2,3 \text {, and } 4 \text { hours after dexamethasone } \\
\text { Secondary outcomes } \\
\text { - PONV measured on dichotomous scales } \\
\text { - Insufficient follow-up for complication data }\end{array}$} \\
\hline Notes & \multicolumn{2}{|c|}{$\begin{array}{l}\text { Sources of funding } \\
\text { - This research was supported by the Research Fund of Erciyes University. } \\
\text { Conflict of interest } \\
\text { - Not reported }\end{array}$} \\
\hline \multicolumn{3}{|l|}{ Risk of bias } \\
\hline Bias & Authors' judgement & Support for judgement \\
\hline $\begin{array}{l}\text { Random sequence generation (selection } \\
\text { bias) }\end{array}$ & Unclear risk & Sequence generation was not described. \\
\hline Allocation concealment (selection bias) & Unclear risk & $\begin{array}{l}\text { Unknown how allocation concealment was } \\
\text { achieved }\end{array}$ \\
\hline $\begin{array}{l}\text { Blinding of participants and personnel } \\
\text { (performance bias) } \\
\text { All outcomes }\end{array}$ & Unclear risk & $\begin{array}{l}\text { Control group received a placebo; therefore } \\
\text { participants were probably blinded. Un- } \\
\text { known if personnel were blinded }\end{array}$ \\
\hline $\begin{array}{l}\text { Blinding of outcome assessment (detection } \\
\text { bias) } \\
\text { All outcomes }\end{array}$ & Unclear risk & $\begin{array}{l}\text { Unknown whether researchers were } \\
\text { blinded }\end{array}$ \\
\hline $\begin{array}{l}\text { Incomplete outcome data (attrition bias) } \\
\text { All outcomes }\end{array}$ & High risk & No dropouts described \\
\hline Selective reporting (reporting bias) & Unclear risk & Protocol was not published. \\
\hline Other bias & Unclear risk & $\begin{array}{l}\text { Report does not give a lot of information } \\
\text { on the methods. }\end{array}$ \\
\hline
\end{tabular}


- Randomized controlled trial

- Enrolment took place at a single centre in Japan in 2012.

\section{Participants}

\section{Inclusion criteria}

- Patients aged 20 to 75 undergoing an arthroscopy

\section{Exclusion criteria}

- Refused consent

- Diagnosed with a clinical condition in which ISB was contraindicated

- History of coagulation disorder

- International normalized ratio 1.5

- Skin infection at the site of the block

- Preexisting neuropathy involving the upper limb

- Drug dependency

- Systemic steroid use within the previous 6 months

- Peptic ulcer disease

- Diabetes mellitus

- Renal disease

- Hepatic disease

- Pregnancy

- 39 adult patients were included.

- 10 intervention.

- 12 control.

- In the third arm of the study, participants received perineural dexamethasone and therefore were not included in this meta-analysis.

- Mean age: 55 to 59 years

- $28 \%$ female

- Average duration of surgery: 172 to 178 minutes

\section{Primary outcome}

- Length of the sensory block, defined as time between performance of the sensory block and first administration of analgesia

\section{Secondary outcomes}

- NRS the morning after surgery

- Analgesic need

- Sleep disturbance

- Overall satisfaction score, measuring patient comfort

- Adverse events were evaluated 28 days after surgery.

- No definition of wound infection was stated.

- Not reported

Conflict of interest

- None declared

\section{Risk of bias}

Bias 


\section{Kawanishi 2014 (Continued)}

\begin{tabular}{l|l|l}
\hline $\begin{array}{l}\text { Random sequence generation (selection } \\
\text { bias) }\end{array}$ & Unclear risk & Sequence generation not described \\
\hline $\begin{array}{l}\text { Allocation concealment (selection bias) } \\
\begin{array}{l}\text { Blinding of participants and personnel } \\
\text { (performance bias) } \\
\text { All outcomes }\end{array}\end{array}$ & High risk & Closed envelopes \\
\hline $\begin{array}{l}\text { Blinding of outcome assessment (detection } \\
\text { bias) } \\
\text { All outcomes }\end{array}$ & High risk & No blinding of participants or caregivers \\
\hline $\begin{array}{l}\text { Incomplete outcome data (attrition bias) } \\
\text { All outcomes }\end{array}$ & Low risk & No blinding of researchers \\
\hline $\begin{array}{l}\text { Selective reporting (reporting bias) } \\
\text { Other bias }\end{array}$ & Unclear risk & Reasons for dropouts documented \\
\hline
\end{tabular}

\section{Kirdak 2008}

$\begin{array}{ll}\text { Methods } & \text { - Double-blind randomized controlled trial } \\ \text { - Enrolment took place at a single centre in Turkey in } 2005 .\end{array}$

\begin{tabular}{|l|l}
\hline Inclusion criteria \\
Participants \\
Exclusion criteria \\
- Emergency surgery \\
- Age $<18$ or $>80$ \\
- Diabetes \\
- Recent NSAID use \\
- IBD \\
- Renal failure \\
- COPD \\
- Ascites \\
- Unresectable tumour \\
- 30 adult patients were included. \\
$\quad \circ 14$ intervention \\
$\quad \circ 13$ control \\
$\circ 3$ dropouts \\
- Mean age: 55 to 62 years \\
- $59 \%$ male \\
- Average duration of surgery: 149 to 157 minutes
\end{tabular}


Kirdak 2008

Outcomes
Primary outcome
Unclear. The following outcomes were assessed.
- CRP levels and IL-6 levels measured preoperatively and on days 1 and 2
postoperatively
- Nausea and vomiting measured on a dichotomous scale assessed at days 1, 2, and
3 postoperatively
- Pain measured with the VAS and as morphine consumption on days 1, 2, and 3
postoperatively
- Morbidity or mortality occurring at operation or in the subsequent 30 days
- Diagnosis of surgical site infection according to the definitions of the Centers for
Disease Control and Prevention

Risk of bias

\begin{tabular}{|c|c|c|}
\hline Bias & Authors' judgement & Support for judgement \\
\hline $\begin{array}{l}\text { Random sequence generation (selection } \\
\text { bias) }\end{array}$ & Unclear risk & Unknown \\
\hline Allocation concealment (selection bias) & Low risk & Sealed envelopes \\
\hline $\begin{array}{l}\text { Blinding of participants and personnel } \\
\text { (performance bias) } \\
\text { All outcomes }\end{array}$ & Low risk & $\begin{array}{l}\text { Anaesthesiologists, surgeons, nurses ad- } \\
\text { ministering study drugs, patients, other in- } \\
\text { vestigators who were involved in postoper- } \\
\text { ative care, persons making laboratory mea- } \\
\text { surements, and biostatisticians were un- } \\
\text { aware of patient group allocation until } \\
\text { completion of statistical analysis }\end{array}$ \\
\hline $\begin{array}{l}\text { Blinding of outcome assessment (detection } \\
\text { bias) } \\
\text { All outcomes }\end{array}$ & Low risk & $\begin{array}{l}\text { Investigators involved in postoperative care } \\
\text { were unaware of participant group alloca- } \\
\text { tion until completion of statistical analysis }\end{array}$ \\
\hline $\begin{array}{l}\text { Incomplete outcome data (attrition bias) } \\
\text { All outcomes }\end{array}$ & Low risk & Reasons for dropouts documented \\
\hline Selective reporting (reporting bias) & Unclear risk & Protocol not published \\
\hline Other bias & Low risk & No apparent other bias \\
\hline
\end{tabular}


- Multi-centre parallel-group double-blind randomized placebo-controlled study

- Enrolment took place at 2 centres in Denmark in 2015.

\section{Participants}

\section{Inclusion criteria}

- Adults (aged at least 18 years) with ASA status I to III undergoing a diagnostic laparoscopy for suspected appendicitis between 30 April 2015 and 2 September 2015

\section{Exclusion criteria}

- Inflammatory bowel disease

- Autoimmune disease

- Chronic pain

- Glaucoma

- Ocular herpes simplex

- Cushing's disease

- Myasthenia gravis

- Expected poor compliance with the study protocol

- Systemic use of corticosteroids or other immunosuppressive drugs

- Pregnant or breastfeeding women

- Vaccinated within the last 14 days

- 120 adult patients undergoing laparoscopic appendectomy were included.

- 59 intervention

- 57 placebo

- 4 lost to follow-up

- Patients with diabetes were eligible.

- Mean age: 38 to 41 years.

- $53 \%$ female

- $63 \%$ ASA status I

- $34 \%$ ASA status II

- Average duration of surgery: 47 to 49 minutes

- Incidence of PONV during first postoperative day (first 24 to 32 hours after surgery)

\section{Secondary outcomes}

- Pain at rest

- Pain when coughing

- Fatigue

- Quality of sleep

- Quality of recovery

- Duration of convalescence

- Use of antiemetic and consumption of opioids during first postoperative day

- Use of antiemetic and postoperative analgesics was recorded through the electronic patient medication system.

- Adverse events and postoperative complications were recorded according to the Clavien-Dindo classification of surgical complications on the patient's medical chart and by patient interview 30 days after surgery. 


\begin{tabular}{l} 
Notes $\begin{array}{l}\text { Funding sources } \\
\text { - Work supported by the A.P. Møller Foundation for the Advancement of Medical } \\
\text { Science } \\
\text { - Hans and Nora Buchards Foundation } \\
\text { - Axel Muusfeldts Foundation } \\
\text { - J.K. received a research grant from Nordsjællands Hospital and financial support } \\
\text { from the Department of Surgery, Nordsjællands Hospital, Copenhagen University } \\
\text { Hospital. } \\
\text { Conflict of interest } \\
\text { - None declared }\end{array}$ \\
\hline
\end{tabular}

Risk of bias

\begin{tabular}{|c|c|c|}
\hline Bias & Authors' judgement & Support for judgement \\
\hline $\begin{array}{l}\text { Random sequence generation (selection } \\
\text { bias) }\end{array}$ & Low risk & Computer-generated list \\
\hline Allocation concealment (selection bias) & Low risk & Pharmacy-based randomization \\
\hline $\begin{array}{l}\text { Blinding of participants and personnel } \\
\text { (performance bias) } \\
\text { All outcomes }\end{array}$ & Low risk & $\begin{array}{l}\text { Pharmacy prepared study drug in identica } \\
\text { syringes. }\end{array}$ \\
\hline $\begin{array}{l}\text { Blinding of outcome assessment (detection } \\
\text { bias) } \\
\text { All outcomes }\end{array}$ & Low risk & $\begin{array}{l}\text { Researchers were not aware of study group } \\
\text { until data analysis was completed }\end{array}$ \\
\hline $\begin{array}{l}\text { Incomplete outcome data (attrition bias) } \\
\text { All outcomes }\end{array}$ & Low risk & Reasons for dropouts are provided. \\
\hline Selective reporting (reporting bias) & Low risk & $\begin{array}{l}\text { Protocol was registered at clinicaltrials.gov } \\
\text { (NCT02415335). }\end{array}$ \\
\hline Other bias & Low risk & No apparent other bias \\
\hline
\end{tabular}

Koh 2013

\section{Methods}

Participants
- Multi-centre parallel randomized controlled trial

- Enrolment took place in 2011 in Korea.

\section{Inclusion criteria}

- 18 years or older who were scheduled for unilateral TKA for primary osteoarthritis Exclusion criteria

- History of intolerance or allergy to any drug used in the current study

- Severe impairment of bowel motility

- Administration of another antiemetic drug or systemic steroid 24 hours before surgery 
- History of cardiovascular or respiratory disease, or alcohol or opioid dependence

- Impairment of renal or hepatic function

- Regional anaesthesia contraindicated

- Spinal anaesthesia failed

- Femoral nerve block and/or intravenous patient-controlled analgesia (PCA) discontinued before the planned schedule

- Declined to participate in the trial

- Unable to provide informed consent

- 290 adult patients undergoing TKA were included.

- 146 randomized to intervention; 135 analysed

- 145 randomized to control; 134 analysed

- Patients with diabetes were eligible.

- Mean age: 72 years

- $88 \%$ female

- Average duration of surgery: 107 minutes

- Incidence of PONV assessed during 4 postoperative periods ( 0 to 6 hours, 6 to 24 hours, 24 to 48 hours, and 48 to 72 hours)

\section{Secondary outcomes}

- Severity of nausea

- Rescue antiemetic requirement and complete response

- Pain level measured on a VAS ranging from 0 to 10 assessed during the 4 above mentioned periods

- Amount of opioid consumption

- Incidence of wound complications (Wound complications including periprosthetic joint infection and inadequate wound healing (including delayed wound healing or wound dehiscence) were evaluated by 1 of 2 surgeons at 2 weeks, 6 weeks, 3 months, 6 months, and 1 year after surgery at follow-up. Periprosthetic joint infection was diagnosed using the criteria outlined by the Musculoskeletal Infection Society.)

\begin{tabular}{|c|c|}
\hline Notes & Sources of funding \\
$\bullet$ Not reported \\
Conflict of interest \\
$\bullet$ None declared
\end{tabular}

Risk of bias

\begin{tabular}{l|ll}
\hline Bias & Authors' judgement & Support for judgement \\
\hline $\begin{array}{l}\text { Random sequence generation (selection } \\
\text { bias) }\end{array}$ & Low risk & Computer-generated randomization table \\
\hline
\end{tabular}


Blinding of participants and personnel High risk (performance bias)

Participants were blinded; caregivers were All outcomes not.

Blinding of outcome assessment (detection Low risk bias)

Researcher was blinded until analysis was complete.

All outcomes

Incomplete outcome data (attrition bias) Low risk All outcomes

Selective reporting (reporting bias)

Unclear risk
Reasons for dropouts documented

Definitions of outcome measures were slightly altered since the protocol

Other bias

Unclear risk
Very extensive multi-modal pain treatment in both groups; influence on complication data unknown

Kurz 2015

Methods
- Muliti-centre factorial randomized controlled trial

- Patients were enrolled between 2002 and 2007 in Austria, USA, Ireland, and Switzerland.

\section{Inclusion criteria}

- Adult patients under 80 years undergoing elective colorectal resection, expected to last 2 to 6 hours

\section{Exclusion criteria}

- Chemotherapy within 6 months before surgery

- Secondary wound closure anticipated

- Fever or infection at admission

- COPD

- Unstable AP

- Cardiomyopathy

- Heart failure

- MI within 6 months

- Bowel obstruction

- ASA IV or higher

- 585 adult patients undergoing bowel surgery were included.

- 283 intervention

- 272 placebo

- Patients with diabetes were eligible.

- Mean age: 53 years

- $53 \%$ male

- $14 \%$ ASA status I

- $60 \%$ ASA status II

- $26 \%$ ASA status III

- Average duration of surgery: 208 to 210 minutes 
Kurz 2015 (Continued)

\begin{tabular}{|c|c|c|}
\hline Interventions & \multicolumn{2}{|c|}{ Dexamethasone $4 \mathrm{mg}$ during induction vs normal saline during induction } \\
\hline Outcomes & \multicolumn{2}{|c|}{$\begin{array}{l}\text { Primary outcome } \\
\text { - Incidence of SSI within } 30 \text { days of surgery } \\
\text { Secondary outcomes } \\
\text { - Wound-healing scores (ASEPSIS) } \\
\text { - Return of bowel function } \\
\text { - Duration of hospitalization (measured in days) } \\
\text { Wound infection and delayed wound healing were assessed, diagnosed according to CDC } \\
\text { criteria. Assessed } 30 \text { days after surgery }\end{array}$} \\
\hline Notes & \multicolumn{2}{|c|}{$\begin{array}{l}\text { Fundings sources } \\
\text { - This study was supported in part by the Gheens Foundation (Louisville, KY, } \\
\text { USA) and the Mater College for Postgraduate Research (Ireland). Viasys Healthcare } \\
\text { (Wheeling, IL, USA) provided the Hi-Ox oxygen masks. } \\
\text { Conflicts of interest } \\
\text { - Not reported }\end{array}$} \\
\hline \multicolumn{3}{|l|}{ Risk of bias } \\
\hline Bias & Authors' judgement & Support for judgement \\
\hline $\begin{array}{l}\text { Random sequence generation (selection } \\
\text { bias) }\end{array}$ & Low risk & Computer-generated randomization \\
\hline Allocation concealment (selection bias) & Low risk & $\begin{array}{l}\text { Sealed opaque envelopes, sequentially } \\
\text { numbered }\end{array}$ \\
\hline $\begin{array}{l}\text { Blinding of participants and personnel } \\
\text { (performance bias) } \\
\text { All outcomes }\end{array}$ & Low risk & $\begin{array}{l}\text { Surgeons were blinded; anaesthesiologists } \\
\text { were not. Anaesthetic records were sealed } \\
\text { after surgery. Treatment was prepared by an } \\
\text { independent investigator }\end{array}$ \\
\hline $\begin{array}{l}\text { Blinding of outcome assessment (detection } \\
\text { bias) } \\
\text { All outcomes }\end{array}$ & Low risk & $\begin{array}{l}\text { Investigator assessing outcomes was } \\
\text { blinded to who received treatment }\end{array}$ \\
\hline $\begin{array}{l}\text { Incomplete outcome data (attrition bias) } \\
\text { All outcomes }\end{array}$ & Low risk & $\begin{array}{l}\text { Study was ceased early owing to futility. } \\
\text { Reasons for dropouts were documented }\end{array}$ \\
\hline Selective reporting (reporting bias) & High risk & $\begin{array}{l}\text { Protocol was published. Not all prespeci- } \\
\text { fied outcomes are reported }\end{array}$ \\
\hline Other bias & Unclear risk & $\begin{array}{l}\text { Participants were also randomized to re- } \\
\text { ceive } 30 \% \text { or } 80 \% \text { oxygen }\end{array}$ \\
\hline
\end{tabular}

Adverse side effects of dexamethasone in surgical patients (Review) 
Methods

Participants
- Parallel randomized controlled clinical trial

- Enrolment took place from April to September 2017 in China.

\begin{tabular}{|l}
\hline Exclusion criteria \\
- Revisions \\
- Bilateral procedures \\
- Allergy to dexamethasone \\
- Administration of any glucocorticoids during the 3 months before surgery \\
- Administration of any strong opioids during the past 7 days \\
- Presence of rheumatoid disease \\
- Presence of systemic lupus erythematosus \\
- Presence of ankylosing spondylitis \\
- Serious cardiac or cerebrovascular problems \\
- Severe liver or kidney function deficiency \\
- 210 participants were randomized. \\
$\circ 70$ to group A \\
$\circ 70$ to group B \\
$\circ 70$ to group C
\end{tabular}

Interventions
- Group A received 3 doses of normal saline.

- Group B received $10 \mathrm{mg}$ dexamethasone at induction and $10 \mathrm{mg}$ dexamethasone when discharged from recovery.

- Group $\mathrm{C}$ received 3 doses of $10 \mathrm{mg}$ dexamethasone and thus was excluded from this meta-analysis.

\begin{tabular}{|c|c|c|}
\hline Outcomes & $\begin{array}{l}\text { - Postoperative nausea and vomiting } \\
\text { - Pain scores } \\
\text { - Hip movement } \\
\text { - Infection parameters }\end{array}$ & \\
\hline Notes & $\begin{array}{l}\text { Conflicts of interest } \\
\text { - None }\end{array}$ & \\
\hline \multicolumn{3}{|l|}{ Risk of bias } \\
\hline Bias & Authors' judgement & Support for judgement \\
\hline $\begin{array}{l}\text { Random sequence generation (selection } \\
\text { bias) }\end{array}$ & Unclear risk & $\begin{array}{l}\text { Method of random sequence generation } \\
\text { not described }\end{array}$ \\
\hline Allocation concealment (selection bias) & Low risk & Opaque envelopes \\
\hline $\begin{array}{l}\text { Blinding of participants and personnel } \\
\text { (performance bias) } \\
\text { All outcomes }\end{array}$ & Unclear risk & $\begin{array}{l}\text { Anaesthetist and nurses not blinded but } \\
\text { was not involved in the trial; rest of staff } \\
\text { was blinded }\end{array}$ \\
\hline
\end{tabular}


Lei 2017 (Continued)

Blinding of outcome assessment (detection Low risk bias)

All outcomes
Anaesthetist and nurses not blinded but not involved in the trial; rest of staff was blinded
Incomplete outcome data (attrition bias) Low risk

All outcomes

Selective reporting (reporting bias) Low risk
CONSORT flow diagram included in paper. No dropouts after randomization

All outcomes reported; protocol was published in Chinese register

This research was funded by the National Health and Family Planning Commission of the People's Republic of China $(\mathrm{CN})$ programme (201302007)

Murphy 2011a

$\begin{array}{ll}\text { Methods } & \text { - Parallel double-blind randomized placebo-controlled trial } \\ & \text { - Single centre in the USA } \\ & \text { - Dates of enrolment unknown }\end{array}$

Participants

Inclusion criteria

- Undergoing elective coronary artery bypass graft (CABG) surgery with $\mathrm{CPB}$ or single valvular repair/replacement surgery and anticipated early tracheal extubation Exclusion criteria

- Combined (CABG/valve) procedures

- Ejection fraction $30 \%$

- Preoperative use of inotropic agents or an intra-aortic balloon pump

- Preoperative use of steroids

- Preoperative use of antiemetic agents

- Acute or chronic renal failure

- Pulmonary disease necessitating oxygen therapy

- Potentially requiring prolonged postoperative mechanical lung ventilation

- Poorly controlled diabetes

- Poor English comprehension or psychiatric/central nervous system disturbances precluding completion of the QoR-40 questionnaire

- 117 adult patients undergoing CABG or valve repair
- 67 intervention

- 50 placebo

- Mean age: 63 years

- $71 \%$ female

- $15 \%$ had diabetes.

- Average duration of surgery: 322 to 338 minutes

Interventions

$8 \mathrm{mg}$ dexamethasone at induction plus $8 \mathrm{mg}$ dexamethasone when cardiopulmonary bypass was initiated vs normal saline at induction and when cardiopulmonary bypass was initiated 


\begin{tabular}{|c|c|c|}
\hline Outcomes & \multicolumn{2}{|c|}{$\begin{array}{l}\text { Primary outcome variable of this } \\
\text { - Postoperative QoR- } 40 \text { score } \\
\text { - Postoperative infection assessed for } 6 \text { days postoperatively, defined as infection } \\
\text { requiring surgical or antibiotic treatment (Postoperative infection data were not } \\
\text { included in this meta-analysis owing to the short follow-up.) } \\
\text { - Glucose measured } 6 \text { hours postoperatively }\end{array}$} \\
\hline Notes & \multicolumn{2}{|l|}{$\begin{array}{l}\text { Sources of funding } \\
\text { - Not reported } \\
\text { Conflict of interest } \\
\text { - Not reported }\end{array}$} \\
\hline \multicolumn{3}{|l|}{ Risk of bias } \\
\hline Bias & Authors' judgement & Support for judgement \\
\hline $\begin{array}{l}\text { Random sequence generation (selection } \\
\text { bias) }\end{array}$ & Low risk & Random sequence generation via computer \\
\hline Allocation concealment (selection bias) & Low risk & Pharmacy-based randomization \\
\hline $\begin{array}{l}\text { Blinding of participants and personnel } \\
\text { (performance bias) } \\
\text { All outcomes }\end{array}$ & Low risk & $\begin{array}{l}\text { Patients, investigators, and surgeons } \\
\text { blinded; placebo controlled }\end{array}$ \\
\hline $\begin{array}{l}\text { Blinding of outcome assessment (detection } \\
\text { bias) } \\
\text { All outcomes }\end{array}$ & Low risk & Researchers were blinded. \\
\hline $\begin{array}{l}\text { Incomplete outcome data (attrition bias) } \\
\text { All outcomes }\end{array}$ & Low risk & $\begin{array}{l}\text { Reasons for dropouts documented; compa- } \\
\text { rable between groups }\end{array}$ \\
\hline Selective reporting (reporting bias) & Unclear risk & $\begin{array}{l}\text { Reasonable outcome parameters; no proto- } \\
\text { col published }\end{array}$ \\
\hline Other bias & Low risk & No apparent other bias \\
\hline
\end{tabular}

Murphy 2014

Methods

Participants
- Randomized controlled trial conducted

- Single centre in the USA

- Dates of enrolment unknown

\section{Inclusion criteria}

- Undergoing a hysterectomy

- Aged 18 to 80

Exclusion criteria

- Preoperative use of steroids or antiemetic drugs 
- History of allergy to any study medications

- Preoperative diagnosis of type 1 or 2 diabetes

- Severe renal (serum creatinine $>1.6 \mathrm{mg} / \mathrm{dL}$ ) or liver (liver enzymes $>2 \times$ normal values) disease

- ASA physical status IV and V

- 200 adult women undergoing a hysterectomy were randomized into 6 groups.

- Three subgroups included in this meta-analysis

- Late $8 \mathrm{mg}: 33$ participants

- Late $4 \mathrm{mg}: 32$ participants

- Late control: 34 participants

- Mean age: 54 years

- All participants were female.

- Average duration of surgery: 213 to 243 minutes

- Perioperative glucose concentrations, measured in all patients via a point-of-care device. Glucose values were measured 8 and 24 hours postoperatively.

\section{Secondary outcomes}

- PONV scores assessed every 15 minutes at the PACU

- Pain scores measured on a VAS evaluated when discharged from recovery

- Total dose of hydromorphone during admission assessed

- Postoperative fatigue, which may be reduced by steroids, assessed at PACU discharge on a 4 -point ordinal scale $(0=$ none, $1=$ mild fatigue, $2=$ moderate fatigue, 3 = severe fatigue)

- All participants were followed until the time of discharge from the hospital for any postoperative complications, including any evidence of postoperative wound infection or impaired wound healing (diagnosed by the surgical service). This followup period was too short for our meta-analysis.

- Support was provided solely by institutional and/or departmental sources.

\section{Conflicts of interest}

- None

\section{Risk of bias}

\begin{tabular}{|c|c|c|}
\hline Bias & Authors' judgement & Support for judgement \\
\hline $\begin{array}{l}\text { Random sequence generation (selection } \\
\text { bias) }\end{array}$ & Low risk & $\begin{array}{l}\text { Computer generated with block random- } \\
\text { ization }\end{array}$ \\
\hline
\end{tabular}

Pharmacy based; blinding of all care providers, participants, and researchers 
Murphy 2014 (Continued)

Blinding of participants and personnel Low risk

Pharmacy provides blinded syringes.

(performance bias)

All outcomes

Blinding of outcome assessment (detection Low risk bias)

Researchers were blinded to group assignment.

All outcomes

Incomplete outcome data (attrition bias) Low risk

Reasons for dropouts documented

All outcomes

\begin{tabular}{l|ll}
\hline Selective reporting (reporting bias) & Low risk & Consistent with published protocol \\
\hline Other bias & Low risk & No apparent other bias \\
\hline
\end{tabular}

Nazar 2009

\begin{tabular}{|c|c|}
\hline Methods & $\begin{array}{l}\text { - Prospective double-blind randomized trial } \\
\text { - Single centre in Chile } \\
\text { - Dates of enrolment unknown }\end{array}$ \\
\hline Participants & $\begin{array}{l}\text { Inclusion criteria } \\
\text { - ASA physical status II or III } \\
\text { - Did not receive premedication } \\
\text { - Scheduled to undergo laparoscopic Roux-en-Y gastric bypass surgery } \\
\text { Exclusion criteria } \\
\text { - Under treatment with corticosteroids } \\
\text { - Oral hypoglycaemic drugs or insulin } \\
\text { - Received glucose in the last } 12 \text { hours before surgery } \\
\text { - } 30 \text { adult patients with glucose intolerance undergoing a Roux-en-Y anastomosis } \\
\text { were included. } \\
\quad \circ 15 \text { intervention } \\
\text { - Mean age: } 37 \text { to } 40 \text { years } \\
\text { - } 20 \% \text { male } \\
\text { - Average duration of surgery: } 103 \text { to } 107 \text { minutes }\end{array}$ \\
\hline Interventions & $\begin{array}{l}8 \mathrm{mg} \text { dexamethasone }(2 \mathrm{~mL}) \text { immediately after induction vs normal saline }(2 \mathrm{~mL}) \mathrm{im} \text { - } \\
\text { mediately after induction }\end{array}$ \\
\hline Outcomes & $\begin{array}{l}\text { Primary outcome } \\
\text { - Glucose values, not specified at which time point. Glucose was measured at 2, } 4 \text {, } \\
6,8,10 \text {, and } 12 \text { hours after dexamethasone. }\end{array}$ \\
\hline Notes & $\begin{array}{l}\text { Sources of funding } \\
\text { - Not reported } \\
\text { Conflict of interest } \\
\text { - Not reported }\end{array}$ \\
\hline
\end{tabular}


Nazar 2009 (Continued)

\section{Risk of bias}

\begin{tabular}{|c|c|c|}
\hline Bias & Authors' judgement & Support for judgement \\
\hline $\begin{array}{l}\text { Random sequence generation (selection } \\
\text { bias) }\end{array}$ & Low risk & Random numbers generated by a computer \\
\hline Allocation concealment (selection bias) & Unclear risk & $\begin{array}{l}\text { Not reported if there was a list with random } \\
\text { numbers or if the computer randomized } \\
\text { every participant separately }\end{array}$ \\
\hline $\begin{array}{l}\text { Blinding of participants and personnel } \\
\text { (performance bias) } \\
\text { All outcomes }\end{array}$ & Unclear risk & Unclear; not specifically stated \\
\hline $\begin{array}{l}\text { Blinding of outcome assessment (detection } \\
\text { bias) } \\
\text { All outcomes }\end{array}$ & Low risk & $\begin{array}{l}\text { Researcher was unaware of group alloca- } \\
\text { tion. }\end{array}$ \\
\hline $\begin{array}{l}\text { Incomplete outcome data (attrition bias) } \\
\text { All outcomes }\end{array}$ & Unclear risk & $\begin{array}{l}\text { There appear to be no dropouts in this } \\
\text { study. }\end{array}$ \\
\hline Selective reporting (reporting bias) & Unclear risk & All expected outcomes are reported. \\
\hline Other bias & Unclear risk & Unknown \\
\hline
\end{tabular}

Nazar 2011

\begin{tabular}{l|l}
\hline Methods & - Randomized controlled trial \\
& - Single centre in Chile \\
& - Dates of enrolment unknown \\
\hline
\end{tabular}

Participants

\section{Inclusion criteria}

- Patients with and without diabetes type 2, with BMI of 20 to 30, undergoing a laparoscopic cholecystectomy

\section{Exclusion criteria}

- Corticosteroids

- Insulin

- Vasoactive drugs

- Oral antidiabetics on the day of surgery

- 70 adult participants with and without diabetes undergoing laparoscopic cholecystectomy were randomized into 4 groups.

- Healthy dexa: 20 participants

- Healthy control: 20 participants

- DMdexa: 15 participants

- DMcontrol: 15 participants

- Mean age: 41 to 56 years

- $30 \%$ male 
- Average duration of surgery: 51 to 66 minutes

\begin{tabular}{l|l}
\hline Interventions & $8 \mathrm{mg}$ dexamethasone after induction vs $2 \mathrm{~mL}$ normal saline after induction \\
\hline Outcomes & $\begin{array}{l}\text { Primary outcome } \\
\text { - Glucose levels measured } 12 \text { hours postoperatively } \\
\text { No secondary outcomes reported }\end{array}$ \\
\hline Notes & $\begin{array}{c}\text { Sources of funding } \\
\text { - Department supported the study. } \\
\text { Conflict of interest } \\
\text { - None declared }\end{array}$ \\
\hline
\end{tabular}

\section{Risk of bias}

\begin{tabular}{l|lll}
\hline Bias & Authors' judgement & Support for judgement \\
\hline $\begin{array}{l}\text { Random sequence generation (selection } \\
\text { bias) }\end{array}$ & Low risk & Computer-generated random sequence \\
\hline $\begin{array}{l}\text { Allocation concealment (selection bias) } \\
\text { Blinding of participants and personnel } \\
\text { (performance bias) } \\
\text { All outcomes }\end{array}$ & Unclear risk & Web-based randomization \\
\hline $\begin{array}{l}\text { Blinding of outcome assessment (detection } \\
\text { bias) } \\
\text { All outcomes }\end{array}$ & Low risk & Unclear who was in charge of preparing the \\
\hline $\begin{array}{l}\text { Incomplete outcome data (attrition bias) } \\
\text { All outcomes }\end{array}$ & High risk & Researchers were blinded. \\
\hline \begin{tabular}{l} 
Selective reporting (reporting bias) \\
\hline
\end{tabular} & Unclear risk & No information on dropouts reported \\
\hline \begin{tabular}{l} 
Other bias \\
\hline
\end{tabular} & Unclear risk & Study protocol not published or registered. \\
\hline
\end{tabular}

Nielsen 2015

\begin{tabular}{|c|c|}
\hline Methods & $\begin{array}{l}\text { - Single-centre prospective randomized blinded } \\
\text { - Enrolment took place in Denmark from } 2012\end{array}$ \\
\hline Participants & $\begin{array}{l}\text { Inclusion criteria } \\
\text { - Adult patients } 18 \text { to } 85 \text { years } \\
\text { - ASA status I to III } \\
\text { - BMI } 18 \text { to } 40 \\
\text { - Undergoing 1- to 2-level lumbar discectomy } \\
\text { Exclusion criteria }\end{array}$ \\
\hline
\end{tabular}


Nielsen 2015 (Continued)

- Unco-operative

- Unable to speak Danish

- Previous surgery

- Pregnancy

- Allergy to dexamethasone

- Daily use of opioid or corticosteroids

- Alcohol or drug abuse

- 160 adult patients undergoing lumbar discectomy

- 77 intervention

- 76 placebo

- 7 dropouts

- Patients with diabetes were eligible.

- Mean age: 45 years

- $60 \%$ male

- Average duration of surgery: 51 to 60 minutes

- Pain during mobilization 2 to 24 hours postoperatively calculated as a "weighted average level" area under the curve (AUC) (in millimetres)

\section{Secondary outcomes}

- Pain at rest (AUC 2 to 24 hours)

- Total morphine consumption (0 to 24 hours and 24 to 48 hours)

- Pain at rest and during mobilization 48 hours postoperatively

- Morphine-related adverse effects (nausea, vomiting, sedation, and postoperative use of antiemetics)

- Quality of sleep 24 hours postoperatively

\section{Outcomes for 3-month follow-up}

- Back and leg pain (VAS 0 to $100 \mathrm{~mm}$ )

- Use of analgesics

- Postoperative complications including wound infections

- Walking distance

- Duration of sick leave

- Working capability

- Contentment with results of the operation

- Wound infections self-reported and treated with antibiotics

\begin{tabular}{|c|c|}
\hline Notes & $\begin{array}{l}\text { Sources of funding } \\
\text { - None } \\
\text { Conflict of interest } \\
\text { - None }\end{array}$ \\
\hline
\end{tabular}

Risk of bias

Bias Authors' judgement

Support for judgement 
Nielsen 2015 (Continued)

\begin{tabular}{llll}
\hline $\begin{array}{l}\text { Random sequence generation (selection } \\
\text { bias) }\end{array}$ & Low risk & $\begin{array}{l}\text { Computer-generated, block randomiza- } \\
\text { tion }\end{array}$ \\
\hline $\begin{array}{l}\text { Allocation concealment (selection bias) } \\
\text { Blinding of participants and personnel } \\
\begin{array}{l}\text { (performance bias) } \\
\text { All outcomes }\end{array}\end{array}$ & Low risk & $\begin{array}{l}\text { Pharmacy-based randomization. Pharmacy } \\
\text { was in charge of preparing the study drugs }\end{array}$ \\
\hline $\begin{array}{l}\text { Blinding of outcome assessment (detection } \\
\text { bias) } \\
\text { All outcomes }\end{array}$ & Low risk & $\begin{array}{l}\text { Participants, investigators, surgeons, and } \\
\text { clinical personnel were blinded }\end{array}$ \\
\hline $\begin{array}{l}\text { Incomplete outcome data (attrition bias) } \\
\text { All outcomes }\end{array}$ & Low risk & $\begin{array}{l}\text { Investigators were blinded. Unblinding was } \\
\text { done after follow-up and exclusion of data } \\
\text { and statistical handling were complete }\end{array}$ \\
\hline $\begin{array}{l}\text { Selective reporting (reporting bias) } \\
\text { Other bias }\end{array}$ & Low risk & $\begin{array}{l}\text { Missing data balanced between groups. } \\
\text { Reasons for dropouts documented }\end{array}$ \\
\hline
\end{tabular}

\section{Rafiq 2014}

Methods
- Single-centre parallel randomized controlled trial

- Enrolment took place from 2007 to 2009 in Denmark.
Participants

\section{Inclusion criteria}

- Age over 18 years

- Any cardiac procedure with sternotomy

- Able to give informed consent

\section{Exclusion criteria}

- Cardiac surgery without sternotomy

- Peripheral neuropathy

- Neurological disease

- Psychiatric illness

- History of gastrointestinal bleeding

- Chronic pain (i.e. back pain, cancer, arthritis)

- Serum creatinine $>150 \mu \mathrm{mol} / \mathrm{L}$

- Hepatic disease with elevated liver enzymes (SGPT and SGOT elevated to 1.5 times maximum normal value)

- Allergic to study medication

- Alcohol abuse

- Abuse of narcotics or medication

- Pregnancy

- Participation in other clinical trials

- Insufficient language skill 
Rafiq 2014 (Continued)

- ICU stay longer than 24 hours (used as a predefined post-randomization exclusion criterion)

- 180 adult participants undergoing cardiac surgery with sternotomy

- 77 intervention

- 74 control

- 6 withdrawals

- 23 dropouts

- Patients with diabetes were included.
- 8 intervention
- 16 control

- Mean age: 62 to 64 years

- $21 \%$ female

Outcomes

\section{Primary outcome}

- Pain measured on the 11-NRS

Secondary outcomes (evaluated during hospital stay)

- Additional analgesic consumption

- Hospital stay in days

- Evaluation of side effects by daily questionnaire.

Secondary outcomes (measured at 30 days)

- Renal complications: increase in creatinine, dialysis, cardiac complications

- Myocardial infarction (MI)

- Postoperative pericardial effusion

- Heart failure requiring inotropic support

- Atrial fibrillation

- Other complications: cerebral (stroke, bleeding)

- Gastrointestinal bleeding

- Blood component requirements and sternal complications

- Death from all causes

- Wound infection and wound dehiscence (no definition stated)

\begin{tabular}{c|c} 
Sotes & $\begin{array}{c}\text { Sources of funding } \\
\bullet \text { None } \\
\text { Conflict of interest } \\
\bullet \text { None declared }\end{array}$ \\
\hline
\end{tabular}

\section{Risk of bias}

\begin{tabular}{l|l|l}
\hline Bias & Authors' judgement & Support for judgement \\
\hline $\begin{array}{l}\text { Random sequence generation (selection } \\
\text { bias) }\end{array}$ & Unclear risk & Sequence generation is not described. \\
\hline Allocation concealment (selection bias) & Low risk & $\begin{array}{l}\text { Opaque sealed envelopes, sequentially } \\
\text { numbered }\end{array}$
\end{tabular}




\section{Rafiq 2014 (Continued)}

Blinding of participants and personnel Unclear risk (performance bias)

All outcomes
No blinding of participants. Primary endpoint of study (pain) might be biased. Endpoint of this meta-analysis (wound infection) might be biased by lack of blinding

No blinding of outcome assessors

Blinding of outcome assessment (detection High risk bias)

All outcomes

\begin{tabular}{l|l|l}
\hline $\begin{array}{l}\text { Incomplete outcome data (attrition bias) } \\
\text { All outcomes }\end{array}$ & Low risk & Reasons for dropouts described \\
\hline Selective reporting (reporting bias) & Low risk & $\begin{array}{l}\text { Protocol published. Same outcomes re- } \\
\text { ported as stated in the protocol }\end{array}$ \\
\hline Other bias & High risk & $\begin{array}{l}\text { Participants with prolonged ICU stay were } \\
\text { excluded. These patients are vulnerable to } \\
\text { developing wound infection }\end{array}$ \\
\hline
\end{tabular}

Sanchez-Rodriguez 2010

$\begin{array}{ll}\text { Methods } & \text { - Single-centre randomized controlled double-blind trial } \\ \text { - Enrolment was from } 2007 \text { to } 2008 \text { in Mexico. }\end{array}$

Participants

Inclusion criteria

- Adult patients undergoing laparoscopic cholecystectomy

Exclusion criteria

- American Society of Anesthesiologists (ASA) status III and IV

- Age $>80$ years

- Pregnancy

- Treatment with steroids

- Severe diabetes mellitus (haemoglobin A1c (HbA1c) > 8\%)

- Use of opioids

- Sedatives or any kind of analgesics 1 week before LC

- History of alcohol or drug abuse

- Preoperative diagnosis of acute cholecystitis

- Acute pancreatitis

- Choledocholithiasis

- Gallbladder carcinoma and/or conversion of the LC to an open procedure

- 210 adult patients undergoing laparoscopic cholecystectomy were included.

- 105 intervention

- 105 placebo

- Mean age: 36 to 38 years

- $42 \%$ male

- $59 \%$ ASA status I

- $41 \%$ ASA status II

- Average duration of surgery: 71 to 73 minutes 


\begin{tabular}{|c|c|c|}
\hline Interventions & \multicolumn{2}{|c|}{$8 \mathrm{mg}$ dexamethasone before skin incision vs normal saline before skin incision } \\
\hline Outcomes & \multicolumn{2}{|c|}{$\begin{array}{l}\text { Primary outcomes }(6,12 \text {, and } 24 \text { hours after surgery) } \\
\text { - Degree of postoperative nausea measured on a 4-point scale } \\
\text { - Vomiting } \\
\text { - Pain measured on VAS } \\
\text { - Fatigue } \\
\text { - Need for additional analgesic and antiemetic drugs } \\
\text { - Postoperative complications were assessed until } 30 \text { days after surgery (no } \\
\text { definition is stated). }\end{array}$} \\
\hline Notes & \multicolumn{2}{|l|}{$\begin{array}{l}\text { Sources of funding } \\
\text { - Not reported } \\
\text { Conflict of interest } \\
\text { - Not reported }\end{array}$} \\
\hline \multicolumn{3}{|l|}{ Risk of bias } \\
\hline Bias & Authors' judgement & Support for judgement \\
\hline $\begin{array}{l}\text { Random sequence generation (selection } \\
\text { bias) }\end{array}$ & Unclear risk & Sequence generation not described \\
\hline Allocation concealment (selection bias) & Low risk & Opaque envelopes \\
\hline $\begin{array}{l}\text { Blinding of participants and personnel } \\
\text { (performance bias) } \\
\text { All outcomes }\end{array}$ & Unclear risk & Not described who prepared study drugs \\
\hline $\begin{array}{l}\text { Blinding of outcome assessment (detection } \\
\text { bias) } \\
\text { All outcomes }\end{array}$ & Unclear risk & $\begin{array}{l}\text { Not described how blinding of researcher } \\
\text { was maintained }\end{array}$ \\
\hline $\begin{array}{l}\text { Incomplete outcome data (attrition bias) } \\
\text { All outcomes }\end{array}$ & High risk & No dropouts described \\
\hline Selective reporting (reporting bias) & Unclear risk & $\begin{array}{l}\text { Protocol was not published, but expected } \\
\text { outcomes are reported }\end{array}$ \\
\hline Other bias & Unclear risk & Unknown \\
\hline
\end{tabular}




\section{Methods}

Participants
- Single-centre randomized placebo-controlled double-blind trial

- Enrolment was from March 2005 to April 2008 in Italy.

\section{Inclusion criteria}

- Adult patients undergoing a laparoscopic Nissen fundoplication

\section{Exclusion criteria}

- ASA physical class III or IV

- Age > 75 years

- Pregnancy

- Chronic pain due to disease other than gastroesophageal reflux disease (GERD)

- Endocrine, renal, hepatic, or immunological disease

- Received opioids or tranquillizers (treatment 1 week before LFNF)

- Spoke only a foreign language

- Mental disorder

- History of alcohol or drug abuse

- If the operation was converted from LFNF to open procedure

- If an additional fifth trocar was needed to complete the operation. Since development of surgical complications might influence chosen outcome parameters, these patients were excluded and results were analysed by protocol.

- 82 adult patients undergoing laparoscopic Nissen fundoplication were randomized.

$$
\begin{aligned}
& -41 \text { intervention } \\
& \circ 41 \text { placebo }
\end{aligned}
$$

- Mean age: 46 to 49 years

- $41 \%$ male

- $22 \%$ ASA II status

- Average duration of surgery: 56 to 57 minutes

- Pain (measured on VAS and VRS daily during first postoperative week)

- PONV (measured on VRS during first 6 hours and from 6 to 24 hours)

\section{Secondary outcomes}

- CRP

- IL-1 and IL-6 levels

- Measured at 0, 30, 60, 90, 120, 180 minutes and 12 and 24 hours postoperatively

- Wound infections were assessed 30 days after surgery (no definition stated).

\begin{tabular}{|c|c|c|} 
Notes & $\begin{array}{c}\text { Sources of funding } \\
\bullet \text { Not stated } \\
\text { Conflict of interest } \\
\bullet \text { None declared }\end{array}$ \\
\hline
\end{tabular}

\section{Risk of bias}

Bias

Authors' judgement

Support for judgement 
Schietroma 2010 (Continued)

\begin{tabular}{|c|c|c|}
\hline $\begin{array}{l}\text { Random sequence generation (selection } \\
\text { bias) }\end{array}$ & Low risk & Computer-generated list \\
\hline Allocation concealment (selection bias) & Low risk & Opaque envelopes \\
\hline $\begin{array}{l}\text { Blinding of participants and personnel } \\
\text { (performance bias) } \\
\text { All outcomes }\end{array}$ & Low risk & $\begin{array}{l}\text { Nurse not participating in the trial pre- } \\
\text { pared drugs in identical-looking syringes }\end{array}$ \\
\hline $\begin{array}{l}\text { Blinding of outcome assessment (detection } \\
\text { bias) } \\
\text { All outcomes }\end{array}$ & Low risk & Researchers were blinded. \\
\hline $\begin{array}{l}\text { Incomplete outcome data (attrition bias) } \\
\text { All outcomes }\end{array}$ & Low risk & Reasons for dropouts documented \\
\hline Selective reporting (reporting bias) & Unclear risk & $\begin{array}{l}\text { No protocol published but all relevant out- } \\
\text { comes reported }\end{array}$ \\
\hline Other bias & Unclear risk & Unknown \\
\hline
\end{tabular}

\section{Schietroma 2013}

Methods

Participants
- Parellel randomized placebo-controlled trial

- Enrolment took place at a single centre in Italy between 2008 and 2011.

\section{Inclusion criteria}

- Adult patients aged 18 to 75 undergoing thyroidectomy

Exclusion criteria

- American Society of Anesthesiologists (ASA) physical class III or IV

- Older than 75 years

- Pregnancy

- Chronic pain due to a disease other than thyroid disease

- Any signs of renal, hepatic, and immunological disease

- Received opioids or tranquillizers (1 week of treatment before thyroidectomy)

- Spoke only a foreign language

- Mental disorders

- History of alcohol or drug abuse

- 328 adult patients undergoing thyroidectomy were included.

- 163 intervention

○ 165 placebo

- Patients with diabetes were eligible.

- Mean age: 46 to 49 years

- $40 \%$ male

- $64 \%$ ASA status I

- Average duration of surgery: 56 to 57 minutes 
Schietroma 2013 (Continued)

Interventions

$8 \mathrm{mg}$ dexamethasone 90 minutes before induction vs normal saline 90 minutes before skin incision

Outcomes

Primary outcome

- Temporary or permanent recurrent laryngeal nerve palsy, evaluated through flexible laryngoscopic examinations

\section{Secondary outcomes}

- Pain, measured on VAS and VRS ( 0 = no pain; 1 = light pain; 2 = moderate pain; 3 = severe pain). Moreover, pain was recorded at rest (supine position) and during mobilization (supine to sitting position) preoperatively and at 1, 2, 3, 6, and 24 hours after surgery.

- Nausea and vomiting scores evaluated separately for the 0 through 6-hour period and the 6 through 24-hour period

- Blood was drawn at 0, 30, 60, 90, 120, and 180 minutes, at 12 and 24 hours, and on the first 6 postoperative days for CRP, IL-1, and IL- 6 levels.

- A 30-day follow-up for morbidity was performed in all cases.

- Wound infection was assessed 30 days after surgery. No definition for wound infection was stated.

Notes

Sources of funding

- Not reported

Conflict of interest

- None declared

\section{Risk of bias}

\begin{tabular}{|c|c|c|}
\hline Bias & Authors' judgement & Support for judgement \\
\hline $\begin{array}{l}\text { Random sequence generation (selection } \\
\text { bias) }\end{array}$ & High risk & Block randomization computer generated \\
\hline Allocation concealment (selection bias) & High risk & $\begin{array}{l}\text { Sealed opaque envelopes; researcher un- } \\
\text { aware of randomization sequence }\end{array}$ \\
\hline $\begin{array}{l}\text { Blinding of participants and personnel } \\
\text { (performance bias) } \\
\text { All outcomes }\end{array}$ & High risk & $\begin{array}{l}\text { A nurse drew up the study medication in } \\
\text { identical-looking syringes }\end{array}$ \\
\hline $\begin{array}{l}\text { Blinding of outcome assessment (detection } \\
\text { bias) } \\
\text { All outcomes }\end{array}$ & High risk & Researchers were blinded. \\
\hline $\begin{array}{l}\text { Incomplete outcome data (attrition bias) } \\
\text { All outcomes }\end{array}$ & High risk & $\begin{array}{l}\text { Dropouts were reported, without reasons; } \\
\text { evenly distributed across groups }\end{array}$ \\
\hline Selective reporting (reporting bias) & High risk & $\begin{array}{l}\text { Protocol was published without outcome } \\
\text { measures. }\end{array}$ \\
\hline
\end{tabular}

Adverse side effects of dexamethasone in surgical patients (Review) 
Other bias

High risk
An expression of concern was issued. Scientific and ethical concerns surround this paper; therefore all domains have been set to high risk of bias (Piccirillo 2017).

Tien 2016

Methods

Participants

Interventions

Outcomes
- Parallel randomized controlled trial

- Dates of patient enrolment were not stated.

- Single centre in the USA

\begin{tabular}{|c|c|}
\hline & $\begin{array}{l}\text { - English-speaking adult patients scheduled for elective surgery under general } \\
\text { anaesthesia that was expected to last for at least } 1 \text { hour and who were routinely } \\
\text { admitted to hospital for at least } 24 \text { hours } \\
\text { Exclusion criteria } \\
\text { - Pregnancy } \\
\text { - Preoperative blood glucose levels }>11.1 \mathrm{mmol} / \mathrm{L} \\
\text { - Currently, or recently, receiving steroid treatment } \\
\text { - } 88 \text { adult patients undergoing surgery lasting }>1 \text { hour were randomized into } 4 \\
\text { groups. } \\
\text { O NonDM-Dexa } 20 \text { participants } \\
\text { O NonDM-Zofran } 21 \text { participants } \\
\text { O DM-Dexa } 20 \text { participants } \\
\text { - DM-Zofran } 27 \text { participants } \\
\text { - Mean age: } 44 \text { to } 63 \\
\text { participants. } \\
\text { - } 85 \% \text { of non-diabetic participants had ASA status II. } \\
\text { - } 75 \% \text { of diabetic participants had ASA status III. } \\
\text { - Average duration of surgery: } 165 \text { minutes in non-diabetic groups, } 231 \text { minutes in } \\
\text { diabetic group }\end{array}$ \\
\hline Interventions & Dexamethasone $8 \mathrm{mg}$ at induction vs ondansetron $4 \mathrm{mg}$ toward the end of surgery \\
\hline Outcomes & $\begin{array}{l}\text { Primary outcome } \\
\text { - Glucose values, not specifically stated at which time point. Glucose was measured } \\
2 \text {, 4, and } 24 \text { hours after surgery. }\end{array}$ \\
\hline Notes & $\begin{array}{l}\text { Sources of funding } \\
\text { - M. Tien was supported by the Foundation of Anesthesia Education and Research } \\
\text { through the Medical Student Anesthesia Research Fellowship. } \\
\text { Conflict of interest } \\
\text { - None declared }\end{array}$ \\
\hline
\end{tabular}

Risk of bias

Bias

Authors' judgement

Support for judgement

Adverse side effects of dexamethasone in surgical patients (Review) 
Tien 2016 (Continued)

\begin{tabular}{l|l|l}
\hline $\begin{array}{l}\text { Random sequence generation (selection } \\
\text { bias) }\end{array}$ & Low risk & $\begin{array}{l}\text { Computer-generated } \\
\text { software }\end{array}$ \\
\hline $\begin{array}{l}\text { Allocation concealment (selection bias) } \\
\text { Blinding of participants and personnel } \\
\text { (performance bias) } \\
\text { All outcomes }\end{array}$ & Low risk risk & Sealed opaque envelopes \\
\hline $\begin{array}{l}\text { Blinding of outcome assessment (detection } \\
\text { bias) } \\
\text { All outcomes }\end{array}$ & High risk & $\begin{array}{l}\text { Anaesthetist not involved in the study pre- } \\
\text { pared study drugs; not placebo controlled }\end{array}$ \\
\hline $\begin{array}{l}\text { Incomplete outcome data (attrition bias) } \\
\text { All outcomes }\end{array}$ & Low risk & $\begin{array}{l}\text { Not described whether researchers were } \\
\text { blinded }\end{array}$ \\
\hline $\begin{array}{l}\text { Selective reporting (reporting bias) } \\
\text { Other bias }\end{array}$ & Unclear risk & Reasons for dropouts documented \\
\hline
\end{tabular}

Wakasugi 2015

Methods

Japan

- Multi-centre randomized double-blind placebo-controlled trial at 8 hospitals in

- Enrolment was from 2010 to 2012 .

\section{Inclusion criteria}

- Adult patients undergoing laparoscopic cholecystectomy with normal WBC, Hb, platelets, and liver function

\section{Exclusion criteria}

- Emergency surgery

- ASA III/IV

- Previous abdominal surgery

- High risk of conversion

- Continuous corticoid treatment

- Opioid treatment

- Mental disorder

- Cardiac or respiratory disease

- Day surgery

- Contraindication for dexamethasone

- 270 adult patients undergoing laparoscopic cholecystectomy

- 136 intervention

- 134 placebo

- Patients with diabetes were eligible.

- Mean age: 58 to 59 years 
Wakasugi 2015 (Continued)

- $54 \%$ male

- $54 \%$ ASA status I

- Average operation time: 101 to 105 minutes

Interventions

Outcomes
$8 \mathrm{mg}$ dexamethasone after induction vs normal saline after induction

\section{Primary outcome}

- Degree of PONV and antiemetic requirements within 24 hours after surgery

Secondary outcomes

- Postoperative complications

- Postoperative hospital stay, cost of hospital stay

- CRP levels measured preoperatively, not postoperatively

- Postoperative infection and delayed wound healing assessed according to CDC criteria at 30 days postoperatively

\begin{tabular}{l|l}
\hline Notes & Sources of funding \\
& $\bullet$ None \\
& Conflict of interest \\
& $\bullet$ None declared \\
\hline
\end{tabular}

\section{Risk of bias}

Bias Authors' judgement

Random sequence generation (selection Low risk bias)

\begin{tabular}{l|l|l}
\hline Allocation concealment (selection bias) & Low risk & Sufficient allocation concealment \\
\hline $\begin{array}{l}\text { Blinding of participants and personnel } \\
\text { (performance bias) } \\
\begin{array}{l}\text { All outcomes } \\
\text { Low risk }\end{array}\end{array}$ & $\begin{array}{l}\text { Participants and personnel were masked to } \\
\text { group assignment. How this was done is } \\
\text { unknown. It is not described how the med- } \\
\text { ication was prepared }\end{array}$ \\
\hline
\end{tabular}

Blinding of outcome assessment (detection Low risk bias)

All outcomes

\begin{tabular}{|c|c|c|}
\hline $\begin{array}{l}\text { Incomplete outcome data (attrition bias) } \\
\text { All outcomes }\end{array}$ & Low risk & Reasons for dropouts documented \\
\hline Selective reporting (reporting bias) & Unclear risk & Study was not registered. \\
\hline Other bias & Unclear risk & $\begin{array}{l}\text { Different analgesics and anaesthetics could } \\
\text { be used; not standardized for all partici- } \\
\text { pants } \\
\text { This has no effect on the primary outcome } \\
\text { of this review. }\end{array}$ \\
\hline
\end{tabular}

Adverse side effects of dexamethasone in surgical patients (Review)

Copyright ( 2018 The Cochrane Collaboration. Published by John Wiley \& Sons, Ltd.

\section{Support for judgement}

Computer-generated en block randomization. Blocks of 4 were used (1:1), balanced by institution

Researchers were blinded to treatment. 


\begin{tabular}{|c|c|}
\hline Methods & $\begin{array}{l}\text { - Single-centre randomized controlled trial conducted in China } \\
\text { - Dates of enrolment are unknown. }\end{array}$ \\
\hline Participants & $\begin{array}{l}\text { Inclusion criteria } \\
\text { - Adult patients scheduled for surgery under combined intravenous-inhalational } \\
\text { anaesthesia with ASA status I or II } \\
\text { Exclusion criteria } \\
\text { - Diabetes } \\
\text { - Glucose intolerance } \\
\text { - Use of corticosteroids } \\
\text { - } 30 \text { adult patients were randomized into } 3 \text { groups. } \\
\quad \text { o } 10 \text { to the intervention group } \\
\quad \circ 10 \text { to the control group } \\
\quad 010 \text { received too much dexamethasone to be included in this review. } \\
\text { - Mean age: } 36 \text { to } 40 \text { years } \\
\text { - In the dexamethasone group, } 50 \% \text { were male. } \\
\text { - In the saline group, } 60 \% \text { were male. } \\
\text { - Average duration of surgery: } 222 \text { to } 234 \text { minutes }\end{array}$ \\
\hline Interventions & $10 \mathrm{mg}$ dexamethasone vs normal saline \\
\hline Outcomes & $\begin{array}{l}\text { Primary outcome } \\
\text { - Glucose values, measured at baseline, } 1,2 \text {, and } 3 \text { hours after dexamethasone }\end{array}$ \\
\hline Notes & $\begin{array}{l}\text { Sources of funding } \\
\text { - Not reported } \\
\text { Conflict of interest } \\
\text { - Unknown }\end{array}$ \\
\hline
\end{tabular}

\section{Risk of bias}

\begin{tabular}{l|l|l} 
Bias & Authors' judgement & Support for judgement \\
\hline $\begin{array}{l}\text { Random sequence generation (selection } \\
\text { bias) }\end{array}$ & Unclear risk & Unknown \\
\hline $\begin{array}{l}\text { Allocation concealment (selection bias) } \\
\text { Blinding of participants and personnel } \\
\text { (performance bias) } \\
\text { All outcomes }\end{array}$ & Unclear risk & Unknown \\
\hline $\begin{array}{l}\text { Blinding of outcome assessment (detection } \\
\text { bias) } \\
\text { All outcomes }\end{array}$ & Unclear risk & Unknown \\
\hline
\end{tabular}

Incomplete outcome data (attrition bias) High risk

No dropouts described

All outcomes 
Wang 2009 (Continued)

\begin{tabular}{l|l|l}
\hline Selective reporting (reporting bias) & Unclear risk & Protocol not published \\
\hline Other bias & High risk & Very little information in report \\
\hline
\end{tabular}

\section{Worni 2008}

\begin{tabular}{|c|c|}
\hline Methods & $\begin{array}{l}\text { - 2-arm, double-blind, randomized controll } \\
\text { - Conducted at a single centre in Switzerlan }\end{array}$ \\
\hline Participants & $\begin{array}{l}\text { Inclusion criteria } \\
\text { - Adult patients undergoing thyroidectomy } \\
\text { Exclusion criteria } \\
\text { - Pregnancy } \\
\text { - Antiemetic therapy } \\
\text { - }<18 \text { years old } \\
\text { - Malignant disease } \\
\text { - Thyroid or neck surgery } \\
\text { - Depression } \\
\text { - Chronic pain disorder } \\
\text { - Insulin-dependent diabetes } \\
\text { - } 80 \text { adult patients were included. } \\
\quad \text { } 37 \text { intervention } \\
\circ 35 \text { placebo } \\
\circ 8 \text { dropouts }\end{array}$ \\
\hline
\end{tabular}

- Mean age: 52 years

- $85 \%$ female.

- Average duration of surgery: 172 to 195 minutes

\section{Primary outcome}

- Nausea (nausea and vomiting assessed on a 4-point scale: 0 no nausea, 1 mild nausea, 2 severe nausea, 3 vomiting)

\section{Secondary outcomes}

- Pain (assessed with a VAS)

- Voice disturbances (evaluated by laryngoscopy both preoperatively and 2 days postoperatively)

- Postoperative wound infection measured at 30 days postoperatively

Notes

\section{Sources of funding}

- Not reported

Conflict of interest

- Not reported

\section{Risk of bias}

Bias 
Worni 2008 (Continued)

\begin{tabular}{|c|c|c|}
\hline $\begin{array}{l}\text { Random sequence generation (selection } \\
\text { bias) }\end{array}$ & Low risk & Computerized random number table \\
\hline Allocation concealment (selection bias) & Low risk & $\begin{array}{l}\text { The list was kept separate and was un- } \\
\text { known to investigators. }\end{array}$ \\
\hline $\begin{array}{l}\text { Blinding of participants and personnel } \\
\text { (performance bias) } \\
\text { All outcomes }\end{array}$ & Low risk & $\begin{array}{l}\text { Study drugs were prepared off the ward } \\
\text { in identical syringes and were given by a } \\
\text { blinded nurse }\end{array}$ \\
\hline $\begin{array}{l}\text { Blinding of outcome assessment (detection } \\
\text { bias) } \\
\text { All outcomes }\end{array}$ & Low risk & Researchers were blinded. \\
\hline $\begin{array}{l}\text { Incomplete outcome data (attrition bias) } \\
\text { All outcomes }\end{array}$ & Low risk & Reasons for dropouts documented \\
\hline Selective reporting (reporting bias) & Low risk & Protocol was registered: NCT00619086. \\
\hline Other bias & Low risk & No apparent other bias \\
\hline
\end{tabular}

Zargar-Shoshtari 2009

Methods

Participants
- Single-centre randomized double-blind placebo-controlled trial

- Conducted in New Zealand

- Dates of enrolment were from 2006 to 2008.

\section{Inclusion criteria}

- Adult patients undergoing open colonic resection

Exclusion criteria

- ASA status IV or higher

- Stoma requirement

- Not speaking English

- Cognitive impairment

- 60 adult patients undergoing colonic surgery

- 29 intervention

- 31 placebo

- Patients with diabetes were eligible.

- Mean age: 69 to 71 years

- $58 \%$ female

- $52 \%$ ASA II status

Interventions

$8 \mathrm{mg}$ dexamethasone vs normal saline 90 minutes before induction

Outcomes

Primary outcome

- Fatigue, measured before surgery and on days 3, 7, 30, and 60 via the IdentityConsequence Fatigue Scale

\section{Secondary outcomes}


Zargar-Shoshtari 2009 (Continued)

- Cytokine, WBC, neutrophil, and CRP levels at day 1 postoperatively

- VAS scores for nausea, vomiting, and pain on days 1 and 2 postoperatively

- Postoperative complications, including wound infection and postoperative infection, assessed at 60 days (criteria for wound infection: documented erythema, discharge requiring antibiotic treatment, or wound dehiscence requiring closure)

\begin{tabular}{l|l}
\hline Notes & $\begin{array}{l}\text { Sources of funding } \\
\text { - This research was conducted during tenure by K.Z.-S. of a Clinical Research } \\
\text { Training Fellowship from the Health Research Council of New Zealand, and was } \\
\text { supported by a research grant from the Auckland Medical Research Fund. } \\
\text { Conlicts of interest } \\
\bullet \text { None }\end{array}$ \\
\hline
\end{tabular}

\section{Risk of bias}

\begin{tabular}{l|ll}
\hline Bias & Authors' judgement & Support for judgement \\
\hline $\begin{array}{l}\text { Random sequence generation (selection } \\
\text { bias) }\end{array}$ & Low risk & Computer generated \\
\hline $\begin{array}{l}\text { Allocation concealment (selection bias) } \\
\text { Blinding of participants and personnel } \\
\text { (performance bias) } \\
\text { All outcomes }\end{array}$ & Low risk & Opaque envelopes \\
\hline $\begin{array}{l}\text { Blinding of outcome assessment (detection } \\
\text { bias) } \\
\text { All outcomes }\end{array}$ & Low risk & Individual not participating in the trial pre- \\
\hline $\begin{array}{l}\text { Incomplete outcome data (attrition bias) } \\
\text { All outcomes }\end{array}$ & Low risk & pared identical study drugs \\
\hline $\begin{array}{l}\text { Selective reporting (reporting bias) } \\
\text { Other bias }\end{array}$ & Low risk & Researchers were blinded. \\
\hline
\end{tabular}

Zhang 2016

Methods

Participants
- Multi-centre parallel-group double-blind placebo-controlled study

- Conducted in China

- Enrolment of participants occurred in 2014.

\section{Inclusion criteria}

- Adult patients undergoing thyroidectomy

- ASA status I or II

- Age: 23 to 65 years

- Intubation under direct vision 


\section{Exclusion criteria}

- Dexamethasone allergy

- Preoperative ulcer

- Use of Shaw body type and analgesic drugs in patients with thyroid surgery

- Hyperthyroidism with thyroid cancer

- Hyperthyroidism

- 233 adult patients undergoing thyroid surgery were included.

- 103 intervention

- 130 placebo

- Patients with diabetes were eligible.

- Mean age: 45 to 47 years

- $23 \%$ male

- $82 \%$ ASA status I

- Average duration of surgery: 75 to 78 minutes

Outcomes

- Wound pain and throat pain, measured on VAS

- Incidence of PONV, assessed on VRS

- Baseline and 24-hour postoperative glucose values

- Postoperative infection assessed; however length of follow-up was 7 days. Criteria for wound infection were redness of the scar, swollen skin around the scar, and heat and pain around the scar. Owing to the short follow-up, data on postoperative infection were not included in this meta-analysis.

Notes

\section{Sources of funding}

- Not reported in the article

Conflicts of interests

- Not reported in the article

\section{Risk of bias}

\begin{tabular}{l|l|l} 
Bias & Authors' judgement & Support for judgement \\
\hline $\begin{array}{l}\text { Random sequence generation (selection } \\
\text { bias) }\end{array}$ & Unclear risk & Not described \\
\hline $\begin{array}{l}\text { Allocation concealment (selection bias) } \\
\begin{array}{l}\text { Blinding of participants and personnel } \\
\text { (performance bias) } \\
\text { All outcomes }\end{array}\end{array}$ & Unclear risk & Not described \\
\hline
\end{tabular}

Blinding of outcome assessment (detection Unclear risk

Not described

bias)

All outcomes

Incomplete outcome data (attrition bias) High risk

No dropouts documented

All outcomes

Adverse side effects of dexamethasone in surgical patients (Review) 
Zhang 2016 (Continued)

\begin{tabular}{|c|c|c|}
\hline Selective reporting (reporting bias) & Unclear risk & $\begin{array}{l}\text { Protocol was not published, and all ex- } \\
\text { pected outcomes were reported }\end{array}$ \\
\hline Other bias & High risk & Very little information in the report \\
\hline
\end{tabular}

\section{Zhou 2012}

Methods

- Randomized controlled trial conducted at a single centre in China

- Enrolment took place from 2009 to 2010.

Participants

Inclusion criteria

- Adult patients undergoing thyroid surgery

Exclusion criteria

- Antiemetic therapy within 48 hours before surgery

- Depression

- Chronic pain disorder

- Gastrointestinal disease

- Insulin-dependent diabetes mellitus

- Pregnancy

- $<18$ years of age

- Known malignant disease

- Previous thyroid or neck surgery

Per-protocol analysis

- Patients who underwent extended lymphadenectomy because of positive findings in the fresh frozen tissue analysis and those who were not given standard anaesthesia and postoperative management were also excluded.

168 adult patients undergoing thyroid surgery were randomized into 3 groups

- 56 patients to the dexamethasone group, 50 analysed; 56 to the tropisetron group, 50 analysed; 56 to the dexamethasone plus tropisetron group, 50 analysed

- Dexamethasone and dexamethasone plus tropisetron groups were combined as the intervention group in this meta-analysis.

- Mean age: 48 years

- $24 \%$ male

- Average duration of surgery: 74 to 82 minutes before induction

Outcomes

\section{Primary outcome}

- Nausea and vomiting (assessed on a 4-point scale at 0 to 6 hours postoperatively and at 6 to 48 hours postoperatively)

- Pain (postoperative pain assessed on VAS)

\section{Secondary outcomes}

- Satisfaction scores at 24 hours postoperatively

- Postoperative complications like laryngeal nerve palsy

- Hypoparathyroidism

- Postoperative bleeding and wound infection

- Postoperative stay and hospital cost for first 24 hours 
- Wound infection/wound healing assessed 30 days after surgery (no definition provided)

\begin{tabular}{|c|c|c|}
\hline Notes & $\begin{array}{l}\text { Sources of funding } \\
\text { - Not stated } \\
\text { Conflict of interest } \\
\text { - None declared }\end{array}$ & \\
\hline \multicolumn{3}{|l|}{ Risk of bias } \\
\hline Bias & Authors' judgement & Support for judgement \\
\hline $\begin{array}{l}\text { Random sequence generation (selection } \\
\text { bias) }\end{array}$ & Low risk & Computer generated \\
\hline Allocation concealment (selection bias) & High risk & $\begin{array}{l}\text { Random number list on a computer spread } \\
\text { sheet }\end{array}$ \\
\hline $\begin{array}{l}\text { Blinding of participants and personnel } \\
\text { (performance bias) } \\
\text { All outcomes }\end{array}$ & Unclear risk & $\begin{array}{l}\text { Personnel not part of the study prepared } \\
\text { study drug. Unknown if participants were } \\
\text { blinded }\end{array}$ \\
\hline $\begin{array}{l}\text { Blinding of outcome assessment (detection } \\
\text { bias) } \\
\text { All outcomes }\end{array}$ & Low risk & Researchers were blinded \\
\hline $\begin{array}{l}\text { Incomplete outcome data (attrition bias) } \\
\text { All outcomes }\end{array}$ & Low risk & Reasons for drop-outs documented \\
\hline Selective reporting (reporting bias) & Unclear risk & $\begin{array}{l}\text { The study was registered at a Chinese trial } \\
\text { register }\end{array}$ \\
\hline Other bias & Unclear risk & Unknown \\
\hline
\end{tabular}

\section{Acronyms and abbreviations used in this table}

ANZCA: Australian and New Zealand Anaesthetic Counsel; AP: angina pectoris; ASA PS: American Association of Anesthesiologists Physical Status; ASEPSIS: name of scoring questionnaire of delayed wound healing; AUC: area under curve; BMI: body mass index; BSSO: bilateral split mouth osteotomy; CABG: coronary artery bypass graft operation; CDC: Centers for Disease Control and Prevention; CPB: cardiac pulmonary bypass; COPD: obstructive lung disease; CRP: C-reactive protein; DM: diabetes mellitus; ECMC: experimental cancer medicine centre; ECRP: endoscopic retrograde cholangiopancreatography; ELISA: enzyme-linked immuno sorbent assay; EQ-5D-3L: a standardized measure of health status; FACIT-F: Functional Assessment of Chronic Illness Therapy-Fatigue; GERD: gastro-oesophageal reflux disease; Hb: haemoglobin; HbAlc: glycated haemoglobin; IBD: inflammatory bowel disease; ICMJE: International Committee of Medical Journal Editors; ICU:intensive care unit; IL: interleukin; ISB: interscalene block; LC: laparoscopic cholecystectomy; LFNF: laparoscopic floppy Nissen fundoplication; MI: myocardial infarction; MIO: maximal interincisal opening; NRS: numeric rating scale; NSAID: non-steroidal anti-inflammatory drug; PACU: postoperative care unit; PCA: patient-controlled analgesia; PONV: postoperative nausea and vomiting; QoR-40: Quality of Recovery Questionnaire; ROM: range of motion; SGOT: liver enzymes;SGPT: liver enzymes;SSI: surgical site infection; TKA: total knee arthroplasty; VAS: visual analogue scale; VRS: verbal rating scale; WBC: white blood cell count. 
Characteristics of excluded studies [ordered by study ID]

\begin{tabular}{|c|c|}
\hline Study & Reason for exclusion \\
\hline Abbaszadeh 2012 & $\begin{array}{l}\text { Randomized controlled trial including } 185 \text { participants undergoing CABG surgery. Dexamethasone } 6 \mathrm{mg}+ \\
6 \mathrm{mg} \text { vs placebo. Excluded: length of follow-up: } 3 \text { days }\end{array}$ \\
\hline Al-Shehri 2004 & $\begin{array}{l}\text { Randomized placebo-controlled trial including } 30 \text { participants undergoing tonsillectomy. Dexamethasone } 3 \\
\text { doses of } 6 \mathrm{mg} \text { vs placebo. Excluded: length of follow-up: } 14 \text { days }\end{array}$ \\
\hline Bianchin 2007 & $\begin{array}{l}\text { Randomized controlled trial including } 80 \text { participants undergoing cholecystectomy. Dexamethasone } 8 \mathrm{mg} \text { vs } \\
\text { placebo. Excluded: length of follow-up: } 4 \text { days }\end{array}$ \\
\hline Coloma 2001 & $\begin{array}{l}\text { Randomized controlled trial including } 80 \text { participants undergoing outpatient anorectal surgery. Dexametha- } \\
\text { sone } 4 \mathrm{mg} \text { vs placebo. Excluded: length of follow-up: } 10 \text { days }\end{array}$ \\
\hline Halvorsen 2003 & $\begin{array}{l}\text { Randomized controlled trial including } 300 \text { participants undergoing CABG surgery. Dexamethasone } 2 \text { doses } \\
\text { of } 4 \mathrm{mg} \text { vs placebo. Excluded: length of follow-up: } 6 \text { days }\end{array}$ \\
\hline Ho 2001 & $\begin{array}{l}\text { Randomized controlled trial including } 225 \text { women undergoing a hysterectomy. Dexamethasone } 10 \mathrm{mg} \text { vs } 5 \\
\mathrm{mg} \text { vs } 2.5 \mathrm{mg} \text { vs droperidol vs saline. Excluded: length of follow-up: } 7 \text { to } 8 \text { days }\end{array}$ \\
\hline Jung 2013 & $\begin{array}{l}\text { Randomized controlled trial including } 110 \text { participants undergoing microlaryngeal surgery. Dexamethasone } \\
0.2 \mathrm{mg} / \mathrm{kg} \text { vs saline. Excluded: length of follow-up: until first visit in outpatient clinic, unclear after how many } \\
\text { days }\end{array}$ \\
\hline
\end{tabular}

Kara $1999 \quad$ Randomized controlled trial in 55 participants undergoing rhinoplasty. Dexamethasone $10 \mathrm{mg}$ vs saline. Excluded: length of follow-up: 9 days

Lei 2018a Randomized controlled trial including 110 participants undergoing total hip arthroplasty. Dexamethasone 10 mg vs saline. Excluded: length of follow-up: 14 days

Liu $2001 \quad$ Randomized controlled trial including 80 participants undergoing tympanomastoid surgery. Dexamethasone $10 \mathrm{mg}$ vs saline. Excluded: length of follow-up: during hospital stay

Nasiri 2013 Randomized controlled trial including 64 participants undergoing thyroid surgery, Dexamethasone vs saline. Excluded: length of follow-up: 6 days. Glucose measured once - unclear when

Pasternak 2004 Study in 20 participants undergoing a craniotomy. Dexamethasone vs placebo. Excluded: not a randomized study. Dexamethasone was administered based on a clinical decision

Sethi 2016 Study in 60 participants undergoing a craniotomy. Dexamethasone vs saline. Excluded: not a randomized study. Dexamethasone was administered based on a clinical decision

Snall $2014 \quad$ Post hoc analyses of completed study. Participants were selected from a larger cohort including patients with facial fractures 
(Continued)

Thangaswamy 2010 Randomized controlled trial including 55 participants undergoing a hysterectomy. Dexamethasone 4 mg vs $8 \mathrm{mg}$ vs placebo. Excluded: length of follow-up: 7 days

Tolver $2012 \quad$ Randomized controlled trial including 80 men undergoing a transabdominal, preperitoneal inguinal hernia repair. Dexamethasone $8 \mathrm{mg}$ vs placebo

Excluded: length of follow-up: 2 days

Wang $2000 \quad$ Randomized controlled trial in 225 women undergoing thyroidectomy. Dexamethasone $10 \mathrm{mg}$ vs $5 \mathrm{mg}$ vs 2 $5 \mathrm{mg}$ vs $1.25 \mathrm{mg}$ vs saline. Excluded: length of follow-up: 10 days

Wang $2001 \quad$ Randomized controlled trial in 180 participants undergoing a caesarean section. Dexamethasone $10 \mathrm{mg}$ vs 5 mg vs 2.5 mg. Excluded: length of follow-up: 6 days

Weber 1994

Randomized controlled trial in 23 participants undergoing orthognathic surgery. Dexamethasone 16 mg vs placebo. Excluded: length of follow-up: 3 days

Wu 2007

Randomized controlled trial in 120 women undergoing a caesarean section. Dexamethasone $8 \mathrm{mg}$ vs $4 \mathrm{mg}$ vs placebo. Excluded: length of follow-up: 6 days

\section{Abbreviation used in this table}

CABG: coronary artery bypass graft.

\section{Characteristics of studies awaiting assessment [ordered by study ID]}

\section{Ko-Iam 2015}

\begin{tabular}{|c|c|}
\hline Methods & Double-blind randomized controlled trial (parallel design) \\
\hline Participants & 100 patients, ASA I or II undergoing elective laparoscopic cholecystectomy \\
\hline Interventions & $\begin{array}{l}\text { - Treatment group received } 8 \mathrm{mg} \text { dexamethasone and } 10 \mathrm{mg} \text { metoclopramide } \\
\text { - Control group received } 10 \mathrm{mg} \text { metoclopramide and normal saline solution } 1.6 \mathrm{~mL}\end{array}$ \\
\hline Outcomes & $\begin{array}{l}\text { - PONV } \\
\text { - Pain } \\
\text { Assessed at 2, 6, 12, and } 24 \text { hours postoperatively and at discharge }\end{array}$ \\
\hline Notes & "No postoperative complications occurred in both groups". We were unable to retrieve the full text of this publication \\
\hline
\end{tabular}


Simogai 2016

\begin{tabular}{ll}
\hline Methods & Randomized trial \\
\hline Participants & Patients undergoing surgery \\
\hline Interventions & Participants received $0 \mathrm{mg}, 1.65 \mathrm{mg}, 3.3 \mathrm{mg}$, or $4.95 \mathrm{mg}$ dexamethasone \\
\hline Outcomes & $\bullet$ Postoperative nausea and vomiting \\
\hline Notes & Full text requested but not retrieved \\
\hline
\end{tabular}

Acronyms and abbreviations used in this table

ASA: American Association of Anesthesiologists; PONV: postoperative nausea and vomiting.

\section{Characteristics of ongoing studies [ordered by study ID]}

\section{Kitcharanant 2016}

\begin{tabular}{l|l}
\hline Trial name or title & $\begin{array}{l}\text { Effects of perioperative intravenous dexamethasone on the severity of persistent postsurgical pain after total } \\
\text { knee arthroplasty: a prospective, randomized, double-blind, placebo-controlled trial }\end{array}$ \\
\hline Methods & Parallel randomized double-blind trial \\
\hline Participants & 70 patients with osteoarthritis of the knee \\
\hline Interventions & Dexamethasone vs normal saline \\
\hline Outcomes & - Postsurgical pain: modified WOMAC scores for pain at 12 weeks postoperative \\
\hline Starting date & October 2016 \\
\hline Contact information & nk_win@hotmail.com \\
\hline Notes & Expected end date: June 2017 \\
\hline
\end{tabular}

Sidhu 2017

\begin{tabular}{l|l}
\hline Trial name or title & Perioperative administration of dexamethasone and infection trial \\
\hline Methods & $\begin{array}{l}\text { Multi-centre prospective double-blind active-control parallel-assessment stratified pragmatic non-inferiority } \\
\text { safety and efficacy study }\end{array}$ \\
\hline Participants & $\begin{array}{l}\text { - } 8880 \text { adult patients } \\
\text { - Undergoing elective or expedited (non-cardiac) surgery of at least } 2 \text { hours' duration } \\
\text { - Using general anaesthesia with or without regional block }\end{array}$ \\
\hline $\begin{array}{l}\text { Adverse side effects of dexamethasone in surgical patients (Review) } \\
\text { Copyright @ } \mathbf{2 0 1 8} \text { The Cochrane Collaboration. Published by John Wiley \& Sons, Ltd. }\end{array}$
\end{tabular}


Sidhu 2017 (Continued)

- With a single (or multiple) surgical skin incision $(\mathrm{s})>5 \mathrm{~cm}$ in length and a minimum anticipated hospital stay of at least 1 night

\begin{tabular}{l|l}
\hline Interventions & Dexamethasone vs active control \\
\hline Outcomes & $\begin{array}{c}\text { Primary outcome } \\
\bullet \text { Surgical site infection within 30 days of surgery }\end{array}$ \\
\hline Starting date & Enrolling patients \\
\hline Contact information & jaspreet.sidhu@monash.edu \\
\hline Notes & www.paddi.org.au \\
\hline
\end{tabular}

\section{Wang 2018}

Trial name or title Dexamethasone, flurbiprofen axetil, and delirium after lung cancer surgery

\begin{tabular}{|c|c|}
\hline Methods & Randomized controlled trial \\
\hline Participants & 844 participants \\
\hline Interventions & $\begin{array}{l}\text { Dexamethasone and flurbiprofen axetil vs dexamethasone and lipid microsphere vs normal saline and flur- } \\
\text { biprofen vs normal saline and lipid microsphere }\end{array}$ \\
\hline Outcomes & $\begin{array}{l}\text { - Delirium } \\
\text { - Length of hospital stay } \\
\text { - Postoperative complications }\end{array}$ \\
\hline Starting date & 27 June 2017 \\
\hline Contact information & wangdongxin@hotmail.com \\
\hline Notes & ClinicalTrials.gov Identifier: NCT03200600 \\
\hline
\end{tabular}

Acronyms and abbreviations used in this table

ASA: American Association of Anesthesiologists; WOMAC: Western Ontario and McMaster University Arthritis Index. 
DATA AND ANALYSES

\section{Comparison 1. Dexamethasone versus control}

\begin{tabular}{|c|c|c|c|c|}
\hline Outcome or subgroup title & $\begin{array}{l}\text { No. of } \\
\text { studies }\end{array}$ & $\begin{array}{c}\text { No. of } \\
\text { participants }\end{array}$ & Statistical method & Effect size \\
\hline $\begin{array}{l}1 \text { Postoperative systemic or wound } \\
\text { infection }\end{array}$ & 27 & 4931 & Peto Odds Ratio (Peto, Fixed, 95\% CI) & $1.01[0.80,1.27]$ \\
\hline $\begin{array}{l}\text { 1.1 Low dose ( } 4 \text { to } 5 \mathrm{mg} \text { ) of } \\
\text { dexamethasone }\end{array}$ & 4 & 641 & Peto Odds Ratio (Peto, Fixed, 95\% CI) & $0.94[0.62,1.44]$ \\
\hline $\begin{array}{l}1.2 \text { Intermediate dose ( } 8 \text { to } 10 \\
\mathrm{mg} \text { ) of dexamethasone }\end{array}$ & 19 & 3637 & Peto Odds Ratio (Peto, Fixed, 95\% CI) & $0.93[0.69,1.26]$ \\
\hline $\begin{array}{l}1.3 \text { High dose ( } 12 \text { to } 20 \mathrm{mg} \text { ) } \\
\text { of dexamethasone }\end{array}$ & 4 & 653 & Peto Odds Ratio (Peto, Fixed, 95\% CI) & $1.61[0.87,2.95]$ \\
\hline $\begin{array}{l}2 \text { Subgroup analysis for } \\
\text { postoperative systemic or } \\
\text { wound infection: single } \\
\text { vs multiple doses of } \\
\text { dexamethasone }\end{array}$ & 27 & 4931 & Peto Odds Ratio (Peto, Fixed, 95\% CI) & $1.01[0.80,1.27]$ \\
\hline $\begin{array}{l}\text { 2.1 Single dose of } \\
\text { dexamethasone }\end{array}$ & 25 & 4410 & Peto Odds Ratio (Peto, Fixed, 95\% CI) & $0.96[0.76,1.22]$ \\
\hline $\begin{array}{l}\text { 2.2 Multiple doses of } \\
\text { dexamethasone }\end{array}$ & 2 & 521 & Peto Odds Ratio (Peto, Fixed, 95\% CI) & $1.51[0.75,3.02]$ \\
\hline 3 Delayed wound healing & 8 & 1072 & Peto Odds Ratio (Peto, Fixed, 95\% CI) & $0.99[0.28,3.43]$ \\
\hline $\begin{array}{l}3.1 \text { Intermediate dose ( } 8 \text { to } 10 \\
\mathrm{mg} \text { ) of dexamethasone }\end{array}$ & 6 & 912 & Peto Odds Ratio (Peto, Fixed, 95\% CI) & $0.98[0.24,3.96]$ \\
\hline $\begin{array}{l}3.2 \text { High dose (12 to } 20 \mathrm{mg} \text { ) } \\
\text { of dexamethasone }\end{array}$ & 2 & 160 & Peto Odds Ratio (Peto, Fixed, 95\% CI) & $1.0[0.06,16.27]$ \\
\hline 4 Glycaemic response & 12 & & Mean Difference (IV, Random, 95\% CI) & Subtotals only \\
\hline $\begin{array}{l}\text { 4.1 Change from baseline } \\
\text { within } 2 \text { to } 12 \text { hours after } \\
\text { surgery }\end{array}$ & 10 & 595 & Mean Difference (IV, Random, 95\% CI) & $13.31[5.91,20.71]$ \\
\hline $\begin{array}{l}\text { 4.2 Change from baseline } 24 \\
\text { hours after surgery }\end{array}$ & 6 & 450 & Mean Difference (IV, Random, 95\% CI) & $21.19[-0.17,42.55]$ \\
\hline $\begin{array}{l}\text { 4.3 Change from baseline } 10 \\
\text { to } 24 \text { hours after surgery in } \\
\text { patients with diabetes }\end{array}$ & 2 & 74 & Mean Difference (IV, Random, 95\% CI) & $31.66[14.54,48.78]$ \\
\hline $\begin{array}{l}5 \text { Re-admission or unplanned } \\
\text { hospital admission }\end{array}$ & 4 & 339 & Peto Odds Ratio (Peto, Fixed, 95\% CI) & $1.23[0.39,3.90]$ \\
\hline 6 Mortality & 7 & 2646 & Peto Odds Ratio (Peto, Fixed, 95\% CI) & $0.80[0.38,1.66]$ \\
\hline $\begin{array}{l}7 \text { Sensitivity analysis excluding } \\
\text { high risk of bias studies from } \\
\text { Analysis } 1.1\end{array}$ & 8 & 1860 & Peto Odds Ratio (Peto, Fixed, 95\% CI) & $1.03[0.75,1.42]$ \\
\hline $\begin{array}{l}\text { 7.1 Low dose ( } 4 \text { to } 5 \mathrm{mg} \text { ) of } \\
\text { dexamethasone }\end{array}$ & 1 & 22 & Peto Odds Ratio (Peto, Fixed, 95\% CI) & $0.79[0.12,4.95]$ \\
\hline $\begin{array}{l}7.2 \text { Intermediate ( } 8 \text { to } 10 \mathrm{mg} \text { ) } \\
\text { dose of dexamethasone }\end{array}$ & 5 & 1646 & Peto Odds Ratio (Peto, Fixed, 95\% CI) & $0.99[0.71,1.39]$ \\
\hline
\end{tabular}

Adverse side effects of dexamethasone in surgical patients (Review) 
7.3 High dose (12 to $20 \mathrm{mg}$ ) 2 of dexamethasone

8 Sensitivity analysis excluding skewed glucose data

8.1 Change from baseline to $2 \quad 8$ to 12 hours after surgery

8.2 Change from baseline to 24 hours after surgery

9

4
192 Peto Odds Ratio (Peto, Fixed, 95\% CI)

$1.99[0.56,7.10]$

819

Mean Difference (IV, Random, 95\% CI)

Subtotals only
Mean Difference (IV, Random, 95\% CI)

$16.74[8.88,24.60]$

52 Mean Difference (IV, Random, 95\% CI)

\section{Analysis I.I. Comparison I Dexamethasone versus control, Outcome I Postoperative systemic or wound infection.}

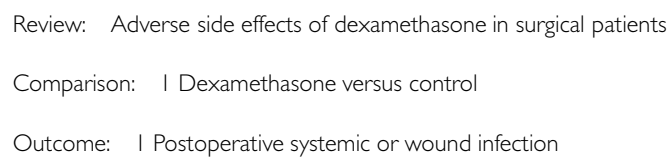

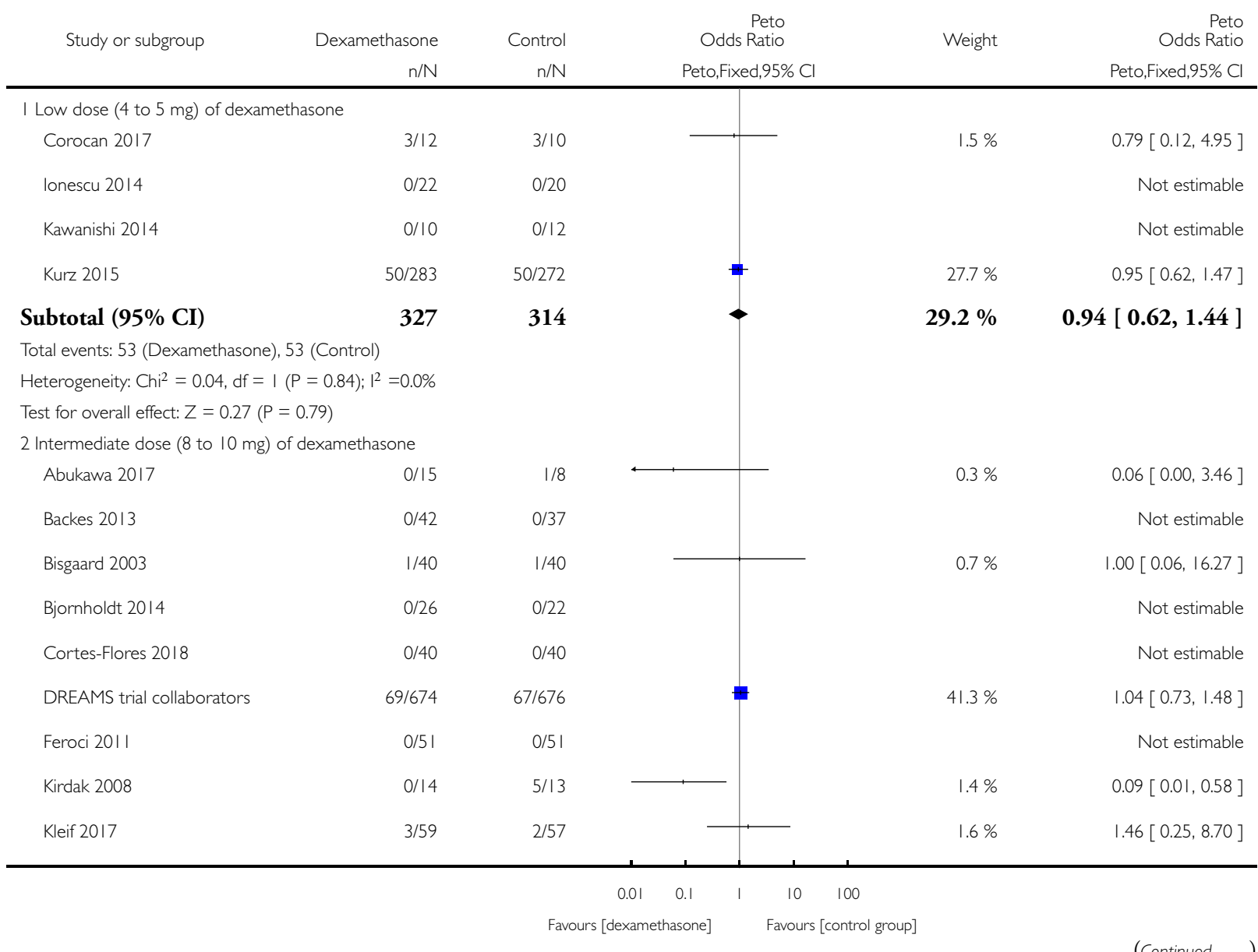




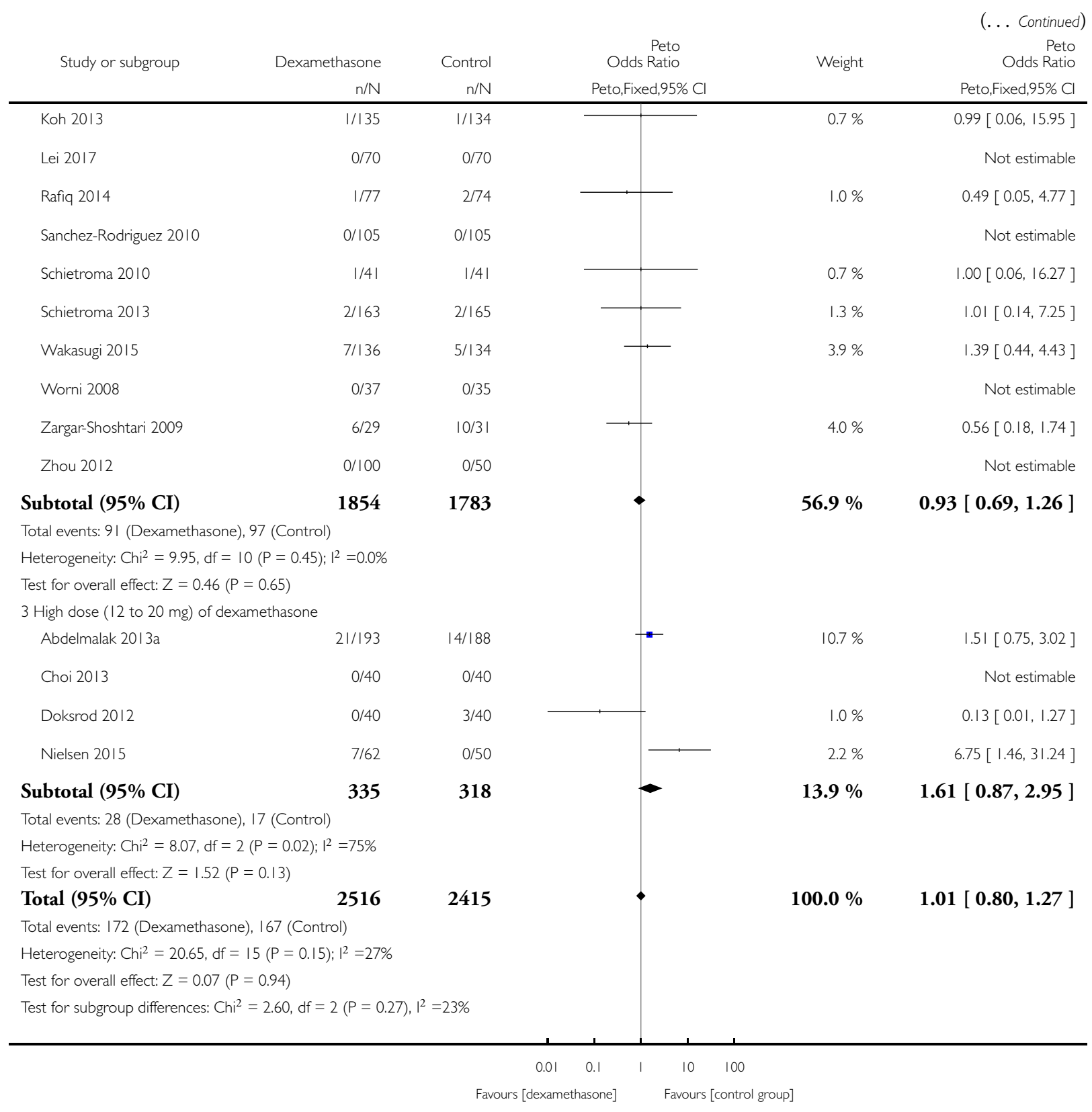




\section{Analysis I.2. Comparison I Dexamethasone versus control, Outcome 2 Subgroup analysis for postoperative systemic or wound infection: single vs multiple doses of dexamethasone.}

Review: Adverse side effects of dexamethasone in surgical patients

Comparison: I Dexamethasone versus control

Outcome: 2 Subgroup analysis for postoperative systemic or wound infection: single vs multiple doses of dexamethasone

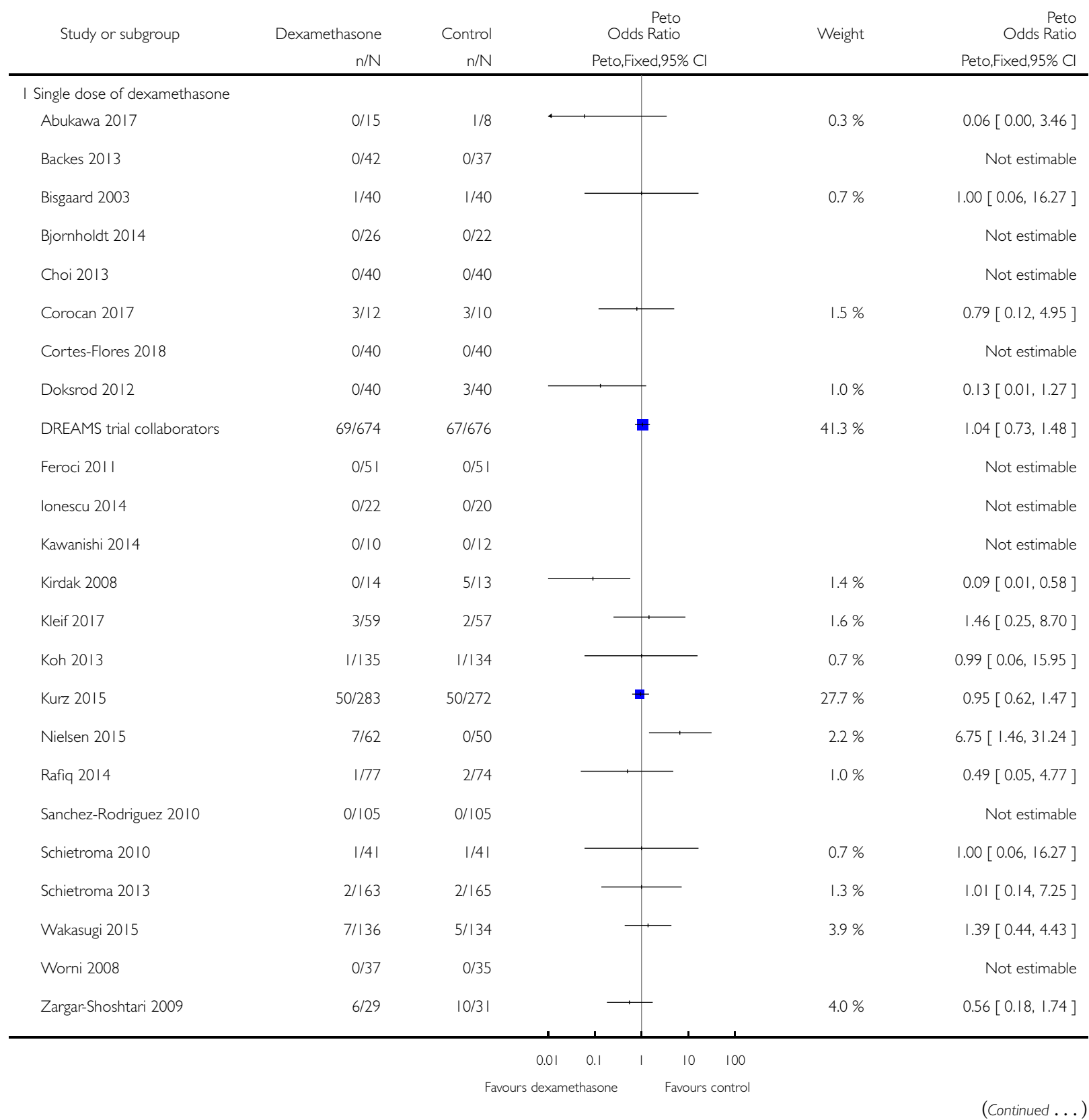

Adverse side effects of dexamethasone in surgical patients (Review) 


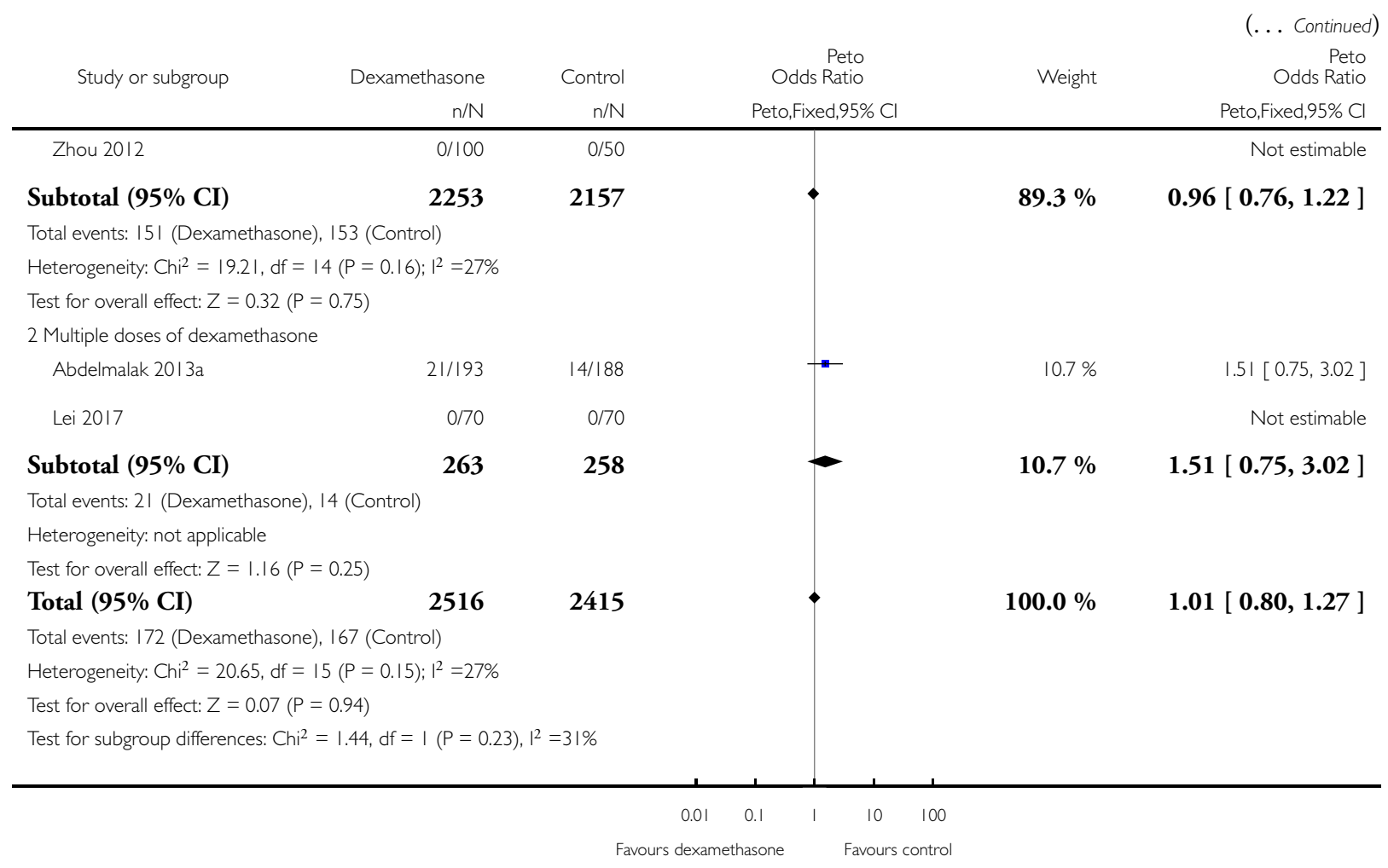




\section{Analysis I.3. Comparison I Dexamethasone versus control, Outcome 3 Delayed wound healing.}

Review: Adverse side effects of dexamethasone in surgical patients

Comparison: I Dexamethasone versus control

Outcome: 3 Delayed wound healing

\begin{tabular}{|c|c|c|c|c|c|}
\hline \multirow[t]{2}{*}{ Study or subgroup } & Dexamethasone & Control & $\begin{array}{r}\text { Peto } \\
\text { Odds Ratio }\end{array}$ & \multirow[t]{2}{*}{ Weight } & $\begin{array}{r}\text { Peto } \\
\text { Odds Ratio }\end{array}$ \\
\hline & $\mathrm{n} / \mathrm{N}$ & $\mathrm{n} / \mathrm{N}$ & Peto,Fixed,95\% Cl & & Peto,Fixed,95\% Cl \\
\hline \multicolumn{6}{|c|}{ I Intermediate dose (8 to $10 \mathrm{mg}$ ) of dexamethasone } \\
\hline Bjornholdt 2014 & $0 / 26$ & $0 / 22$ & & & Not estimable \\
\hline Feroci 2011 & $0 / 51$ & $0 / 51$ & & & Not estimable \\
\hline Koh 2013 & $2 / 135$ & $3 / 134$ & & $49.8 \%$ & $0.66[0.11,3.87]$ \\
\hline Rafiq 2014 & $1 / 77$ & $1 / 74$ & & $20.1 \%$ & $0.96[0.06,|5.5|]$ \\
\hline Wakasugi 2015 & $1 / 136$ & $0 / 134$ & 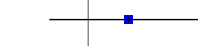 & $10.1 \%$ & $7.28[0.14,366.99]$ \\
\hline Worni 2008 & 0/37 & $0 / 35$ & & & Not estimable \\
\hline Subtotal (95\% CI) & 462 & 450 & & $80.0 \%$ & $0.98[0.24,3.96]$ \\
\hline \multicolumn{6}{|c|}{ Total events: 4 (Dexamethasone), 4 (Control) } \\
\hline \multicolumn{6}{|c|}{ Heterogeneity: $\mathrm{Chi}^{2}=1.20, \mathrm{df}=2(\mathrm{P}=0.55) ; \mathrm{I}^{2}=0.0 \%$} \\
\hline \multicolumn{6}{|c|}{ Test for overall effect: $Z=0.02(P=0.98)$} \\
\hline \multicolumn{6}{|c|}{2 High dose ( 12 to $20 \mathrm{mg}$ ) of dexamethasone } \\
\hline Choi 2013 & $0 / 40$ & $0 / 40$ & & & Not estimable \\
\hline Doksrod 2012 & $1 / 40$ & $1 / 40$ & & $20.0 \%$ & $1.00[0.06,16.27]$ \\
\hline Subtotal (95\% CI) & 80 & 80 & & $20.0 \%$ & $1.00[0.06,16.27]$ \\
\hline \multicolumn{6}{|c|}{ Total events: I (Dexamethasone), I (Control) } \\
\hline \multicolumn{6}{|c|}{ Heterogeneity: not applicable } \\
\hline \multicolumn{6}{|c|}{ Test for overall effect: $Z=0.0(P=1.0)$} \\
\hline Total (95\% CI) & 542 & 530 & & $100.0 \%$ & $0.99[0.28,3.43]$ \\
\hline \multicolumn{6}{|c|}{ Total events: 5 (Dexamethasone), 5 (Control) } \\
\hline \multicolumn{6}{|c|}{ Heterogeneity: $\mathrm{Chi}^{2}=1.20, \mathrm{df}=3(\mathrm{P}=0.75) ; \mathrm{I}^{2}=0.0 \%$} \\
\hline \multicolumn{6}{|c|}{ Test for overall effect: $Z=0.02(P=0.98)$} \\
\hline Test for subgroup differen & $2=0.00, \mathrm{df}=1(\mathrm{P}$ & $\left.\right|^{2}=0.0 \%$ & & & \\
\hline
\end{tabular}

$0.0010 .01 \quad 0.1 \quad 1 \quad 10 \quad 100 \quad 1000$

Favours [dexamethasone] Favours [control group] 


\section{Analysis I.4. Comparison I Dexamethasone versus control, Outcome 4 Glycaemic response.}

Review: Adverse side effects of dexamethasone in surgical patients

Comparison: I Dexamethasone versus contro

Outcome: 4 Glycaemic response

Study or subgroup Dexamethasone Control

Difference Weight

Mean

$N \quad \operatorname{Mean}(\mathrm{SD})[\mathrm{mg} / \mathrm{dl}] \quad \mathrm{N} \quad \operatorname{Mean}(\mathrm{SD})[\mathrm{mg} / \mathrm{dl}] \quad \quad \mathrm{IV}$, Random,95\% C

I Change from baseline within 2 to 12
Abdelmalak $2013 \mathrm{~b}$
Cowie 2010
Doksrod 2012
Kalappa 2017
Karacinar 2009
Murphy $2011 \mathrm{a}$
Murphy 2014
Nazar 2009
Tien 2016
Wang 2009

hours after surgery

$69 \quad 86(4 I) \quad 67$

7

$36(74)$

$58(45)$

(1)

Subtotal (95\% CI)

303

$58(59) \quad 40$

$14(61)$

40

$-6(13) \quad 32$

$26(52)$

32

$27(24) \quad 17$

17

$-12(12)$

$15(27)$

60

$19(46) \quad 49$

25 (44)

33

5 । (42) 34

49 (44)

15

$97(31) \quad 15$

20

$58(31) \quad 21$

70 (32)

$41(31)$

10

$43(14) \quad 10$

$29(15)$

292

Heterogeneity: $\operatorname{Tau}^{2}=60.60 ; \mathrm{Chi}^{2}=17.89, \mathrm{df}=9(\mathrm{P}=0.04) ; \mathrm{I}^{2}=50 \%$

Test for overall effect: $Z=3.53(P=0.00042)$

2 Change from baseline 24 hours after surgery

Corocan 2017
Kawie 2010
Murphy 2014
Tien 2016
Zhang 2016

$\begin{array}{ll}16 & 22(23) \\ 7 & 27(64) \\ 32 & 40(21) \\ 33 & 23(31) \\ 20 & 91(43) \\ 103 & 14(37)\end{array}$

Subtotal (95\% CI)

211

239

Heterogeneity: $\mathrm{Tau}^{2}=577.32 ; \mathrm{Chi}^{2}=65.03, \mathrm{df}=5(\mathrm{P}<0.0000 \mathrm{I}) ; \mathrm{I}^{2}=92 \%$ Test for overall effect: $Z=1.94(P=0.052)$

3 Change from baseline 10 to 24 hours after surgery in patients with diabetes
Nazar 2009
15
$97(31) \quad 15$
Tien 2016
20
$67(49) \quad 24$

$5 \quad 70(32)$
$29(38)$

$23(22)$

$10(70)$

$-11(12)$

$20(31)$

$49(31)$

। (29)

$\frac{-}{\square}$

$12.4 \%$

$28.00[13.52,42.48]$

$1.0 \% \quad 22.00[-49.04,93.04]$

$6.6 \% \quad 32.00[7.63,56.37]$

$20.2 \%$

$6.00[-0.13,12.13]$

$10.4 \%$

$12.00[-5.17,29.17]$

$10.5 \%$

$-6.00[-22.95,10.95]$

$8.3 \%$

$2.00[-18.59,22.59]$

$7.4 \%$

$27.00[4.45,49.55]$

$9.2 \%$

$17.00[-1.98,35.98]$

$13.9 \%$

$14.00[1.28,26.72]$

$100.0 \% \quad 13.31[5.91,20.71]$

Subtotal $(95 \% \mathrm{CI})$

35

39

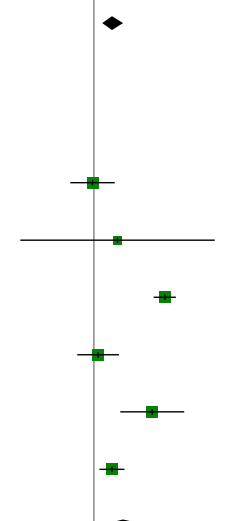

$18.5 \%$

$-1.00[-16.84,14.84]$

$6.4 \%$

$17.00[-53.26,87.26]$

$19.9 \%$

$51.00[42.62,59.38]$

$18.7 \%$

$3.00[-11.85,17.85]$

$16.6 \%$

$42.00[18.96,65.04]$

$19.9 \%$

$13.00[4.29,21.71]$

$100.0 \% 21.19[-0.17,42.55]$

$57.7 \%$

$27.00[4.45,49.55]$

$42.3 \%$

$38.00[|1.69,64.3|]$

$100.0 \% 31.66$ [ $14.54,48.78$ ]

$\begin{array}{lllll}-100 & -50 & 0 & 50 & 100\end{array}$

Favours [dexamethasone] Favours [control group]

(Continued ... )

Adverse side effects of dexamethasone in surgical patients (Review) 


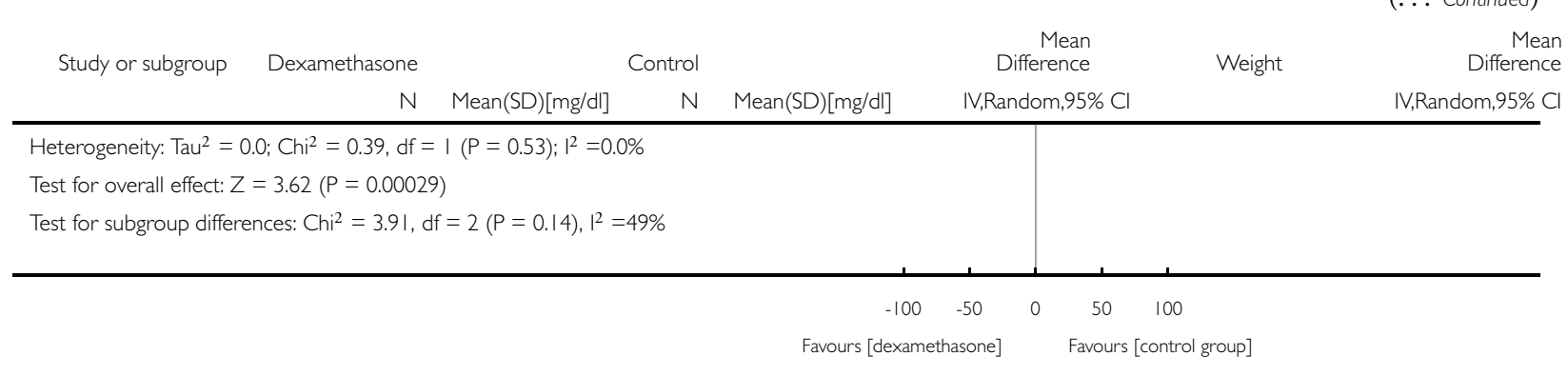

Analysis I.5. Comparison I Dexamethasone versus control, Outcome 5 Re-admission or unplanned hospital admission.

\footnotetext{
Review: Adverse side effects of dexamethasone in surgical patients

Comparison: I Dexamethasone versus control

Outcome: 5 Re-admission or unplanned hospital admission
}

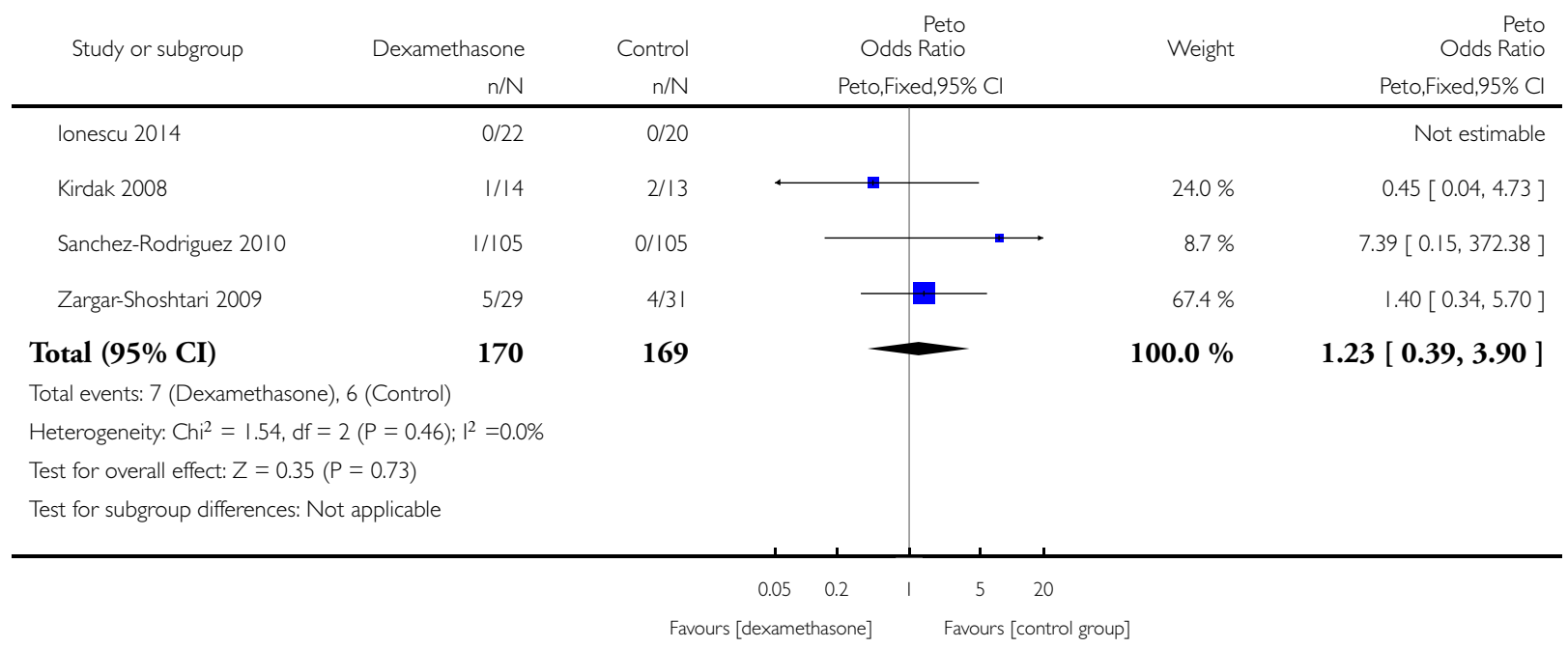




\section{Analysis I.6. Comparison I Dexamethasone versus control, Outcome 6 Mortality.}

Review: Adverse side effects of dexamethasone in surgical patients

Comparison: I Dexamethasone versus control

Outcome: 6 Mortality

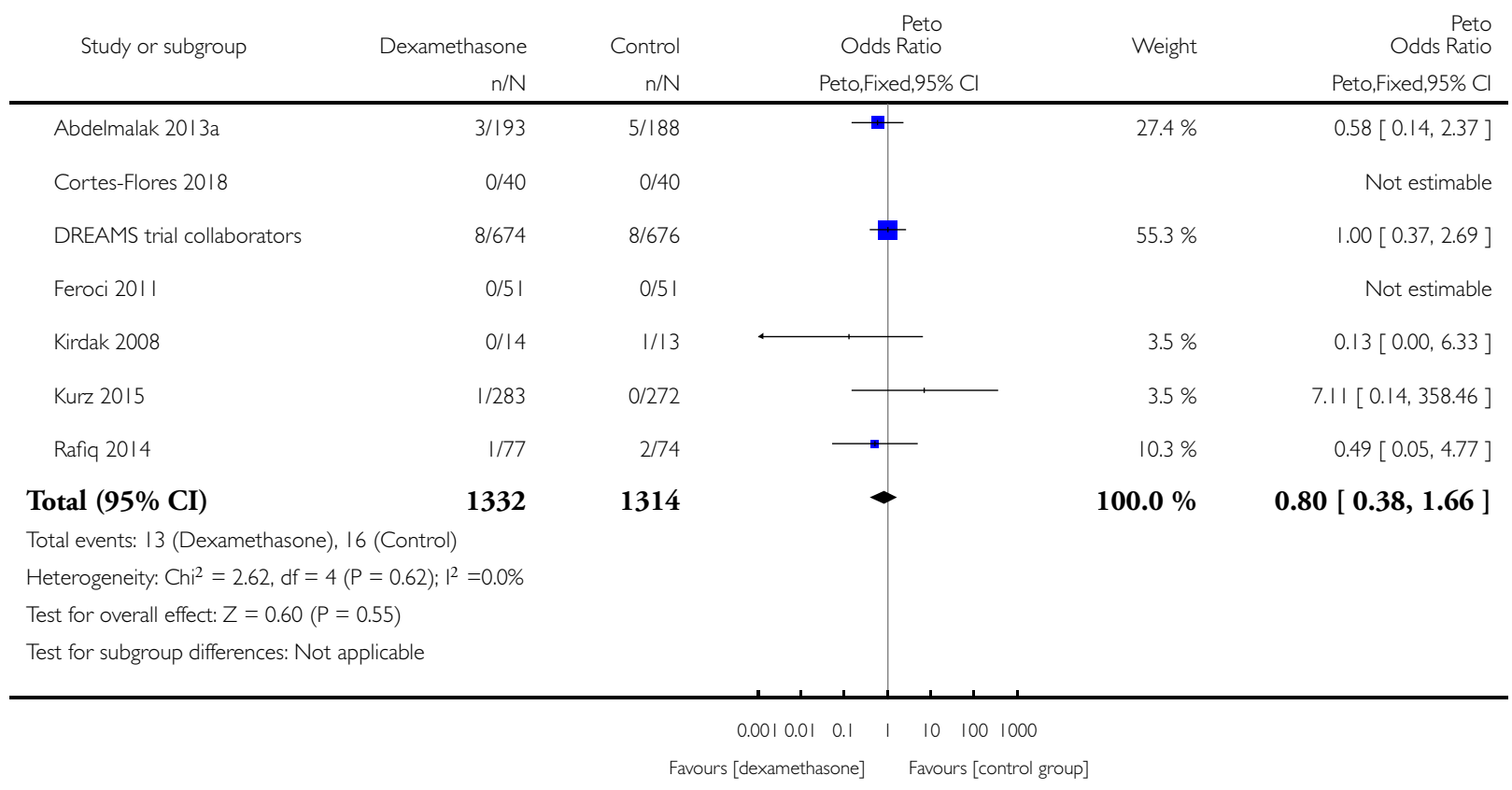

Adverse side effects of dexamethasone in surgical patients (Review) 


\section{Analysis I.7. Comparison I Dexamethasone versus control, Outcome 7 Sensitivity analysis excluding high} risk of bias studies from Analysis I.I.

Review: Adverse side effects of dexamethasone in surgical patients

Comparison: I Dexamethasone versus control

Outcome: 7 Sensitivity analysis excluding high risk of bias studies from Analysis I.I

\begin{tabular}{|c|c|}
\hline $\mathrm{su}$ & Dexamethasone \\
\hline
\end{tabular}

$\mathrm{n} / \mathrm{N} \quad \mathrm{n} / \mathrm{N} \quad$ Peto,Fixed,95\% Cl
Peto,Fixed,95\% Cl

I Low dose (4 to $5 \mathrm{mg}$ ) of dexamethasone

Corocan 2017

$3 / 12=20$

Subtotal (95\% CI)

12

Total events: 3 (Dexamethasone), 3 (Control)

Heterogeneity: not applicable

Test for overall effect: $Z=0.26(P=0.80)$

2 Intermediate ( 8 to $10 \mathrm{mg}$ ) dose of dexamethasone

Bjornholdt 2014 0/26

DREAMS trial collaborators

$69 / 674$

Kleif 2017

$$
3 / 59
$$

Worni 2008

$0 / 37$

Zargar-Shoshtari 2009

$$
6 / 29
$$

Subtotal $(95 \%$ CI)

825

Total events: 78 (Dexamethasone), 79 (Control)

Heterogeneity: $\mathrm{Chi}^{2}=1.22, \mathrm{df}=2(\mathrm{P}=0.54) ; \mathrm{I}^{2}=0.0 \%$

Test for overall effect: $Z=0.03(P=0.98)$

3 High dose ( 12 to $20 \mathrm{mg}$ ) of dexamethasone

Doksrod 2012

Nielsen 2015

Subtotal $(95 \%$ CI)

Total events: 7 (Dexamethasone), 3 (Control)

Heterogeneity: Chi $^{2}=7.93, \mathrm{df}=\mathrm{I}(\mathrm{P}=0.005) ; \mathrm{I}^{2}=87 \%$

Test for overall effect: $Z=1.06(P=0.29)$

Total (95\% CI)

Total events: 88 (Dexamethasone), 85 (Control)

Heterogeneity: Chi $^{2}=10.30, d f=5(P=0.07) ; 1^{2}=51 \%$

Test for overall effect: $Z=0.19(P=0.85)$

Test for subgroup differences: $\mathrm{Chi}^{2}=1.15, \mathrm{df}=2(\mathrm{P}=0.56), \mathrm{I}^{2}=0.0 \%$
$3 / 10$

10

$0 / 22$

$67 / 676$

$2 / 57$

$0 / 35$

$10 / 31$

821

$+$

$3.0 \%$

$0.79[0.12,4.95]$

$3.0 \%$

$0.79[0.12,4.95]$

Not estimable

$1.04[0.73,1.48]$

$1.46[0.25,8.70]$

Not estimable

$0.56[0.18,1.74]$

$90.9 \%$

0.99 [ 0.71, 1.39]

$1.9 \%$

$0.13[0.01,1.27]$

$4.3 \%$

$6.75[1.46,31.24]$

$6.2 \%$

$1.99[0.56,7.10$ ]

90

921

$100.0 \%$

$1.03[0.75,1.42]$

$0.0010 .01 \quad 0.1 \quad 1 \quad 10 \quad 100 \quad 1000$

Favours dexamethasone Favours control 
Analysis I.8. Comparison I Dexamethasone versus control, Outcome 8 Sensitivity analysis excluding skewed glucose data.

Review: Adverse side effects of dexamethasone in surgical patients

Comparison: I Dexamethasone versus control

Outcome: 8 Sensitivity analysis excluding skewed glucose data

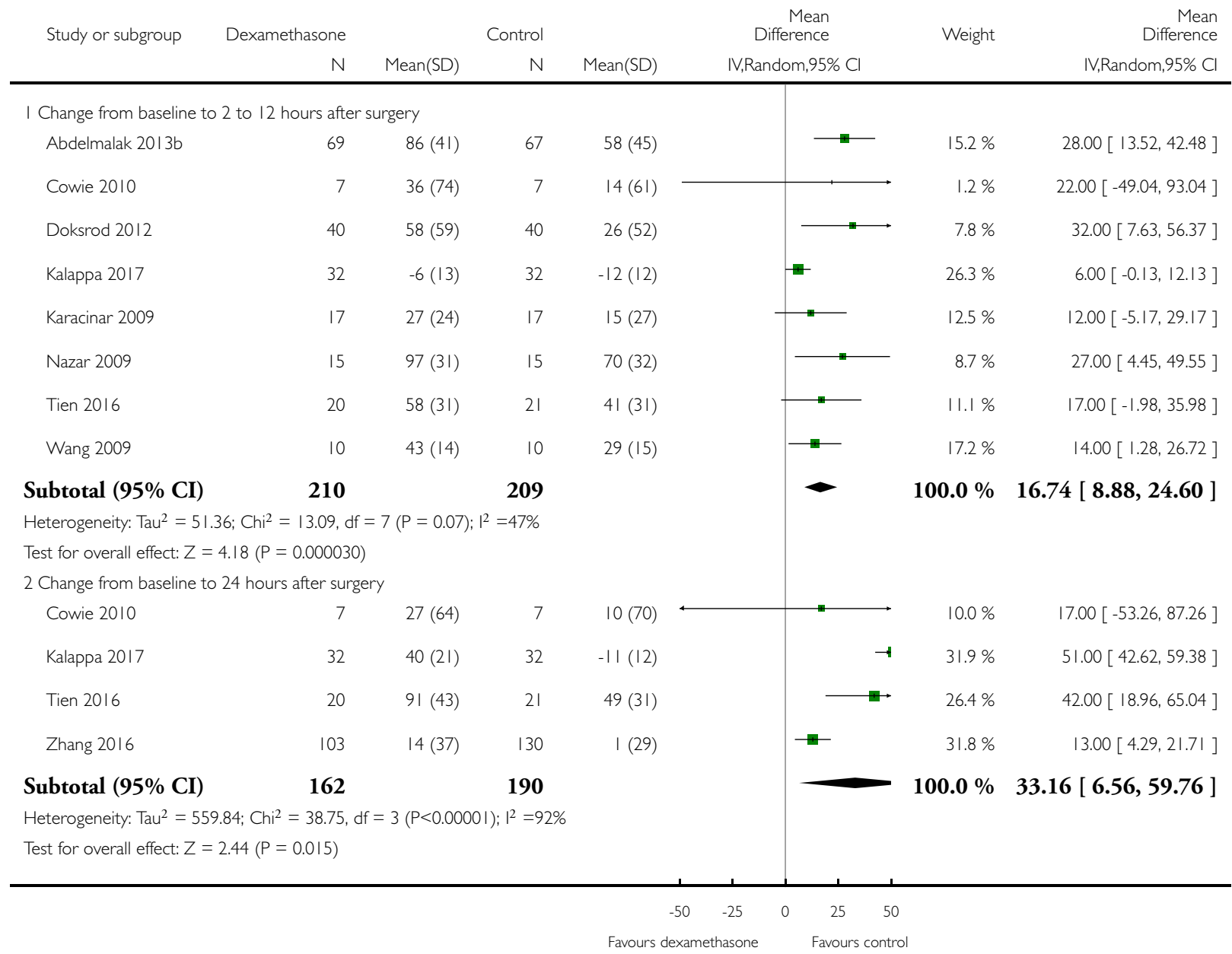




\section{A P P E N D I C E S}

\section{Appendix I. CENTRAL search strategy}

\#1 MeSH descriptor: [Dexamethasone] explode all trees

\#2 dexamethasone:ti,ab,kw (Word variations have been searched)

$\# 3 \# 1$ or \#2

\#4 MeSH descriptor: [Perioperative Period] explode all trees

\#5 MeSH descriptor: [Perioperative Care] explode all trees

\#6 MeSH descriptor: [Anesthesia, General] explode all trees

\#7 MeSH descriptor: [Postoperative Nausea and Vomiting] explode all trees

\#8 perioperat* or surgery or anesthesia or anaesthesia or postoperat* or PONV:ti,ab,kw (Word variations have been searched)

\#9 MeSH descriptor: [Wound Healing] explode all trees

\#10 MeSH descriptor: [Postoperative Care] explode all trees

\#11 MeSH descriptor: [Postoperative Period] explode all trees

\#12 MeSH descriptor: [Postoperative Complications] explode all trees

\#13 MeSH descriptor: [Blood Glucose] explode all trees

\#14 MeSH descriptor: [Analgesia] explode all trees

\#15 wound* near/5 healing:ti,ab,kw (Word variations have been searched)

\#16 postoperative near/5 infection*:ti,ab,kw (Word variations have been searched)

\#17 post-operative near/5 infection*:ti,ab,kw (Word variations have been searched)

\#18 surgery or surgical or an? esthesia or analgesia:ti,ab,kw (Word variations have been searched)

\#19 (hyp?rglyc?emic or glyc?emic) near/3 response:ti,ab,kw (Word variations have been searched)

\#20 blood glucose* or perioperative or postoperative:ti,ab,kw (Word variations have been searched)

$\# 21 \# 4$ or $\# 5$ or \#6 or \#7 or \#8 or \#9 or \#10 or \#11 or \#12 or \#13 or \#14 or \#15 or \#16 or \#17 or \#18 or \#19 or \#20

$\# 22 \# 3$ and \#21 in Trials

\section{Appendix 2. MEDLINE (Ovid SP) search strategy}

1. exp Dexamethasone/ or dexamethasone.ti,ab.

2. exp Wound Healing/ or Postoperative Care/ or Postoperative Complications/ or Postoperative Period/ or "Postoperative Nausea and Vomiting"/ or Perioperative Care/ or Perioperative Period/ or Anesthesia, General/ or (wound* adj5 healing).mp. or (post?operative adj 5 infection*).mp. or (surgery or surgical or an?esthesia or analgesia).ti,ab. or ((hyp?rglyc?emic or glyc?emic) adj3 response).ti,ab. or Blood Glucose/ or blood glucose*.ti,ab. or Analgesia/ or (perioperative or postoperative).ti,ab.

3. ((randomized controlled trial or controlled clinical trial).pt. or randomized.ab. or placebo.ab. or clinical trials as topic.sh. or randomly.ab. or trial.ti.) not (animals not (humans and animals)).sh. (814437)

4. 1 and 2 and 3

\section{Appendix 3. Embase search strategy}

$\# 1$

'dexamethasone'/exp OR dexamethasone.ti,ab

\#2

'wound healing'/exp OR 'postoperative period'/exp OR 'postoperative care'/exp OR 'postoperative complication'/de OR 'postoperative nausea and vomiting'/de OR 'perioperative period'/de OR 'general anesthesia'/de OR (wound* NEAR/5 healing) OR ((postoperative OR 'post operative') NEAR/5 infection*) OR surgery:ti,ab OR surgical:ti,ab OR an?esthesia:ti,ab OR analgesia:ti,ab OR (((hyp* rglyc*emic OR glyc*emic) NEAR/3 response):ti,ab) OR 'glucose blood level'/de OR 'blood glucose*':ti,ab OR 'analgesia'/de OR perioperative:ti,ab OR postoperative:ti,ab

\#3

('randomized controlled trial'/de OR 'controlled clinical trial'/de OR randomized:ab OR placebo:ab OR 'clinical trials as topic': de OR randomly:ab OR trial:ti) NOT ('animal'/de NOT ('human'/de AND 'animal'/de))

\#4

Adverse side effects of dexamethasone in surgical patients (Review)

Copyright (c) 2018 The Cochrane Collaboration. Published by John Wiley \& Sons, Ltd. 
\#1 AND \#2 AND \#3

\section{Appendix 4. Web of Science search strategy}

\#3 AND \#2 AND \#1

Indexes=SCI-EXPANDED, SSCI, A\&HCI, CPCI-S, CPCI-SSH, BKCI-S, BKCI-SSH, ESCI Timespan=All years

TS=clinical trial ${ }^{*}$ OR TS=research design OR TS=comparative stud* OR TS=evaluation stud* OR TS=controlled trial ${ }^{*}$ OR TS= follow-up stud* OR TS=prospective stud* OR TS=random* OR TS=placebo* OR TS=(single blind*) OR TS=(double blind*)

Indexes=SCI-EXPANDED, SSCI, A\&HCI, CPCI-S, CPCI-SSH, BKCI-S, BKCI-SSH, ESCI Timespan=All years

TS=(post $\$$ operative OR perioperative OR surgery OR surgical OR an $\$$ esthesia OR analgesia OR blood glucose*) OR TS=(wound ${ }^{*}$ NEAR/5 healing) OR TS=((hyperglyc $\$$ emic OR glyc $\$$ emic $)$ NEAR/3 response)

Indexes=SCI-EXPANDED, SSCI, A\&HCI, CPCI-S, CPCI-SSH, BKCI-S, BKCI-SSH, ESCI Timespan=All years

TS=Dexamethason*

Indexes=SCI-EXPANDED, SSCI, AひHCI, CPCI-S, CPCI-SSH, BKCI-S, BKCI-SSH, ESCI Timespan=All years

\section{Appendix 5. Data extraction form}

Review title or ID

Study ID (surname of first author and year first full report of study was published (e.g. Smith 2001)

Report IDs of other reports of this study (e.g. duplicate publications, follow-up studies) 
Notes:

\section{General information}

Date form completed (dd/mm/yyyy)

Name/ID of person extracting data

Report title

(title of paper/abstract/report that data are extracted from)

\section{Report ID}

(ID for this paper/abstract/report)

\section{Reference details}

Report author contact details

Publication type

(e.g. full report, abstract, letter)

Study funding sources

(including role of funders)

Possible conflicts of interest

(for study authors)

\section{Notes:}

$+$

\section{Study eligibility}

\begin{tabular}{l|l|l|l|l}
\hline $\begin{array}{l}\text { Study } \\
\text { characteristics }\end{array}$ & $\begin{array}{l}\text { Eligibility criteria } \\
\text { (Insert eligibility criteria for each } \\
\text { characteristic as defined in the } \\
\text { Protocol) }\end{array}$ & Nos Unclear & $\begin{array}{l}\text { Location in text } \\
(p g \text { \&/fg/table) }\end{array}$ \\
\hline Type of study & Randomized controlled trial & & \\
\hline
\end{tabular}


(Continued)

\begin{tabular}{l|l||c|c|}
\hline Participants & $\begin{array}{l}\text { Adult participants undergoing } \\
\text { surgery under general or re- } \\
\text { gional anaesthesia }\end{array}$ \\
\hline
\end{tabular}

Types of inter- One study arm randomized to ventions dexamethasone (max $20 \mathrm{mg}$, including repeated doses)

Other study arm randomized to no treatment/placebo/ antiemetic/analgesic

(no corticosteroid allowed as comparative arm)
Types of out- Wound infection
come measures Delayed wound healing
Glycaemic response

\section{INCLUDE}

\section{EXCLUDE}

When outcome measures are missing in the report: contact corresponding author

Date of contact:

Received information:

Reason for ex-

clusion

Notes:

DO NOT PROCEED IF STUDY EXCLUDED FROM REVIEW

\section{Population and setting}

\begin{tabular}{l|l|l}
\hline & $\begin{array}{l}\text { Description } \\
\text { Include comparative information for each } \\
\text { group (i.e. intervention and control), ifavail- } \\
\text { able }\end{array}$ & $\begin{array}{l}\text { Location in text } \\
\text { (pg/fig/table) }\end{array}$ \\
\hline $\begin{array}{l}\text { Population description } \\
\text { (from which study participants } \\
\text { are drawn) }\end{array}$ & \\
\hline $\begin{array}{l}\text { Setting } \\
\text { (type of surgery) }\end{array}$ & \\
\hline
\end{tabular}

\section{Inclusion criteria}


(Continued)

Exclusion criteria

Design (e.g. parallel, cross-over,

cluster)

\section{Unit of allocation}

(by individuals, cluster/groups, or

body parts)

Sufficient time of follow-up Yes No Unclear

Length:

Notes:

\section{4. 'Risk of bias' assessment}

See Chapter 8 of the Cochrane Handbook for Systematic Reviews of Interventions.

\begin{tabular}{|c|c|c|c|c|c|}
\hline \multirow[t]{2}{*}{ Domain } & \multicolumn{3}{|c|}{ Risk of bias } & \multirow[t]{2}{*}{ Support for judgement } & \multirow{2}{*}{$\begin{array}{l}\text { Location in text } \\
(p g \& \mathrm{~g} / \mathrm{f} g / \mathrm{table})\end{array}$} \\
\hline & Low risk & High risk & Unclear risk & & \\
\hline \multicolumn{6}{|l|}{$\begin{array}{l}\text { Random sequence } \\
\text { generation } \\
\text { (selection bias) }\end{array}$} \\
\hline \multicolumn{6}{|l|}{$\begin{array}{l}\text { Allocation } \\
\text { concealment } \\
\text { (selection bias) }\end{array}$} \\
\hline $\begin{array}{l}\text { Blinding of partic- } \\
\text { ipants and person- } \\
\text { nel } \\
\text { (performance bias) }\end{array}$ & & & & Outcome group: all & \\
\hline (if required) & & & & Outcome group: & \\
\hline $\begin{array}{l}\text { Blinding of out- } \\
\text { come assessment } \\
\text { (detection bias) }\end{array}$ & & & & Outcome group: all & \\
\hline (if required) & & & & Outcome group: & \\
\hline
\end{tabular}

Incomplete

outcome data

(attrition bias) 
(Continued)

Selective outcome

reporting?

(reporting bias)

Other bias

Notes:

\section{Participants}

Provide overall data and, if available, comparative data for each intervention or comparison group.

\section{Description as stated in report/paper Location in text}

(pg \& $\mathbf{9} /$ fig/table)

Total no. randomized

(or total pop. at start of study for NRCTs)

Baseline imbalances

Withdrawals and exclusions

(if not provided below by outcome)

Age

Sex

Race/ethnicity?

\section{ASA classification}

Co-morbidities?

Other treatment received (additional to study intervention)

Type of surgery

Duration of surgery

(min)

Subgroups measured

Subgroups reported

Adverse side effects of dexamethasone in surgical patients (Review)

Copyright @ 2018 The Cochrane Collaboration. Published by John Wiley \& Sons, Ltd. 


\section{Notes:}

\section{Intervention groups}

Copy and paste table for each intervention and comparison group.

Intervention group 1

Description as stated in report/paper Location in text

( $p g$ \& $\mathbf{g} /$ fg/table)

\section{Group name}

No. randomized to group

(specify whether no. people or clusters)

Description (include sufficient detail for replication, e.g. content, dose, components)

Dose and timing (e.g. frequency, duration of each episode)

\section{Co-interventions}

\section{Economic variables}

(i.e. intervention cost, changes in other costs

as result of intervention)

\section{Notes:}

\section{Comparison group 2}

\section{Description as stated in report/paper Location in text} ( $p g$ \& $\mathbf{g} /$ fig/table)

\section{Group name}

No. randomized to group

(specify whether no. people or clusters)

Description (include sufficient detail for

replication, e.g. content, dose, components) 
(Continued)

Dose and timing (e.g. frequency, duration of each episode)

\section{Co-interventions}

Economic variables

(i.e. intervention cost, changes in other costs

as result of intervention)

Notes:

\section{Outcomes}

Copy and paste table for each outcome.

Outcome 1

\section{Reported in paper Location in text \\ ( $p$ \& \&/fig/table)}

\section{Postoperative infection}

\section{Delayed wound healing}

Glycaemic response (preoperative and postoperative glucose)

\section{Length of hospital stay}

Re-admission

C-reactive protein

30-day all-cause mortality

\section{Quality of life}

\section{Notes:}

\section{Results}

Copy and paste the appropriate table for each outcome, including additional tables for each time point and subgroup as required. Dichotomous outcome 


\section{Comparison}

Outcome

\begin{tabular}{l|llll}
\hline Subgroup & & & \\
\hline Results & Intervention & Comparison & \\
\cline { 2 - 5 } & No. events & No. participants & No. events & No. participants \\
\cline { 2 - 5 } & &
\end{tabular}

No. missing participants and reasons

No. participants moved from other group and reasons

Any other results reported

Unit of analysis (by individuals, clusterl groups, or body parts)

Notes:

Continuous outcome

Description as stated in report/paper

\section{Comparison}

\section{Outcome}

\section{Subgroup}

Post intervention or change from baseline?

Results Intervention

\section{Comparison}

Adverse side effects of dexamethasone in surgical patients (Review) 
(Continued)

\begin{tabular}{l|l|l|l|l|l|l|l}
\hline Mean & $\begin{array}{l}\text { SD } \quad \text { (or No. partic- Mean } \\
\text { other vari- ipants } \\
\text { ance) }\end{array}$ & $\begin{array}{l}\text { SD } \\
\text { other vari- ipants } \\
\text { ance) }\end{array}$ \\
\hline
\end{tabular}

No. missing participants and reasons

\begin{tabular}{l|}
\hline No. partic- \\
ipants moved from \\
other group and rea- \\
sons
\end{tabular}

Any other results reported

Unit of analysis

(by individuals, cluster)

groups, or body parts)

Sta-

tistical methods used

and appropriateness

of these methods (e.

g. adjustment for corre-

lation)

Notes:

Other outcome

Description as stated in report/paper

Location in text

( $p g$ \&/fig/table)

\section{Comparison}

\section{Outcome}

\section{Subgroup}

Time point

(specify whether from

start or end of inter-

vention) 
(Continued)

\begin{tabular}{|c|c|c|c|c|}
\hline \multirow[t]{2}{*}{ Results } & Intervention result & $\begin{array}{l}\text { SD (or other vari- } \\
\text { ance) }\end{array}$ & Control result & SD (or other variance) \\
\hline & Overall results & & \multicolumn{2}{|c|}{ SE (or other variance) } \\
\hline No. participants & Intervention & & Control & \\
\hline \multicolumn{5}{|l|}{$\begin{array}{l}\text { No. missing partic- } \\
\text { ipants and reasons }\end{array}$} \\
\hline \multicolumn{5}{|l|}{$\begin{array}{l}\text { No. participants } \\
\text { moved from other } \\
\text { group and reasons }\end{array}$} \\
\hline \multicolumn{5}{|l|}{$\begin{array}{l}\text { Any other results } \\
\text { reported }\end{array}$} \\
\hline $\begin{array}{l}\text { Unit of analysis (by } \\
\text { individuals, cluster) } \\
\text { groups, or body parts) }\end{array}$ & & & & \\
\hline Notes: & & & & \\
\hline
\end{tabular}

\section{Other information}

Description as stated in report/paper Location in text

(pg \& $\mathrm{g} /$ fig/table)

References to other relevant studies 


\section{Appendix 6. Cochrane risk of bias domains}

\section{Random sequence generation}

- Assessment of randomization: the sufficiency of the method in producing two comparable groups before intervention

- Grading:

○ 'Low risk': a truly random process (e.g. random computer number generator, coin tossing, throwing dice)

○ 'High risk': any non-random process (e.g. date of birth; date of admission by hospital, by clinic record number, or by availability of the intervention)

○ 'Unclear risk': if information is insufficient to judge on risk of bias

\section{Allocation concealment}

- Allocation method prevented investigators or participants from foreseeing assignment

- Grading:

- 'Low risk': central allocation or sealed envelopes

- 'High risk': if an open allocation schedule or other unconcealed procedure was used

○ 'Unclear risk': if information is insufficient to judge on risk of bias

\section{Blinding of participants and personnel}

- Assessment of appropriate blinding of investigation team and participants: person responsible for participants' care, participants, and eventual others

- Grading:

○ 'Low risk': we considered blinding as adequate if participants and personnel were kept unaware of intervention allocations after inclusion of participants in the study and if the method of blinding involved a placebo or an intervention disguised in the same manner as a placebo

- 'High risk': not double-blinded; categorized as an open-label study or without the use of a placebo or an intervention disguised in the same manner as a placebo

○ 'Unclear': blinding not described

\section{Blinding of outcome assessor}

- Assessment of appropriate blinding of outcome assessor. Outcomes should not be influenced by the method of blinding used

- Grading:

- 'Low risk': we considered blinding as adequate if outcome assessors were kept unaware of intervention allocations after inclusion of participants in the study and if the method of blinding involved a placebo or an intervention disguised in the same manner as a placebo. Outcomes should not be influenced by the method of blinding used

- 'High risk': not double-blinded; categorized as an open-label study or without the use of a placebo or an intervention disguised in the same manner as a placebo

○ 'Unclear risk': blinding not described

\section{Incomplete outcome data}

- Completeness of outcome data including attrition and exclusions

- Grading:

○ 'Low risk': if the numbers and the reasons for dropouts and withdrawals in the intervention groups were described and if the reasons for dropouts were not likely to be related to the true outcome, or if it was specified that no dropouts or withdrawals occurred

- 'High risk': if no description of dropouts and withdrawals was provided and if missing data were likely to be related to true outcomes

○ 'Unclear risk': if nothing was specifically stated

Adverse side effects of dexamethasone in surgical patients (Review) 


\section{Selective reporting}

- The possibility of selective outcome reporting

- Grading:

○ 'Low risk': if the reported outcomes were those prespecified in an available study protocol or official trial registration, registered before trial initiation

- 'High risk': if not all prespecified outcomes were reported, or if they were reported using non-prespecified subscales or were reported incompletely, or if the report failed to include a key outcome that would have been expected to have been reported for such a study

○ 'Unclear risk': when no study protocol or official trial registration was available. Retrospecitively registered trials were considered as unclear risk

\section{Other bias}

- Assessment of any possible sources of bias not addressed in domains 1 to 5

- Grading:

○ 'Low risk': if the report appeared to be free of such bias

- 'High risk': if at least one important bias related to study design was present, or there was early stopping due to some data dependent process, extreme baseline imbalance, claimed fraudulence, or other problems

○ 'Unclear risk': insufficient information or evidence that an identified problem would have introduced bias

\section{WHAT'S NEW}

\begin{tabular}{|c|c|c|}
\hline Date & Event & Description \\
\hline 31 October 2018 & Amended & $\begin{array}{l}\text { One of the studies included in this review (Schietroma 2013), has now been retracted (Piccirillo } \\
\text { 2018). This study will be excluded from the published Cochrane review. The updated review will } \\
\text { be republished shortly. When the Cochrane review was originally published there was a published } \\
\text { expression of concern regarding the study (Piccirillo 2017), which was regarded as at high risk of } \\
\text { bias. }\end{array}$ \\
\hline
\end{tabular}

\section{H I S T O R Y}

Protocol first published: Issue 11, 2015

Review first published: Issue 8, 2018

\begin{tabular}{lll}
\hline Date & Event & Description \\
\hline 4 October 2018 & Amended & Acknowledgement section amended to include Co-ordinating Editor \\
\hline
\end{tabular}

Adverse side effects of dexamethasone in surgical patients (Review) 


\section{CONTRIBUTIONSOFAUTHORS}

Conceiving the review: JP, JH.

Co-ordinating the review: JP.

Undertaking manual searches: JP, VFR.

Screening search results: JP, VFR.

Organizing retrieval of papers: JP, VFR.

Screening retrieved papers against inclusion criteria: JP, VFR.

Appraising quality of papers: JP, VFR.

Abstracting data from papers: JP, VFR.

Writing to authors of papers for additional information: JP.

Providing additional data about papers: JP.

Obtaining and screening data on unpublished studies: JP.

Managing data for the review: JP, SVD.

Entering data into Review Manager (Review Manager 2014): JP.

Analysing RevMan statistical data: JP, SVD.

Performing other statistical analysis not using RevMan: JP, SVD, JH.

Interpreting data: JP, SVD, HDV, MH, PK, BP, JH.

Making statistical inferences: JP, SVD, HDV, MH, PK, BP, JH.

Writing the review: JP, HDV, MH, PK, BP, JH.

Securing funding for the review: BP.

Performing previous work that was the foundation of the present study: JP, JH.

Serving as guarantor for the review (one review author): JP.

Taking responsibility for reading and checking the review before submission: JP.

\section{DECLARATIONSOF INTEREST}

Jorinde AW Polderman: none declared.

Violet Farhang-Razi: none declared.

Susan Van Dieren: none declared.

Peter Kranke.

- Consultancy (money paid to author): MSD; Fresenius Kabi.

- Grants/grants pending (money to institution): Fresenius Kabi; Premier Research (Acacia Ltd).

- Payment for lectures including service on speakers bureaus (money paid to author): Fresenius Kabi; MSD.

None of the companies listed for Dr Kranke's COI have any relation to the current work.

J Hans DeVries.

Adverse side effects of dexamethasone in surgical patients (Review) 
- Consulting fee or honorarium: Johnson.

- Board membership (money to institution): Novo Nordisk; Johnson \& Johnson; Roche Diagnostics.

- Consultancy (money to institution): Sanofi.

- Grants/grants pending (money to institution): Dexcom; Senseonics; Novartis; Novo Nordisk; ECHO Therapeutics.

- Payment for lectures including service on speakers bureaus (money to institution): Medtronic; Dexcom; Eli Lilly; Roche.

- Diagnostics: Novo Nordisk; Sanofi; MSD.

- Dr DeVries's institution received research support, fees for advice, and speaker's fees from Abbott Diabetes Care; Dexcom Inc; Eli Lilly; Medtronic; Novo Nordisk; Novartis; Roche Diagnostics; and Sanofi.

None of these bear any relation to the current work. None of the companies listed market products/drugs in this area.

Markus W Hollmann.

- Board membership: IARS; Anesthesia \& Analgesia.

- Consultancy (money to institution): Pfizer; Eurocept; B Braun; ECHO; Fresenius; Merck.

- Grants/grants pending (money to institution): ZonMw.

- Payment for lectures including service on speakers bureaus (money to institution): Eurocept/Octapharm; Merck; B Braun; Pfizer.

- Payment for development of educational presentations (money to institution): Merck.

None of the above declared relationships have influenced this work in that all activities are completely unrelated to the work presented in this review. None of the companies listed market products/drugs in this area.

Benedikt Preckel.

- Grants/grants pending (money to institution): European Foundation for the Study of Diabetes; Society of Cardiovascular Anesthesia; Dutch Society of Anesthesia; ZonMw (Dutch Organization for Health Care).

- Payment for lectures including service on speakers bureaus (money to institution): Philips Germany; Abbott Netherlands.

None of the companies listed market products/drugs in this area.

Jeroen Hermanides.

- Research grants: European Foundation for the Study of Diabetes, European Society for Anaesthesiology. Pending funding (to institution) for investigator-initiated trial from NovoNordisk. Speaker fee: Eli Lilly.

None of the above declared relationships have influenced this work in that all activities are completely unrelated to the work presented in this review. None of the companies listed market products/drugs in this area.

Adverse side effects of dexamethasone in surgical patients (Review) 


\section{SOURCES OF SUPPORT}

\section{Internal sources}

- Academic Medical Centre, Netherlands.

The Department of Anaesthesiology provided sufficient time to work on the review.

\section{External sources}

- No sources of support supplied

\section{DIFFERENCESBETWEEN PROTOCOLANDREVIEW}

We made the following changes to the published protocol (Polderman 2015a).

- Objectives: we added 'a steroid load of' to the wording of the objectives. Furthermore, we changed time to wound healing to delayed wound healing to be consistent throughout the review.

- Types of interventions: we changed 'the control group can be...:' to 'which could be either..'

- Outcomes: the published protocol stated, 'measured within 30 days', and in the following sentence, 'should be at least 30 days'. To avoid confusion, this has been changed to 'there needs to be a sufficient follow-up period of 30 days or longer'. Furthermore, we elaborated on how we measured our primary and secondary outcomes.

- Electronic searches: we included information on our search strategy for unpublished studies in the electronic searches section and removed this from the searches in other resources section. We updated the search in the other resources section with information from our handsearching strategy (which was previously noted in the electronic search section).

- Assessment of risk of bias in included studies: our strategy for assessment of risk of bias domains has been moved to Appendix 6 , as apposed to the main text in the protocol.

- Data collection and analysis: we constructed one 'Summary of findings' table for the comparison dexamethasone versus control, reporting on postoperative systemic or wound infection, delayed wound healing, and glycaemic control.

- Measures of treatment effect: we changed the following sentence: "We will present results on delayed wound healing as a summary risk ratio (RR) with $95 \%$ CIs. We will calculate the MD of the change from baseline with corresponding $95 \%$ CIs in preand postoperative blood glucose between the dexamethasone and control group" to "As recommended by the Cochrane Handbook for Systematic Reviews of Interventions, we used Peto's odds ratio to summarise study effects. This provides an unbiased estimate of the treatment effect and has been shown to be particularly appropriate in examining zero-event data. For the glycaemic response, we retrieved the change from baseline results, which is more objective than the final postoperative glucose measurement, as this latter highly depends on the preoperative value. Blood glucose and length of hospital stay often are not normally distributed and frequently are reported as median values with interquartile range. We converted these data to mean values with standard deviations to be able to pool the data (Hozo 2005). Regarding secondary outcomes, we calculated the MD with 95\% CIs for length of stay and CRP between dexamethasone and control groups. We calculated Peto's odds ratio for the number of unplanned admissions and 30-day all-cause mortality".

- Unit of analysis: this section has been updated; we included more information about continuous outcomes and data presented as graphs, which was not included in the protocol. (For the continuous glucose outcomes, we used the mean of the change from baseline with the standard deviation of each group and the number of participants in each group. For the other continuous outcomes, we used mean, standard deviation, and the number of patients in each group. We did not extract data and included in our metaanalysis only data that were presented graphically, as we were unable to determine the exact mean and standard deviations from these figures. Instead, we described these results in the respective section.

- Subgroup analysis and investigation of heterogeneity: we moved the following sentences from the sensitivity analysis to the subgroup analysis section: "We carried out a subgroup analysis for different doses (e.g. $4 \mathrm{mg}$ to $5 \mathrm{mg}$ vs $8 \mathrm{mg}$ to $20 \mathrm{mg}$ ) of

Adverse side effects of dexamethasone in surgical patients (Review)

Copyright ( 2018 The Cochrane Collaboration. Published by John Wiley \& Sons, Ltd. 
dexamethasone, to estimate whether the effect is robust for all doses. Furthermore, we carried out a subgroup analysis for a single dose versus multiple doses of dexamethasone, to estimate whether the effect was comparable".

- Sensitivity analysis: we moved the following sentence from the subgroup analysis to the sensitivity analysis section:

"Furthermore, we included a subgroup analysis for the following outcomes: postoperative risk of systemic or wound infection, delayed wound healing, and glycaemic control, while excluding studies with high risk of bias". We added the following sentence to this section: "Furthermore, we carried out a sensitivity analysis while excluding trials with non-normality glucose data, to assess if these trials induced a systematic bias".

- The following text: "We used the GRADE system to assess...differences of opinion by discussion" was moved to a subheading "Grade analysis", below "Sensitivity analysis". This text was first located under "Data collection and analysis".

\section{NOTES}

\section{October 2018}

One of the studies included in this review (Schietroma 2013), has now been retracted (Piccirillo 2018). This study will be excluded from the published Cochrane review. The updated review will be republished shortly. When the Cochrane review was originally published there was a published expression of concern regarding the study (Piccirillo 2017), which was regarded as at high risk of bias. 